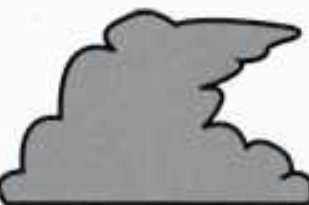 \\ Simpson Weather Associates \\ ENVIRONMENTALCONSULTANTS
}

809 E. Jefferson Street - Charlottesville, Virginia 22902

(434) $979-3571 \quad$ FAX (434) 979-5599

October 21, 2014

Defense Technical Information Center

8725 John J. Kingman Road, Suite 0944

Fort Belvoir, VA 22060-6218

RE: Annual report under Grant No.: N000141110450

Dear Sir/Madam:

Enclosed please find our annual report under the above grant. Please let us know if you have any questions.

Yours sincerely,

Mary Morris

Contract Administrator

Enclosure: Annual report 


\title{
Investigation of the Representation of OLEs and Terrain Effects Within the Coastal Zone in the EDMF Parameterization Scheme: An Airborne Doppler Wind Lidar Perspective
}

\author{
Annual Report \\ Under Grant No.: N000141110450 \\ Covering the Period: \\ 30 June 2013 - 30 September 2014 \\ Submitted by: \\ Simpson Weather Associates, Inc. \\ 809 E. Jefferson Street \\ Charlottesville, VA 22902
}

Prepared by:

G.D. Emmitt, Simpson Weather Associates, Inc.

Ralph Foster, University of Washington

Stephan de Wekker, University of Virginia

20 October 2014

With seven attachments

20141023063 


\section{INTRODUCTION WITH GOALS}

The goal of our segment of the Unified Physical Parameterization for Extended Forecasts DRI continues from prior reporting periods to provide observations related to the partitioning of atmospheric boundary layer (ABL) fluxes into two contributions: eddy diffusivity and vertical mass fluxes (EDMF). In addition to the field campaign, the goal is to validate the existing EDMF expressions and to propose alternatives or modifications to those formalisms.

These goals are being pursued using data sets obtained from the CIRPAS Twin Otter flown in two differing regions: off the coast of California near Monterey and over portions of the Dugway Proving grounds in Utah. Data provided by UCI (Khelif) from the Controlled Towed Platform (CTV) has also been incorporated into our investigations.

\section{OBJECTIVES}

The general objective is to collaborate with NRL (Wang), UCI (Khelif) and the general numerical modeling community working with the WRF and COAMPS to use airborne sensors to probe the ABL for organizing structures such as OLEs and LLJs and, using models when appropriate, construct algorithms that would relate space-based sensor observables to the varying structure dependent $\mathrm{ABL}$ fluxes. Two regions have been used to collect data for the evaluation and modification of the EDMF formalisms:

1. In areas of neutral to stable ABLs capped by cloud cover ranging from zero to $100 \%$, measure the fluxes at the air-sea interface using the TODWL and CTV instruments flown together near the California coastline in September 2012.

2. Using the MATERHORN experiment at Dugway, UT in October 2012 as an opportunity to expand the DWL data base to include ABL surveys in complex terrain as a comparison to the ABL over cold water. Note that the MATERHORN was co-funded by ONR (Ferek).

As this research has progressed, we have added a modeling component (See attachment 4) to better understand the implications of ABL structures being revealed by the TODWL during the September and October 2012 field campaigns.

\section{GENERAL APPROACH}

The work on objective one above continues as we examine several cases in 2012 where the CTV was operating adequately and the ABL contained OLEs and LLJs needed for our investigation. The first important step was to navigate the data from the two systems so that their data sets could be joined. This was not as easy as it seemed since the CTV did not fly faithfully directly below the Twin Otter. This platform relative navigation has been done and is reported in attachment 3 .

The second step is to compute heat, moisture and momentum fluxes for both the CTV and Twin Otter flux sensors. The computation of fluxes from the CTV will be done by both UCI (Khelif) and SWA (Emmitt). 
The third step is to determine the correlations between ABL structures and the fluxes. The end product is envisioned as being a set of PDFs for mass flux contributions as a function of regional model representations of the BL including space-based observations that can be used to infer organized structures such as LLJs (ASCAT and CALIPSO) and OLEs (MODIS, VIIRS and GEOS).

The fourth step is to evaluate several modifications to the EDMF as currently being implemented in models. These modifications would attempt to improve the representation of boundary layer roll (convective and dynamically driven) contribution to the total energy and mass fluxes.

A final effort will be made to relate the fluxes measured at flux tower sites with those measured onboard the Twin Otter during flybys. During those passes the winds and aerosols were mapped by the TODWL. These data sets will be explored for relationships between the BL organization and flux intensities.

\section{WORK COMPLETED}

In the final half of year $3 / 4$ on this project, we have processed more than 50 hours of TODWL data from both the Monterey and DPG areas. We have combined the information from the TODWL, CTV and Twin Otter sensors to establish the relationship between the local fluxes and the energetic of LLJS and OLEs. The WRF model has been setup and run for the 7 MATERHORN missions and comparisons between the TODWL wind profiles and the model profiles have been completed for one day.

The Triad Interaction Model for OLEs has been modified by Foster to investigate "stacked OLEs" seen in the April 2007 datasets (see reported results in attachment 6)

We continue to modify the EDMF (Eddy Diffusivity and Mass Flux) parameterization to account for the differences between thermally driven convection and dynamically driven vertical transports.

Emmitt and de Wekker are using the WRF and COAMPs models to test out sensitivities to changes in the EDMF related to our field data. We have received several versions of the EDMF from Joao Teixeira for testing.

\section{RESULTS}

Most of the results of our last year's research effort were reported at the DRI Workshop in Monterey in August 2014, the annual AGU meeting in December 2013 and at a SPIE Conference in September 2014 in Amsterdam. Five of these presentations are appended to this report:

Boundary Layer Rolls Observed Above and Below a Jet in a Marine Boundary Layer; presented at AGU 2013 by Ralph C. Foster; George D. Emmitt; Kevin Godwin; and Steven Greco

Investigating the impacts of LLJS and OLEs on ABL exchanges and transports using an airborne Doppler wind lidar; presented at AGU 2013 by G.D. Emmitt ${ }^{1}$, R.C. Foster ${ }^{2}$, K. Godwin ${ }^{3}$ and S. Greco ${ }^{1}$ 
Vertical transport of TKE within Organized Large Eddies; presented at the DRI workshop 2014 by G. D. Emmitt (SWA), S. de Wekker (UVA) and R. Foster (Uwash)

EDMF in the Near-Neutrally Stratified Boundary Layer; presented at the DRI workshop 2014 by R. Foster and G. D. Emmitt

Investigation of coastal zone complex boundary circulations and their potential impact on energy transport; presented at SPIE Defense and Security Conference in Amsterdam 2014 by G. D. Emmitt, K. Godwin and R. Foster.

In addition to the presentations provided as appendices, individual reports by Ralph Foster and Stephan de Wekker are also attached. The material presented by de Wekker combines MATERHORN research results that were funded by ONR, ARO and NSF. This work lays the foundation for UPP related investigations that will be carried out in Year 4.

\section{RELATED PROJECTS}

ONR contract to study the utilization of Doppler wind lidar (DWL) data to quantify the contribution of organized large eddies (OLEs) to fluxes in the marine boundary layer (DYNAMO DRI (S. Harper, TPOC). This funded effort is now complete.

\section{PLANS FOR YEAR 5}

We have three primary goals for year 5 of this effort.

1. Finish the application of a methodology (developed last year) for joining airborne DWL data and in situ flux data to achieve an understanding of how the organized ABL structures modulate ABL fluxes.

2. Develop an expression for mass fluxes by OLEs in the MBL that is suitable for use in numerical model parameterizations. This will be derived from flux data measured directly by the CTV (Monterey) and towers (Dugway) and associated with organized ABL structures mapped from the DWL.

3. Use the COAMPS, WRF and SCM to investigate the sensitivity of these models to the ranges of values for the "MF" term as inferred from the Monterey and Dugway data sets.

We will pursue publishing our results should the findings of this research merit this effort. 
Attachment 1

Boundary Layer Rolls Observed Above and Below a Jet in a Marine Boundary Layer presented at AGU 2013

by Ralph C. Foster; George D. Emmitt; Kevin Godwin; and Steven Greco 


\section{BOUNDARY LAYER ROLLS OBSERVED ABOVE AND}

BELOW A JET IN A MARINE BOUNDARY LAYER

Ralph C Foster ${ }^{1}$, G. David Emmitt², Kevin Godwin², Steven Greco ${ }^{2}$

Research supported by ONR Marine Meteorology ${ }^{1}$ University of Washington, Seattle, WA, United States.

2 Simpson Weather Associates, Charlottesville, VA, United States.

- Improve physical parameterization of Atmospheric PBL processes

Local vs. non-local fluxes of momentum, heat and water vapor

- Convection

- highly-skewed, very unstable stratification

- Organized Large Eddies (OLE or rolls)

- Less Skewed, near-neutral to moderately unstable stratification

Aircraft and towed platform observations

- Doppler Wind Lidar to directly measure PBL structure

- Flight-level and near-surface fluxes

Investigating the impacts of LLJs and OLEs on ABL exchanges and transports

using an airborne Doppler wind lidar (A43A-0227)
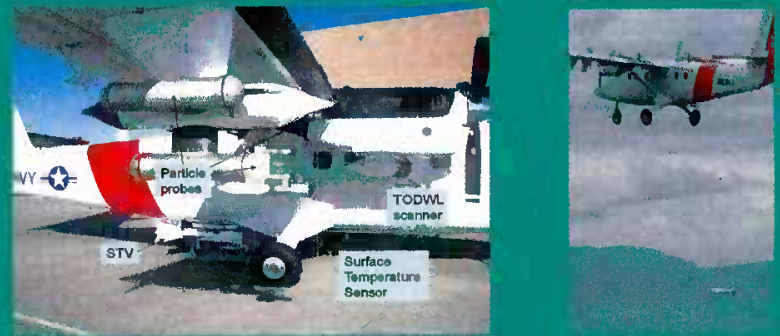

- Off Monterey Bay, 30 Sep, 2012

Prospecting DWL mode

$-2^{\circ}$ forward stare

$\sim 6 \mathrm{~km}$ surface intercept from $300 \mathrm{~m}$ flight level

Line-of-Sight wind speed (VLOS)

Stacked VLOS $\sim 2 \mathrm{~m}$ vertical, $50 \mathrm{~m}$ horizontal resolution

$\sim 0.1 \mathrm{~m} / \mathrm{s}$ VLOS precision

$\sim$ Cross-mean-wind flight legs

Mean state vertical profiles from Twin Otter ascent/descents

Fluxes: see poster A43A-0227

- Multiple cross-wind legs in same region

- Organized Large Eddies found throughou

- Mid-PBL wind maximum (low-level jet)

- Baroclinic mean profile (land PBL advected over the bay?)

- L above and below II]

- Sometimes connected, sometimes not

What dynamics causes this?
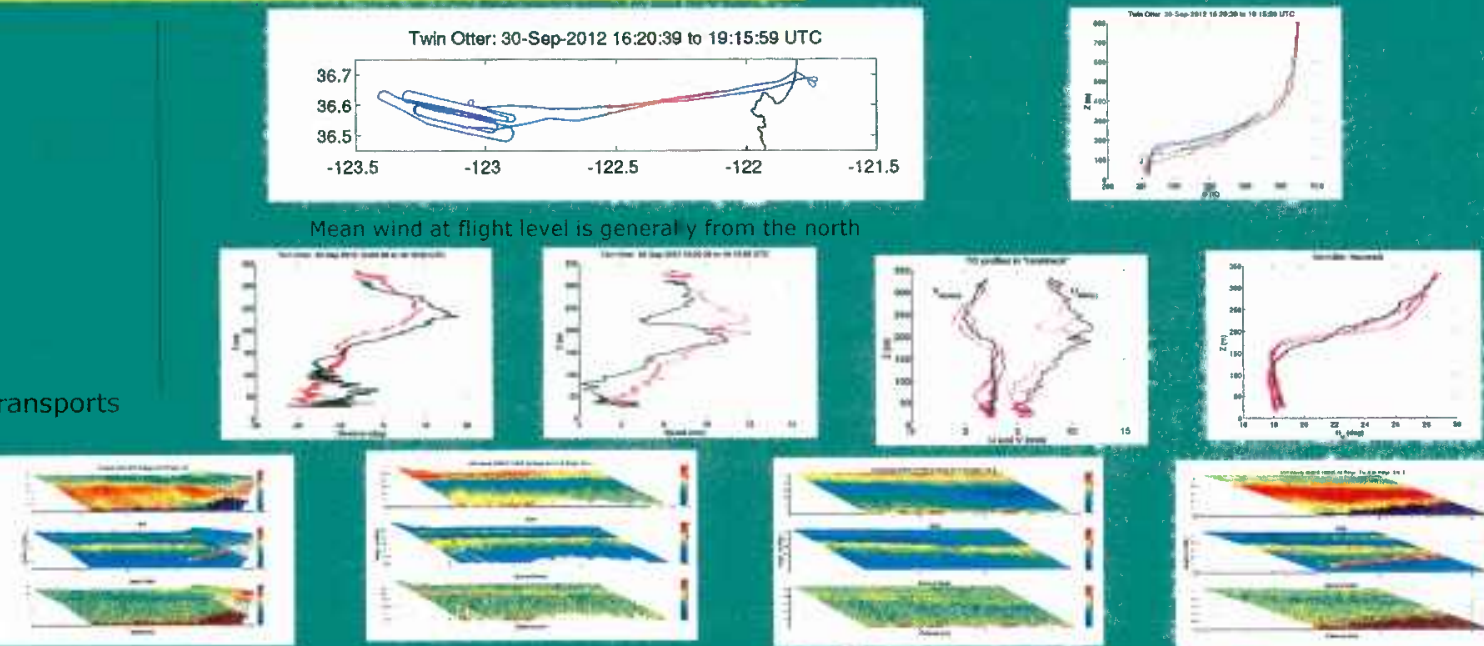

- Simplify Problem

- Neutral stratification

- Shear effects only

- Omit effect of stratification above jet

- No surface buoyancy flux

- Flevated, thin baroclinic layer

- Variable $K(z)$ (akin to MRF/YSU)

- Nonlinear stability analysis

- Floquet triad interaction
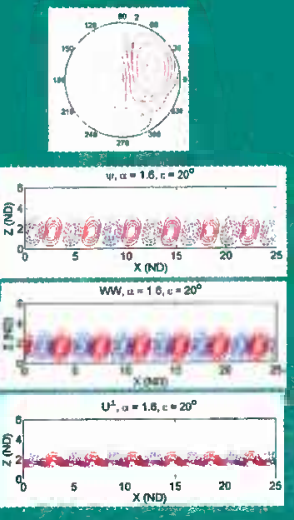

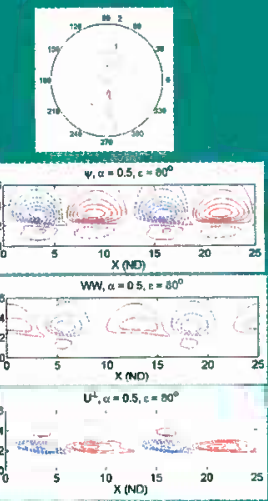

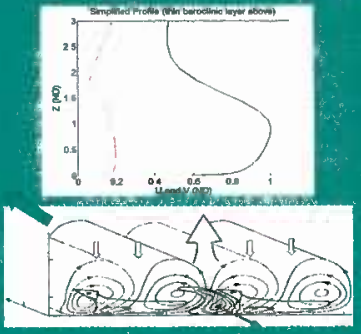

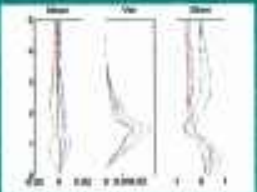

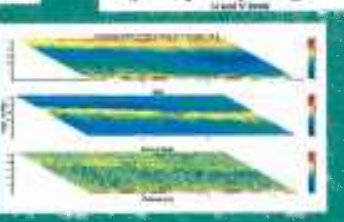

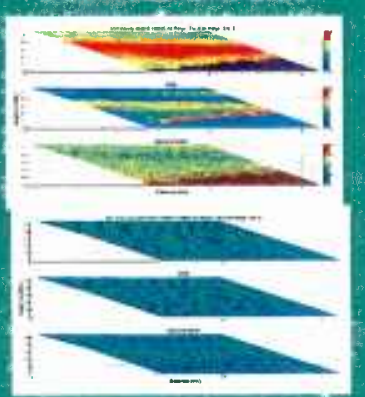

- Co-linear

- Based on dominant mode - Time-dependent solution

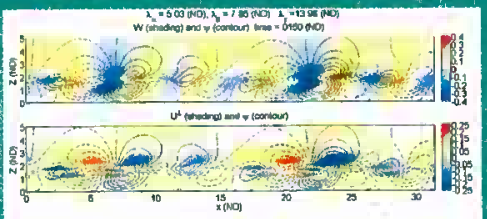

- A PBL jet can induce "stacked" OLE

- Co-linear OLE triads generate complex PBL structures - There is a weaker, larger-scale, oblique above-jet mode - OLE rolls are very common

- Near-neutral

- likely significant flux contribution 
Attachment 2

Investigating the impacts of LLJs and OLEs on ABL exchanges and transports using an airborne Doppler wind lidar

presented at AGU 2013

by G.D. Emmitt ${ }^{1}$, R.C. Foster ${ }^{2}$, K. Godwin ${ }^{3}$ and S. Greco ${ }^{1}$ 
G.D. Emmitt ${ }^{1}$, R.C. Foster ${ }^{2}$, K. Godwin ${ }^{3}$ and S. Greco ${ }^{1}$

${ }^{1}$ - Simpson Weather Associates, Charlottesville, VA, USA ${ }^{2}$ - APL, Univ. of Washington, Seattle, WA, USA; ${ }^{3}$ - KSG Science, Starkville, MS, USA

Objectives

- Utilize the Twin Otter Doppler Wind Lidar (TODWL) and Controlled Towed Vehicle (CTV) to take ABL wind and flux measurements over marine and coastal environments

- Extend prior investigations (2001-2008) of $L U s$ and OLEs in the MBL and PBLS.

- Investigate and characterize the presence of rolls (OLEs) at the boundaries of stratocumulus topped MBLS.

- Study the potential impact on the development and implementation of the EDMF into forecast models.

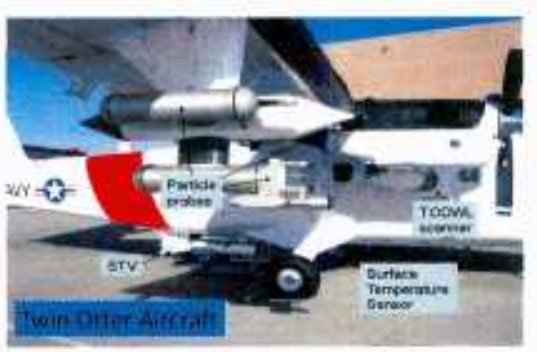

TODWL Data Description

\begin{tabular}{|c|c|c|}
\hline Atrtibute & $\begin{array}{l}\text { Performanoce } \\
\text { Metric }\end{array}$ & Commentat \\
\hline 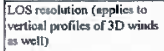 & $30 \mathrm{~m}$ & 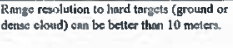 \\
\hline U, U, w rescolution & $<10 \mathrm{~cm} / \mathrm{t}$ & 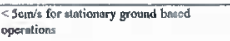 \\
\hline Mavimum nange & $6.30 \mathrm{~km}$ & 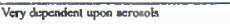 \\
\hline 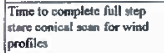 & 20000 & 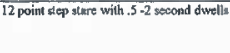 \\
\hline sem & $100 \mathrm{~Hz}$ & 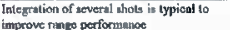 \\
\hline
\end{tabular}

Structure Prospecting with TODWL

- Feature prospecting uses a very shallow angle below the horizon ${ }^{\sim} \sim-1-3$ degrees for a 300m flight altitude).

Results in $\sim 2 \mathrm{~m}$ vertical resolution and $50 \mathrm{~m}$ horizontal resolution with 10 meter sliding sample. It takes $\sim 40$ seconds to profile 100 meters below the aircraft.

$9 / 30 / 2012$ Case Study
- Processed lidar data in search of organized aerosol/wind structures below the Twin 0 tter Processed Twin Otter instrument and CTV data for time series of $u, v, w, q$, and $\theta$.

Match up times and their features from the TODWL and CABIN data sets near flight level and CTV at CTV cruise levels.

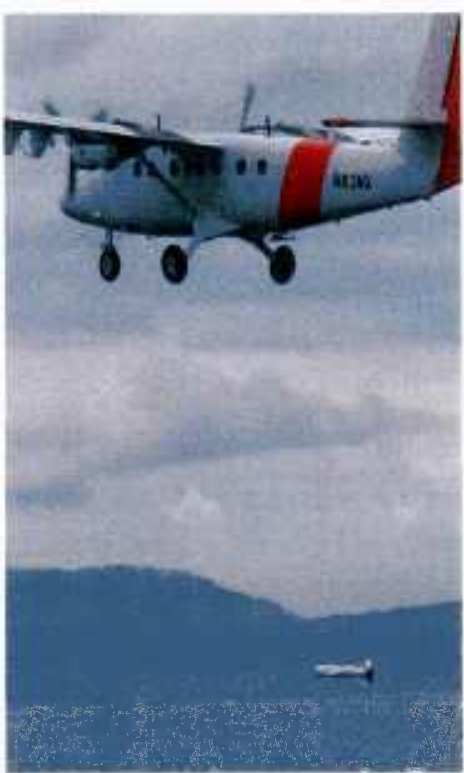

$\frac{102}{2}$

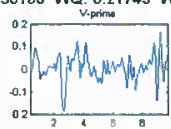

- Theta: 0.087407 Skew. -0.1774
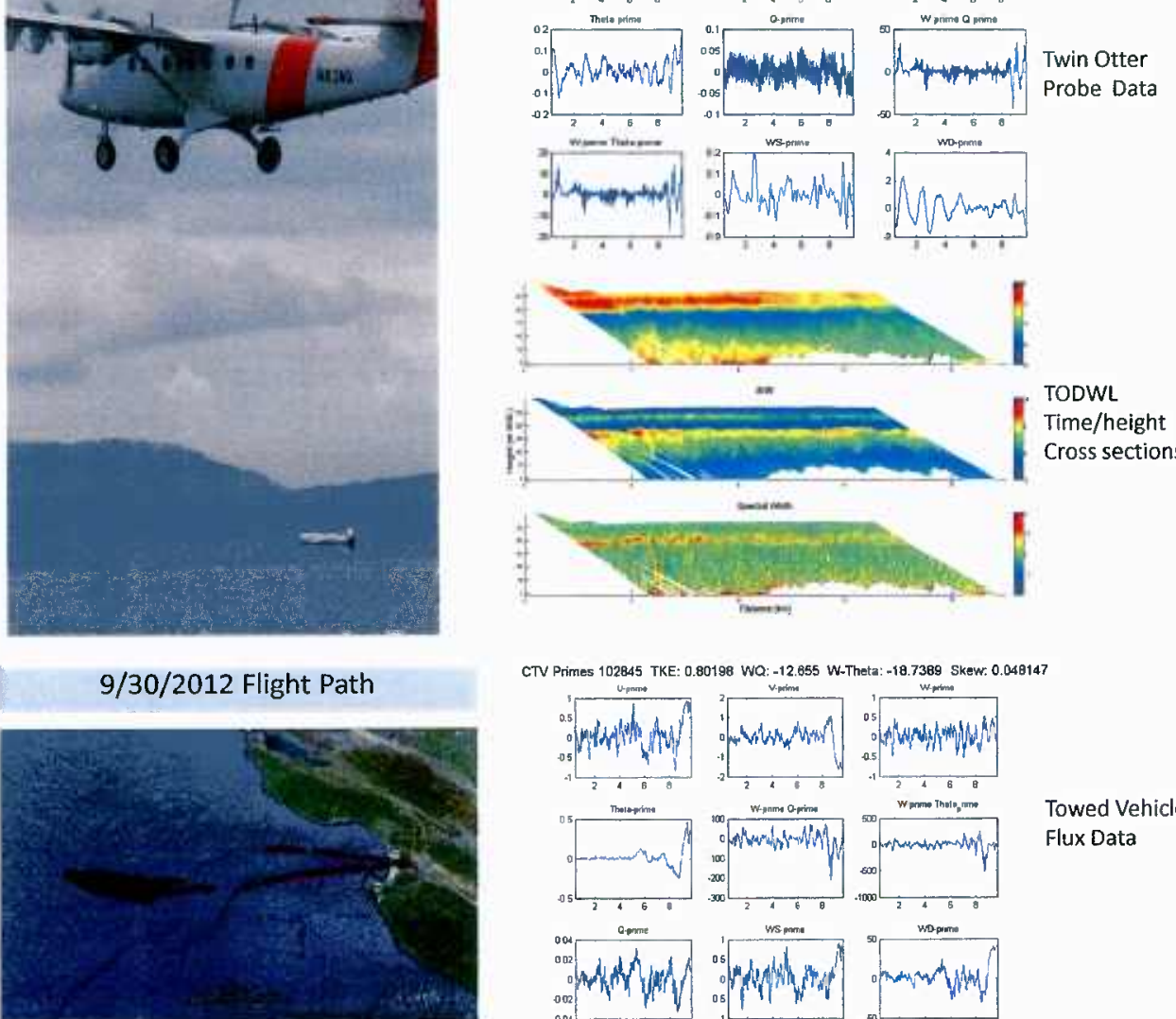

CTV Primes 102845 TKE: 0.80198 WQ: -12.655 W-Theta: -19.7389 Skew: 0.049147
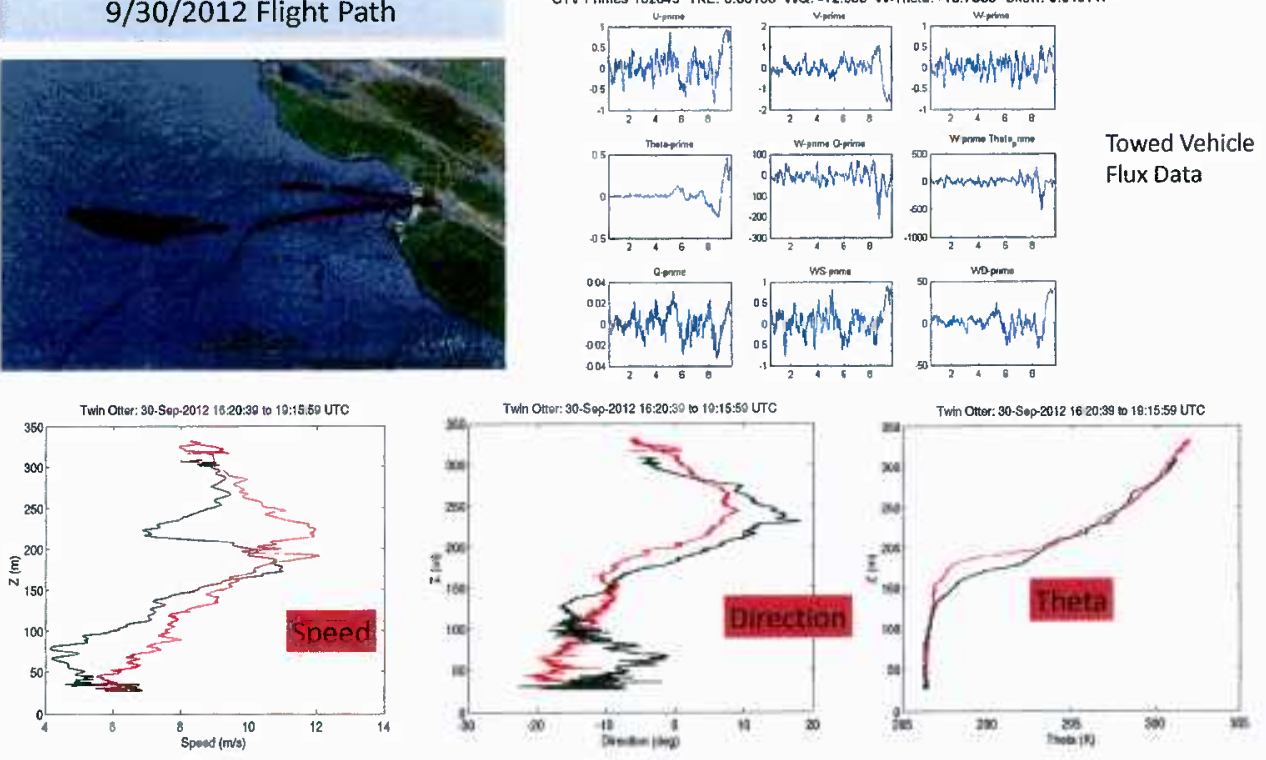

TODWL LOS, SNR and Spectral Width

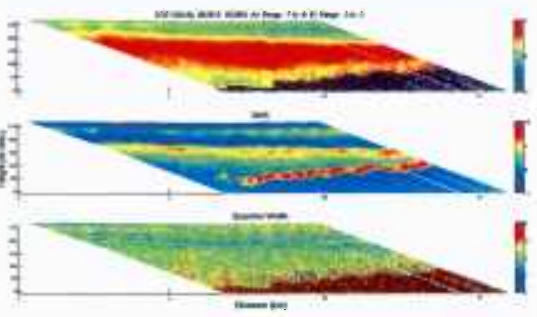

TODWL Rad. Velocity, SNR and Spec. Width (Two Color Processing)

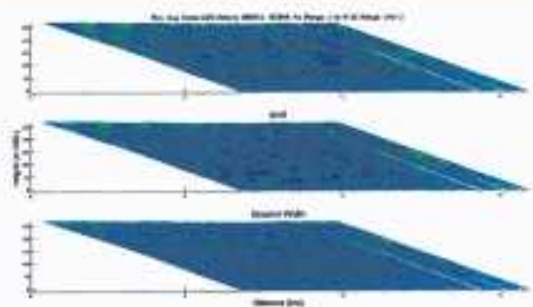

Summary of Segment Statistics

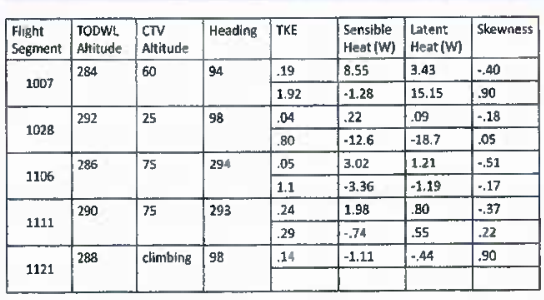

Summary

The combination of an airborne Doppler Wind Lidar and a Controlied Towed Platform holds promise of a transformation of how we investigate air/sea exchanges and construct flux parameterizations for use in numerical weather models.

- This research is being funded by Dr. Ferek of the Office of Naval Research. 
Attachment 3

Vertical transport of TKE within Organized Large Eddies presented at the DRI workshop 2014

by G. D. Emmitt (SWA), S. de Wekker (UVA) and R. Foster (Uwash) 


\section{Vertical transport of TKE within Organized large Eddies}

G. D. Emmitt (SWA), S. de Wekker (UVA) and R. Foster (Uwash)

UPP for Extended Range Prediction

DRI Review

Monterey, CA

27- 28 August 


\section{Objectives}

- Investigate and characterize the presence of rolls (OLEs) within and at the lateral boundaries of stratocumulus topped MBLs.

- Study the potential impact on the development and implementation of the EDMF into forecast models.

- Make (or not) the case for adding an MF term unique to rolls generated by shear instabilities (non-convective). 


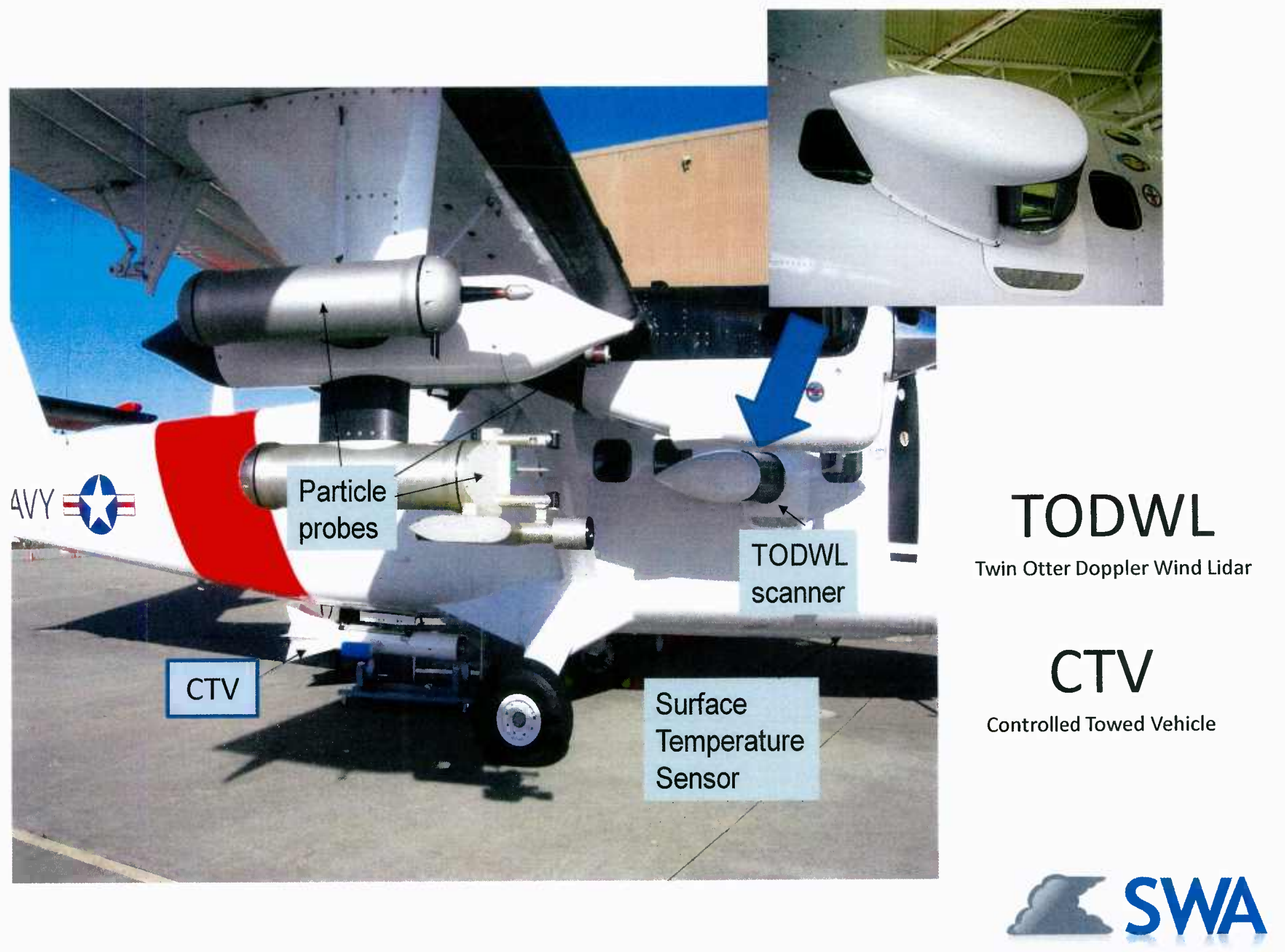




\section{TODWL data description}

\begin{tabular}{|l|l|l|}
\hline \multicolumn{1}{|c|}{ Attribute } & Performance Metric & \multicolumn{1}{c|}{ Comments } \\
\hline $\begin{array}{l}\text { LOS resolution (applies } \\
\text { to vertical profiles of } \\
\text { 3D winds as well) }\end{array}$ & $50 \mathrm{~m}$ & $\begin{array}{l}\text { Range resolution to hard } \\
\text { targets (ground or dense } \\
\text { cloud) can be better than } \\
10 \text { meters. }\end{array}$ \\
\hline U,V,W resolution & $<10 \mathrm{~cm} / \mathrm{s}$ & $\begin{array}{l}<5 \mathrm{~cm} / \mathrm{s} \text { for stationary } \\
\text { groundbased operations }\end{array}$ \\
\hline $\begin{array}{l}\text { Maximum range } \\
\text { step stare conical scan } \\
\text { for wind profiles }\end{array}$ & $6-30 \mathrm{~km}$ & $\begin{array}{l}\text { Very dependent upon } \\
\text { aerosols }\end{array}$ \\
\hline $\begin{array}{l}\text { Sampling frequency } \\
12 \text { point step stare with } \\
.5-2 \text { second dwells }\end{array}$ \\
\hline $100 \mathrm{~Hz}$ & $\begin{array}{l}\text { Integration of several } \\
\text { shots is typical to } \\
\text { improve range } \\
\text { performance }\end{array}$ \\
\hline
\end{tabular}




\section{Data summary for September/October UPP field campaign with TODWL}

- Three quality flights with the DWL

- One quality co-flight with the CTV (9/30).

- Two 5 hour ferry flights between Monterey, CA and Salt Lake City, Utah. (Ruby Mountain waves)

- Seven 4.5 hour flights over DPG, Utah during the MATERHORN

- Co-funded by ONR and ARO

- 3500 vertical profiles used to validate WRF models

- 14 low level flights dedicated to prospecting for OLEs in the vicinity of flux towers. 


\section{CIRPAS Twin Otter with CTV below}

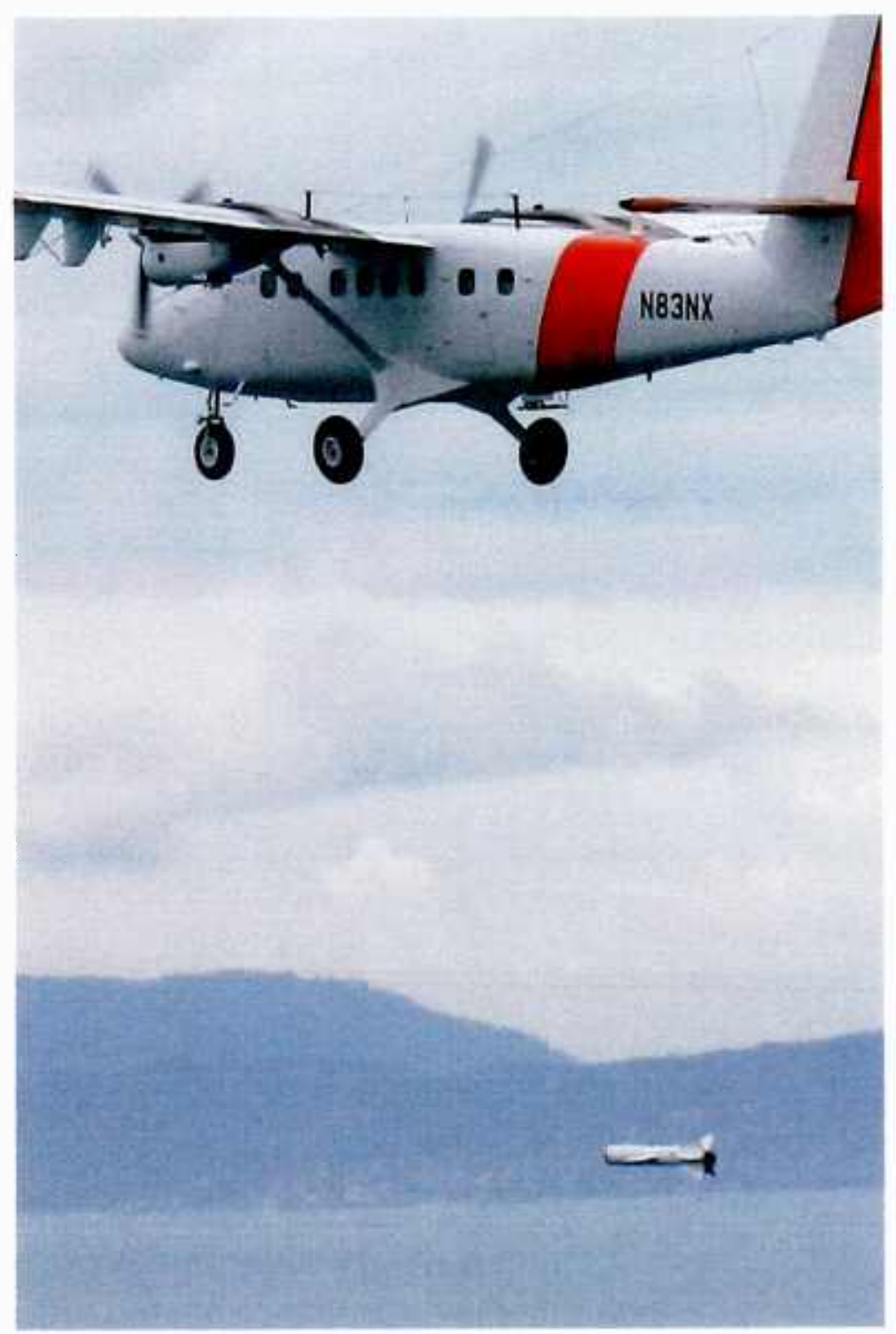

Cabin Primes 102845 TKE: 0.038198 WQ: 0.21743 W-Theta: 0.087407 Skew: -0.1774

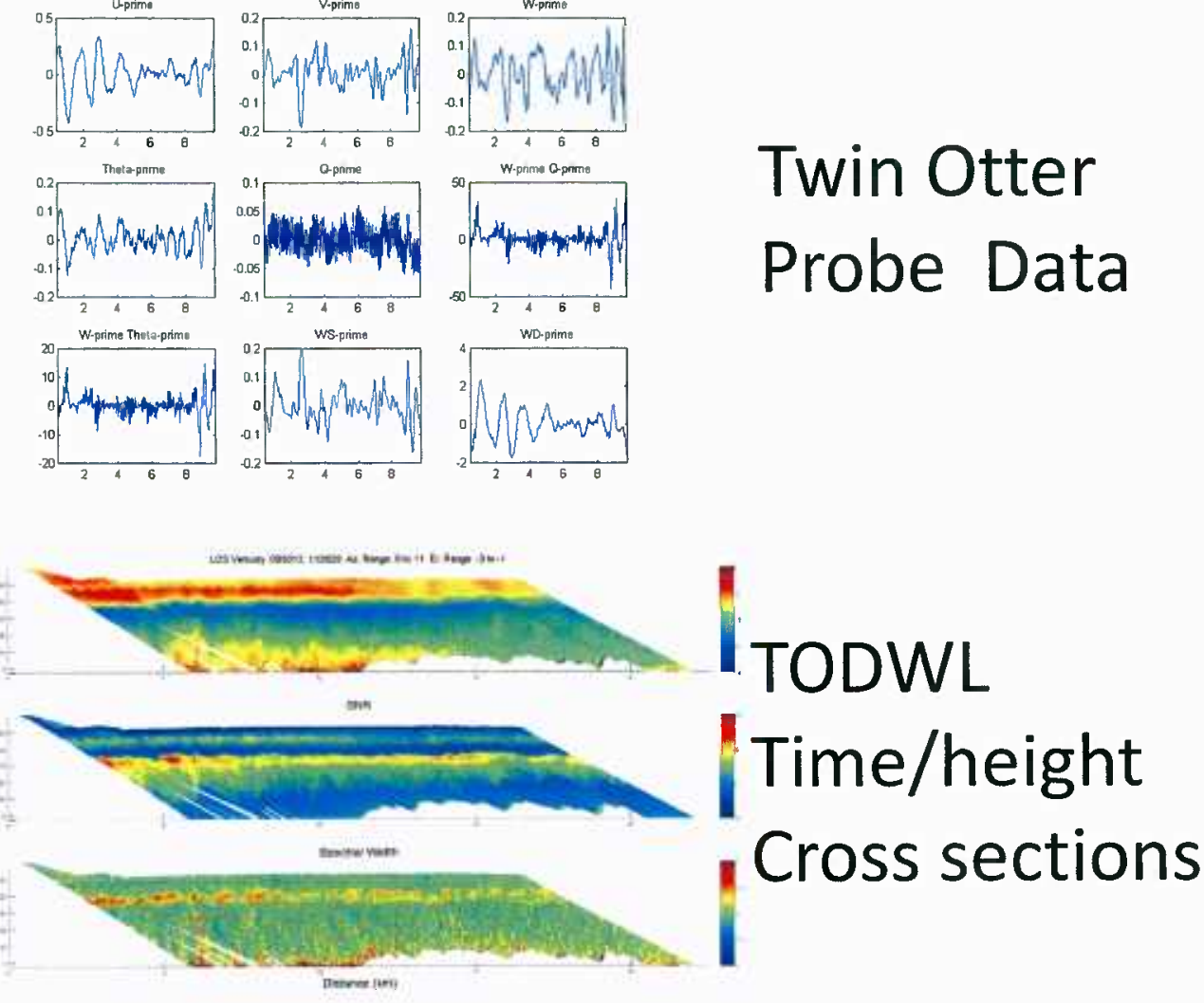

CTV Primes 102845 TKE: 0.80198 WQ: -12.655 W-Theta: -18.7389 Skew: 0.048147
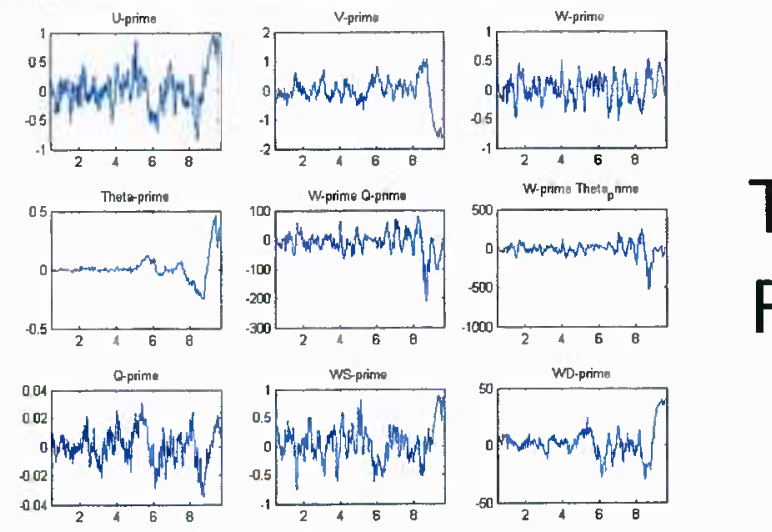

Towed Vehicle Flux Data*

* Derived from data provided by Khelif (UCI) 


\section{Structure prospecting with DWL}

- Feature prospecting uses a very shallow angle below the horizon ( -1 -3 degrees for a 300m flight altitude).

- Results in $2 \mathrm{~m}$ vertical resolution and $50 \mathrm{~m}$ horizontal resolution with $\sim 40$ meter sliding sample.

- It takes 33 seconds to profile 100 meters below the aircraft. 


\section{TODWL prospecting geometries $(9 / 30 / 12)$}

$300 \mathrm{~m}$

-3 degrees elevation angle $(\tan =.052)$

$6 \mathrm{~km}$

\begin{tabular}{|l|l|}
\hline \multicolumn{1}{|c|}{ Metric } & \multicolumn{1}{c|}{ Value } \\
\hline Twin Otter flight altitude & $300 \mathrm{~m} \mathrm{MSL}$ \\
\hline Scan configuration & Straight ahead and down $1-3^{\circ}$ \\
\hline Range gate length & $50 \mathrm{~m}$ \\
\hline Twin Otter ground speed & $50-60 \mathrm{~m} / \mathrm{s}$ \\
\hline Shot frequency & $160 /$ second \\
\hline Shot integration (data granule) & $100(\sim 40$ meters forward motion) \\
\hline Vertical increment between granules & $\sim 2 \mathrm{~m}$ \\
\hline Time to sample 100 m vertical & $\sim 33$ seconds \\
\hline
\end{tabular}


Idealized rolls

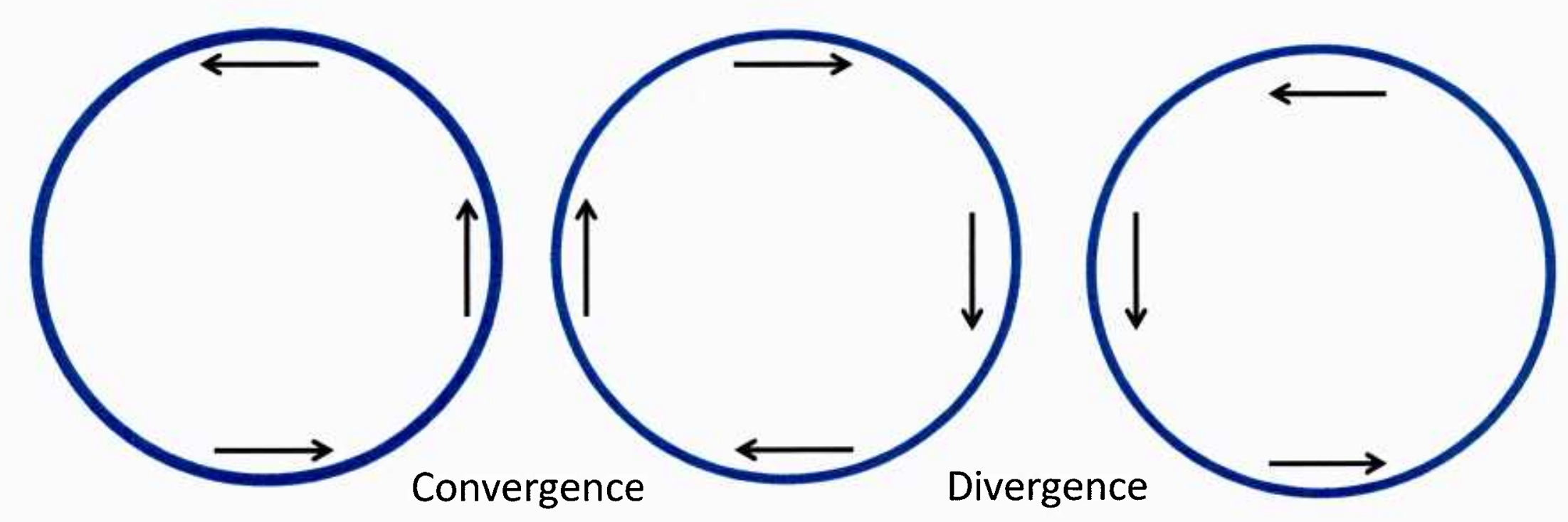




\section{Spectral analyses of TODWL data}

The TODWL is a 2 micron, eyesafe Coherent detection lidar. The returning Signal is heterodyned with a local optical Oscillator and then digitized (200 MHz). An FFT is used to process the resulting Time series with $50 \mathrm{~m}$ line-of-sight Resolution. In homogeneous flows, a single Spectral feature (top figure) is identified as the frequency representation of the radial wind speed.

When probing a turbulent and/or highly Sheared environment, the spectral Feature is broadened. It is this broadening That we desire to use for estimating Turbulence on scales of $25-100$ meters With multipulse integrations over 50 - 200
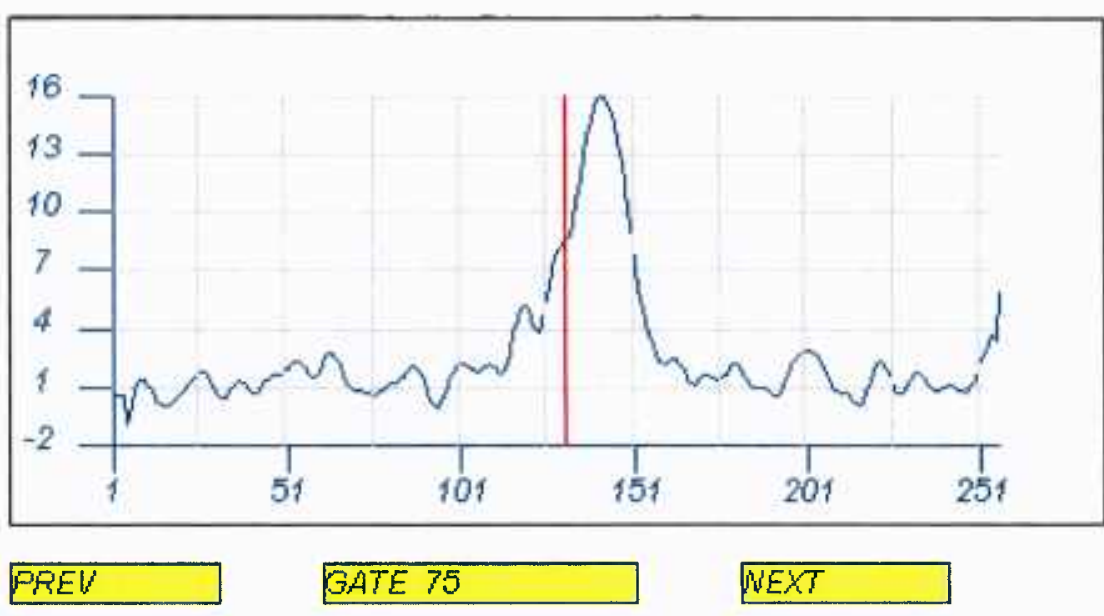

COPP_20120AS1093020121_100709501

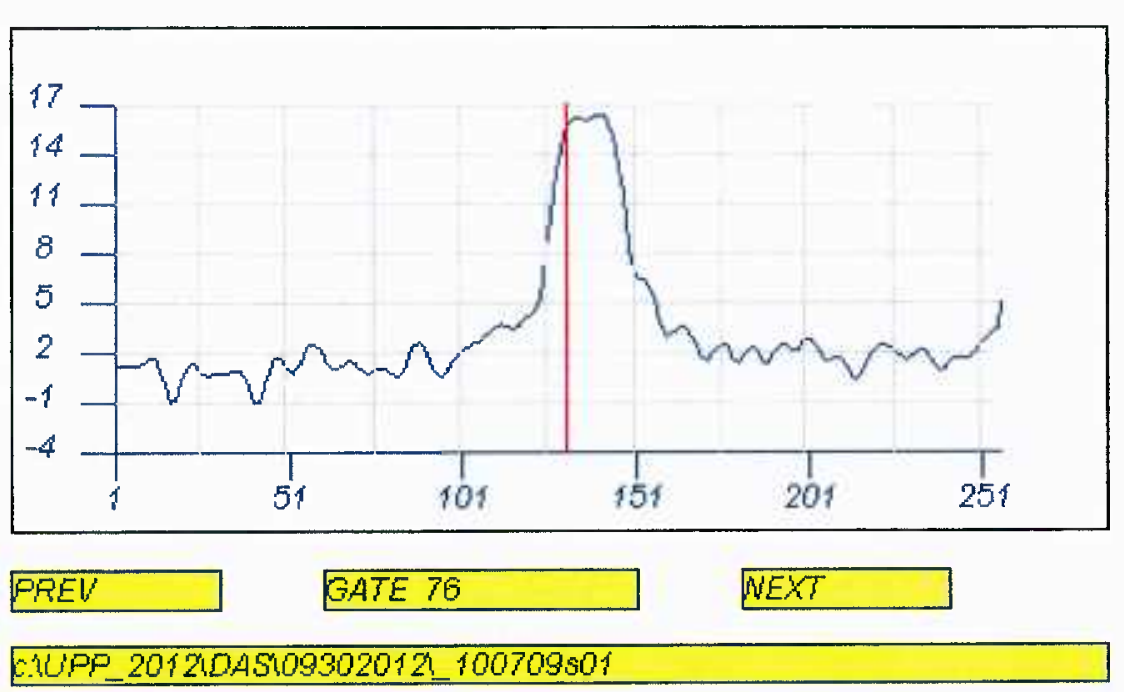




\section{9/30/12 case study}

- Processed lidar data in search of organized aerosol/wind structures below the Twin Otter flight path

- Processed Twin Otter instrument data for time series of $u, v, w, q$, and $\theta$.

- Processed CTV data for $u, v, w, q$ and $\theta$.

- Match up times and then features from the TODWL and CABIN data sets near flight level.

- Match up times and features from TODWL and CTV at CTV cruise levels. 


\section{Flight path}

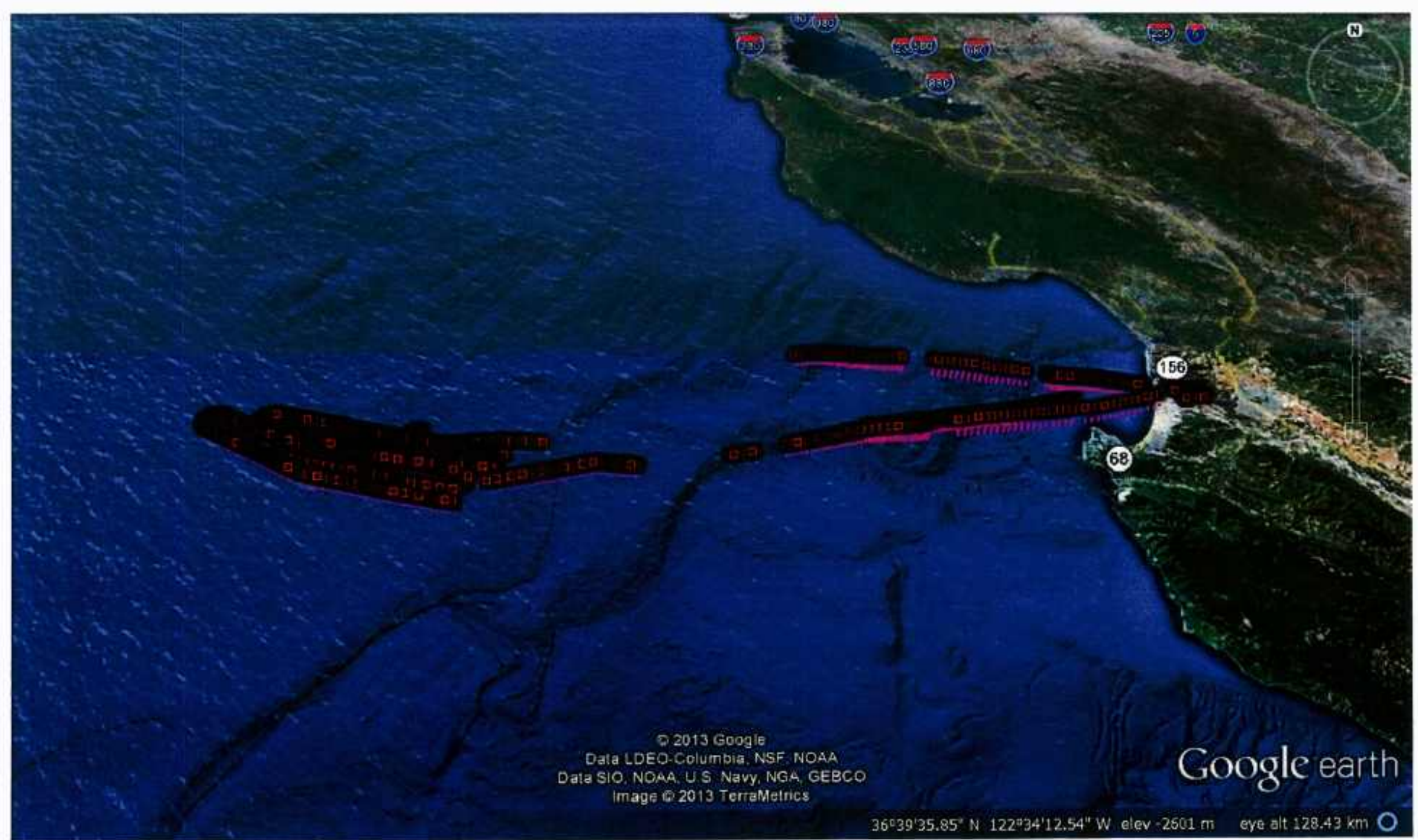


Twin Otter: 30-Sep-2012 16:20:39 to 19:15:59 UTC

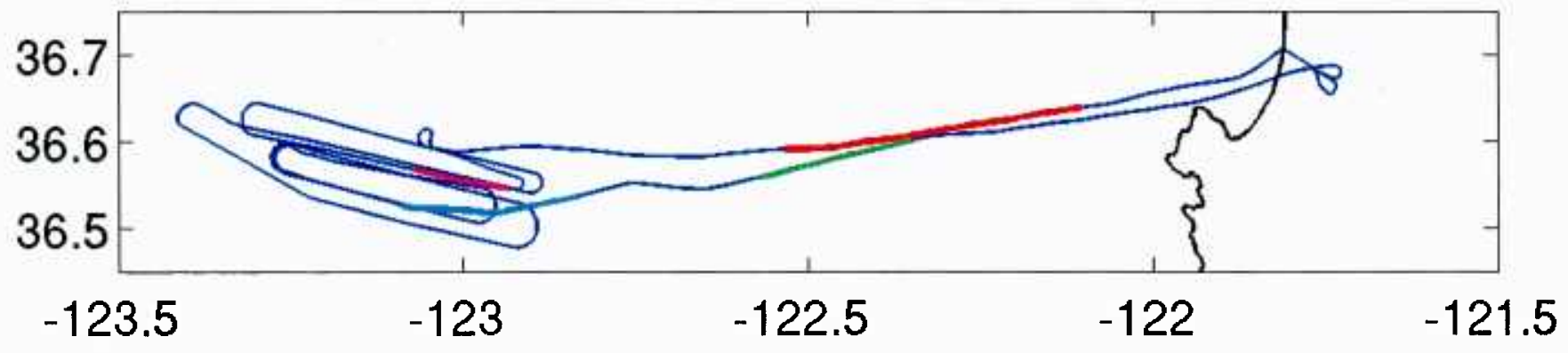

Mean wind at flight level is generally from the north
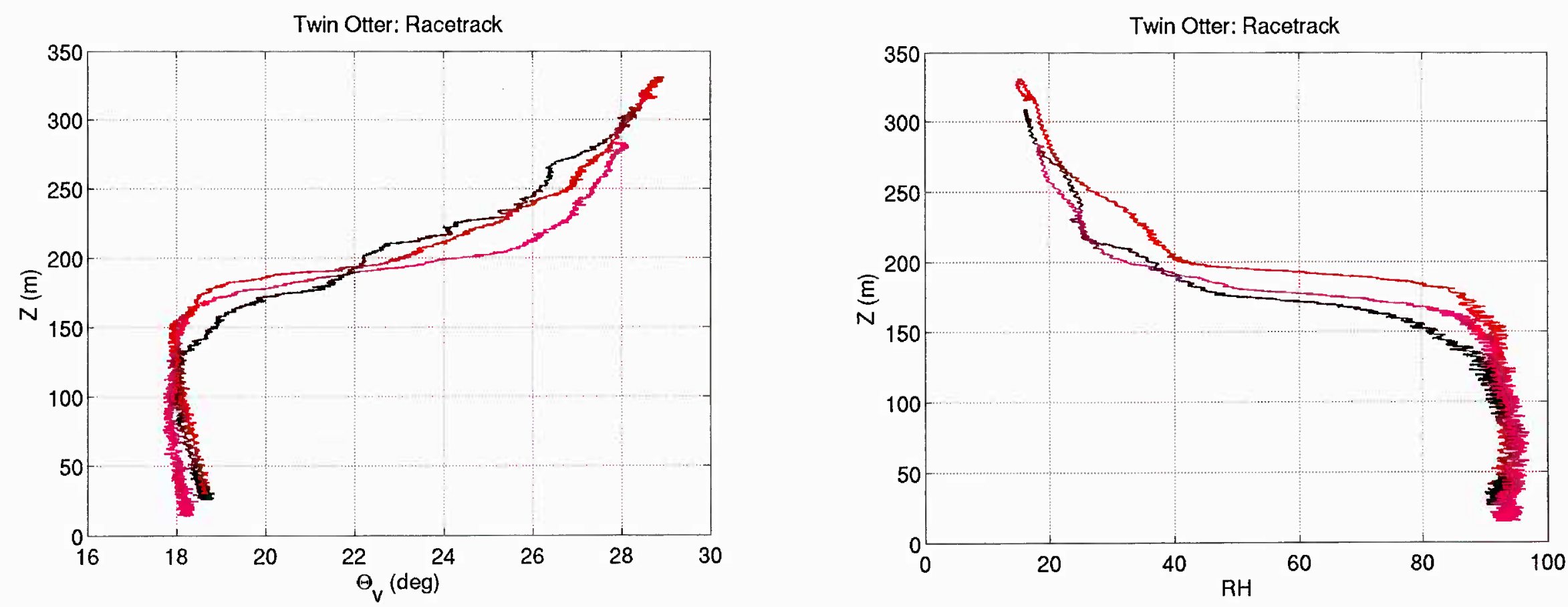


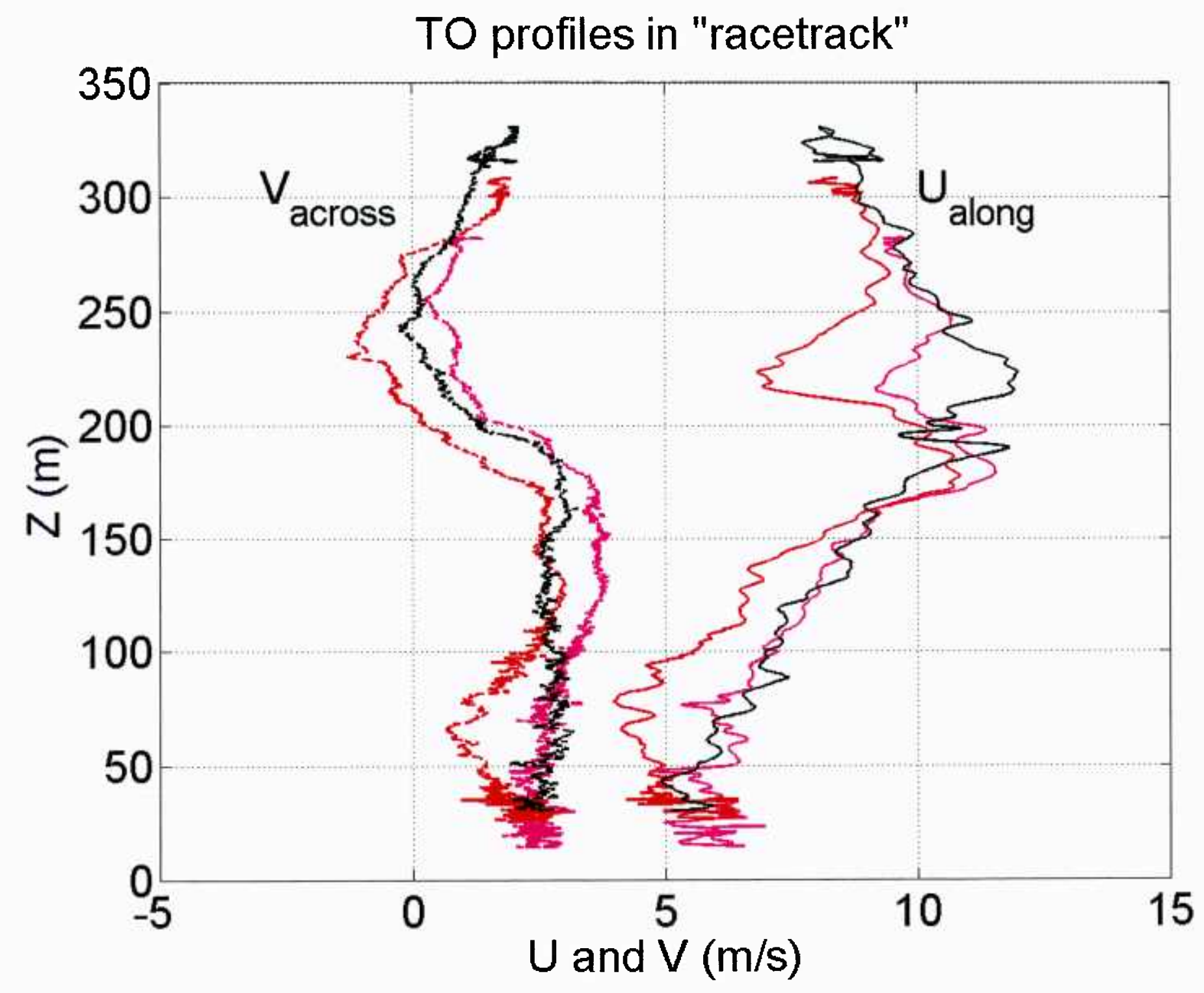



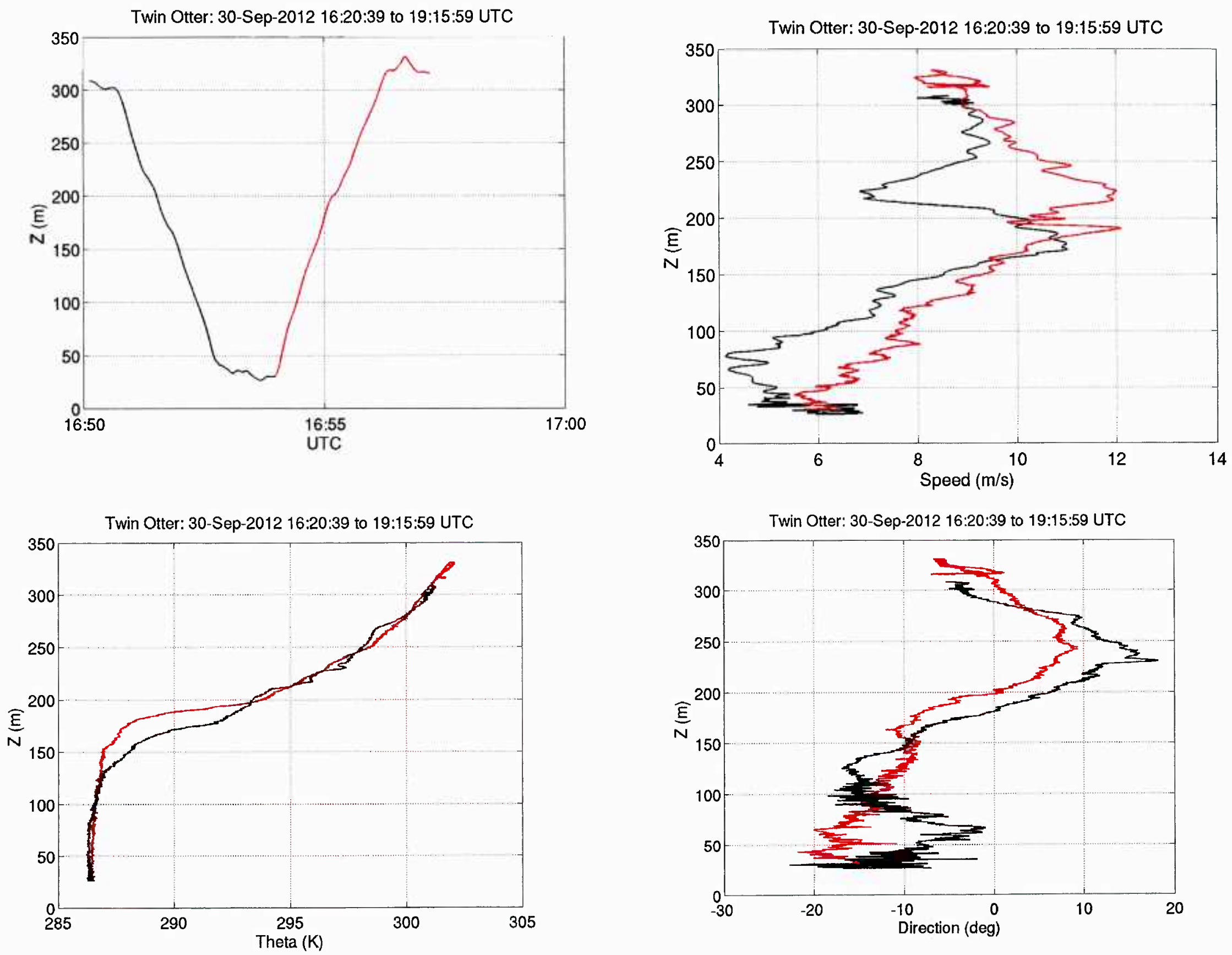


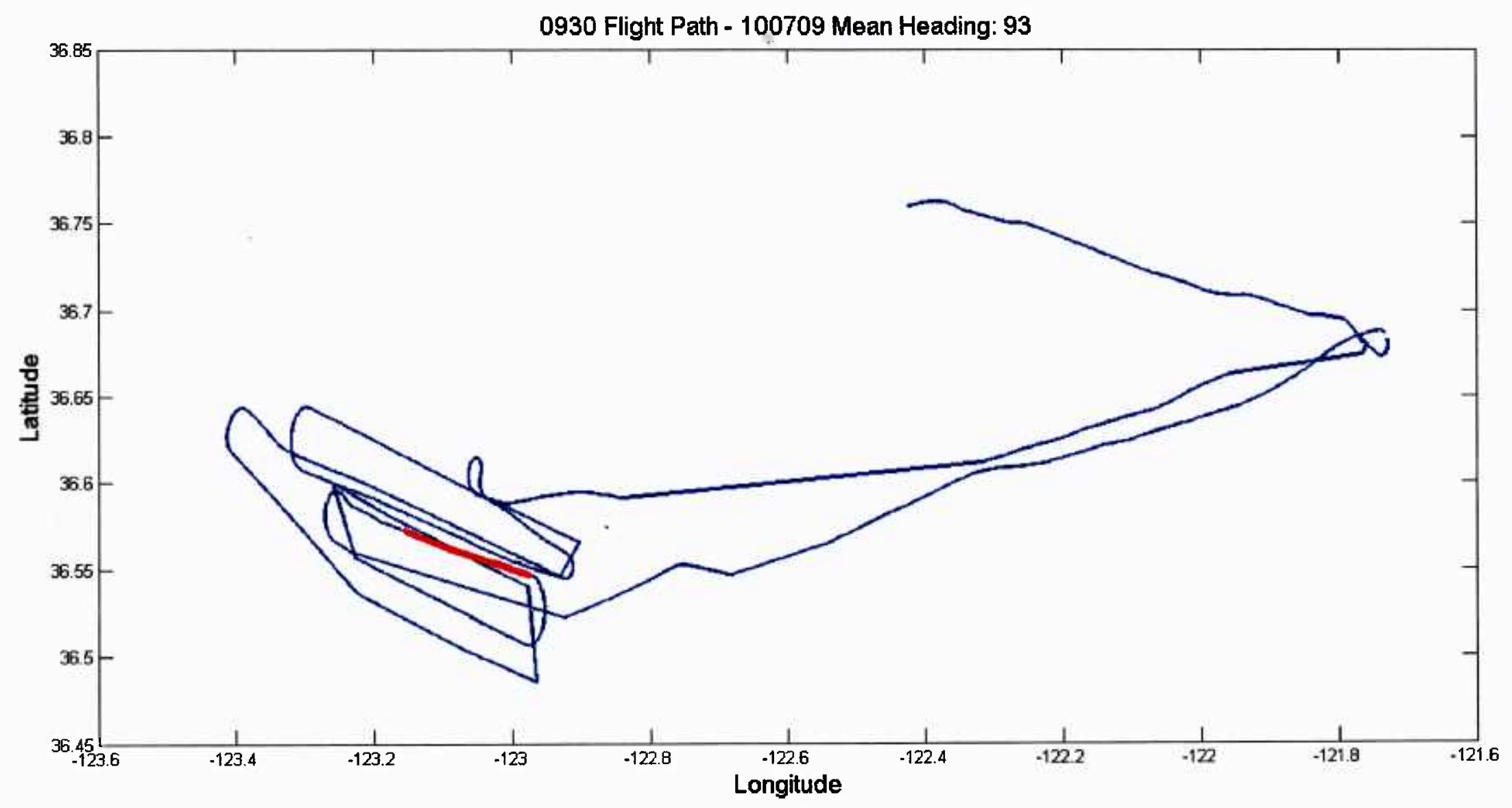




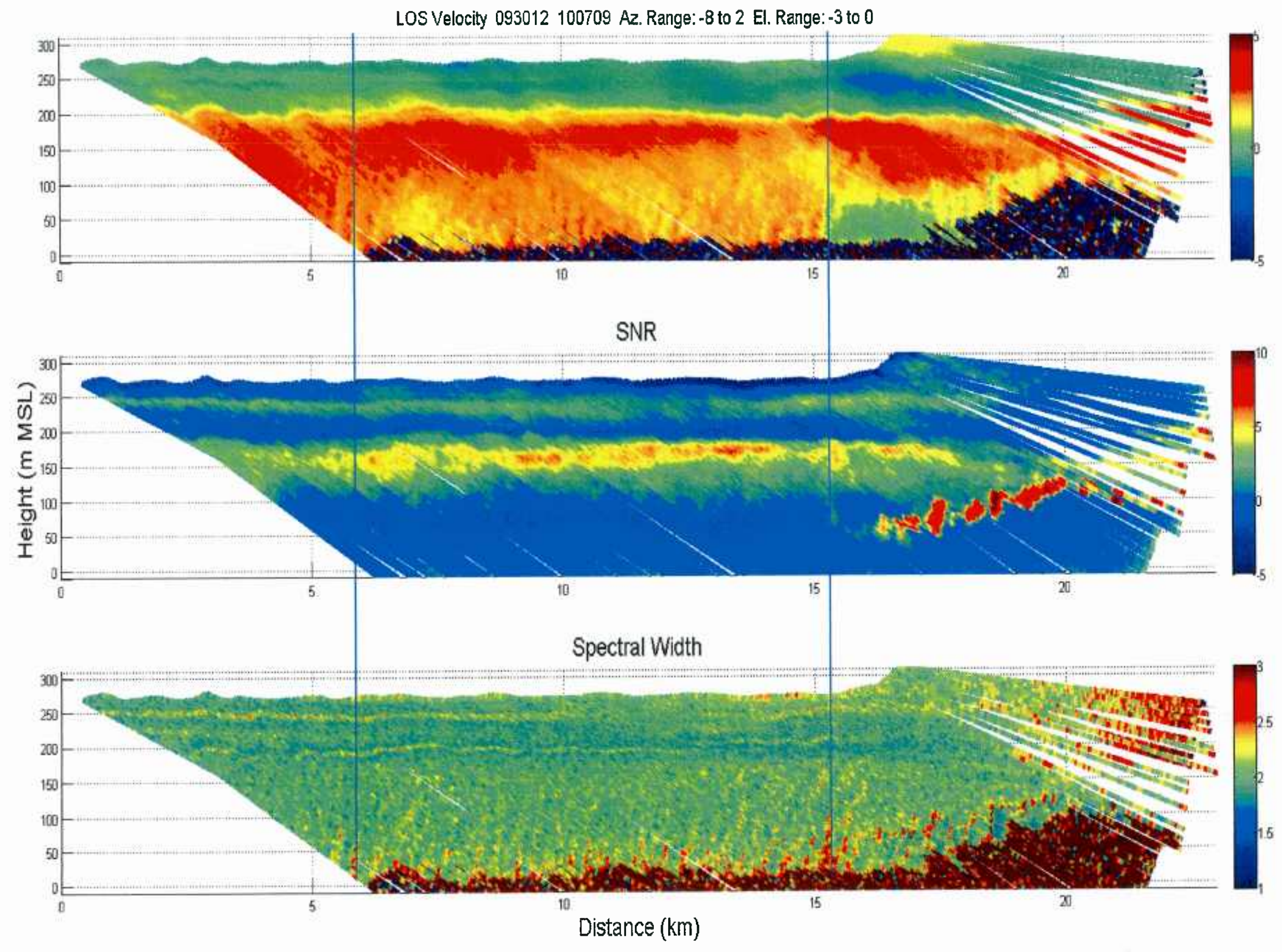




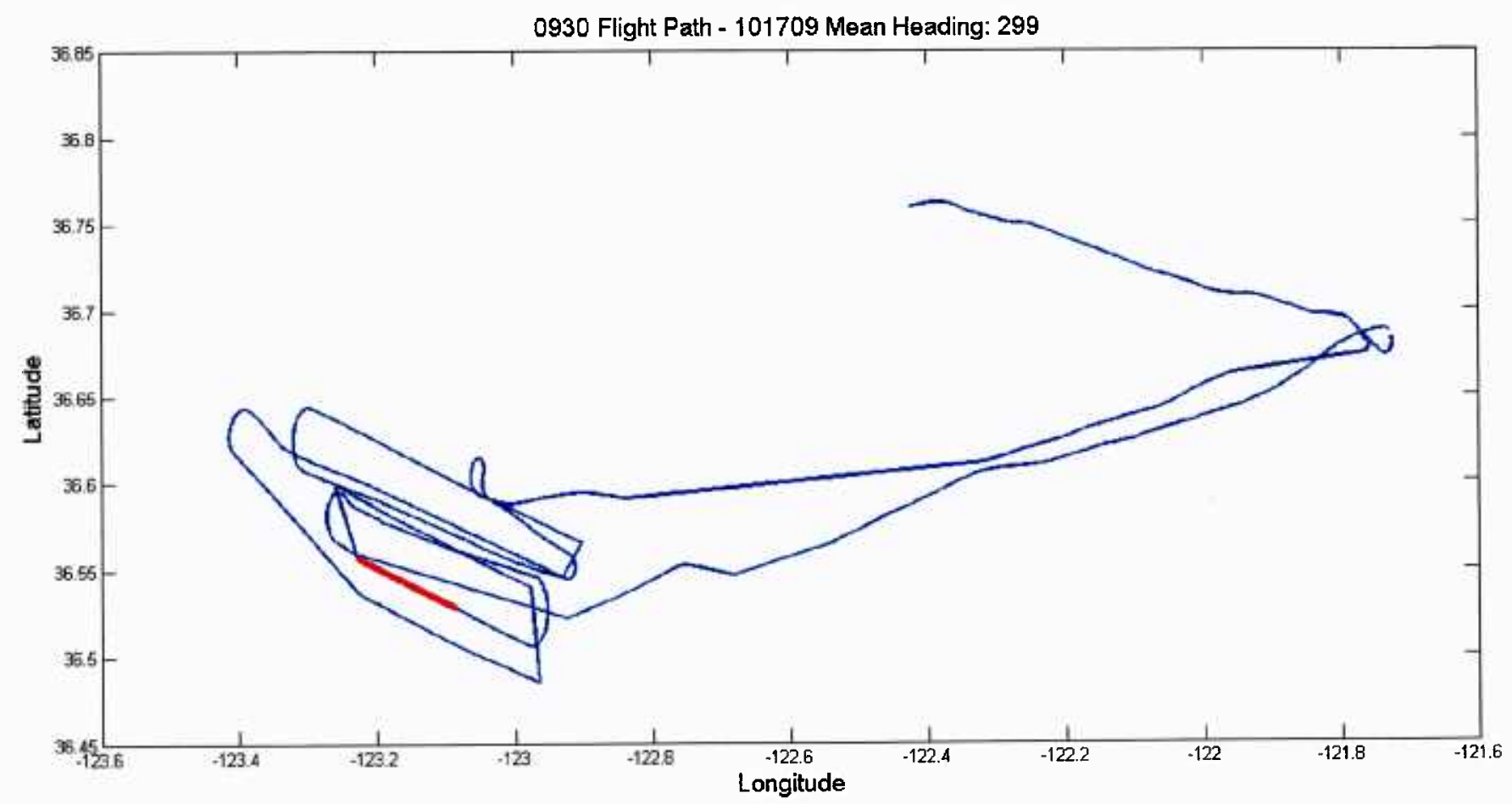


LOS Velocity $093012101709 \mathrm{Az}$. Range: 13.2 to $15.5 \mathrm{El}$. Range: -3.3 to -2.5
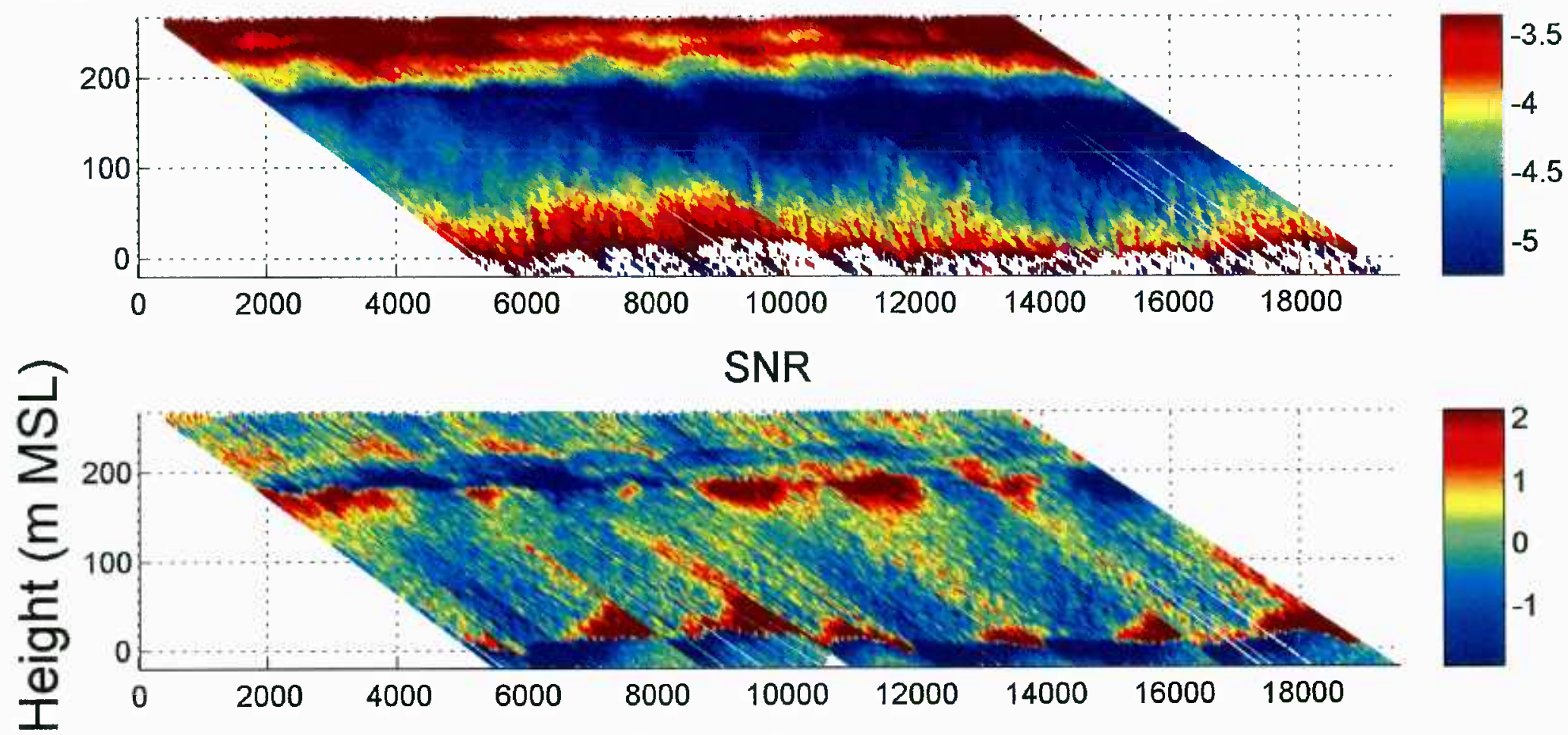

SNR

Spectral Width

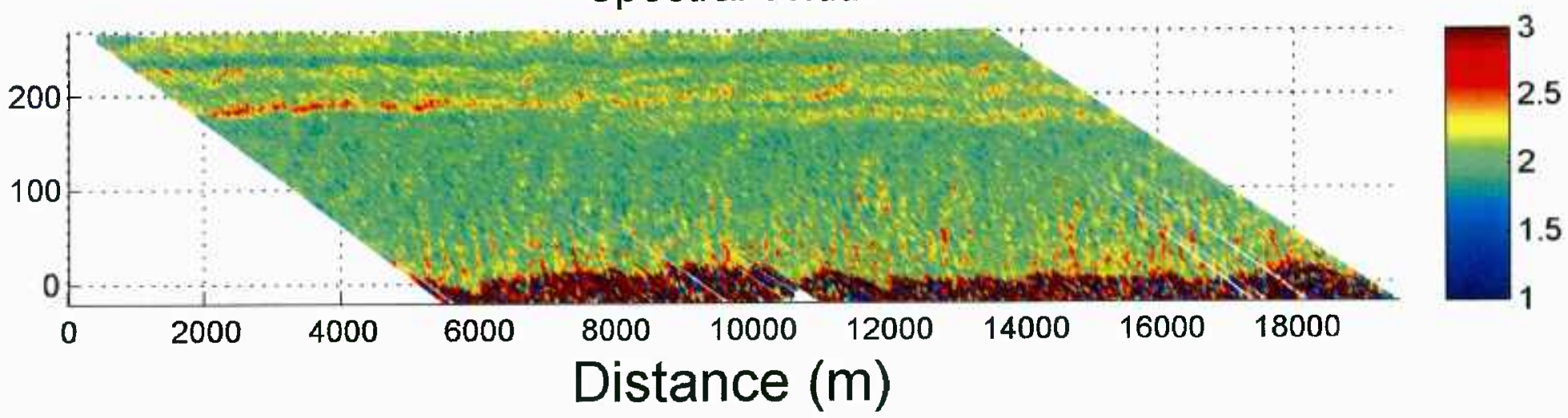




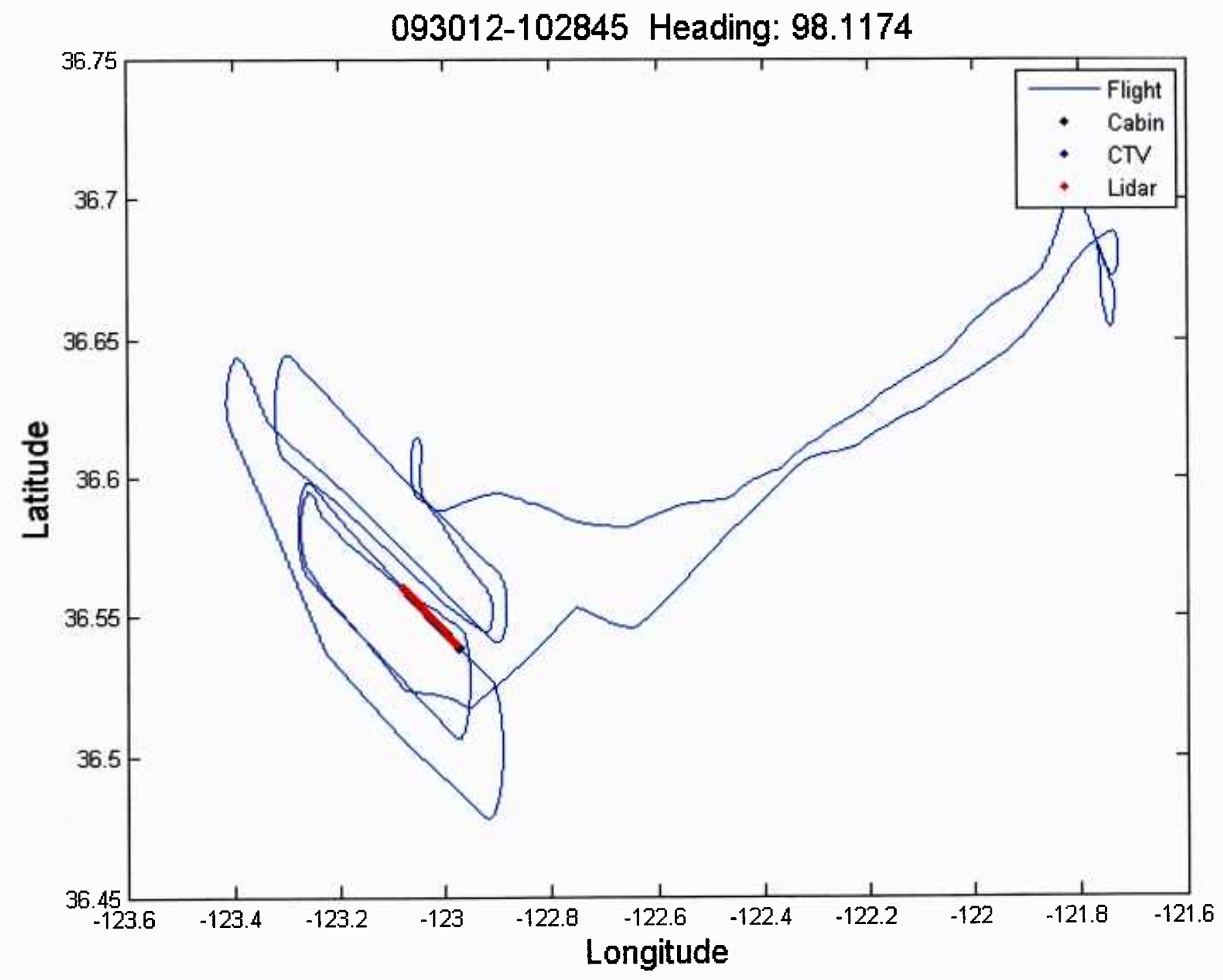




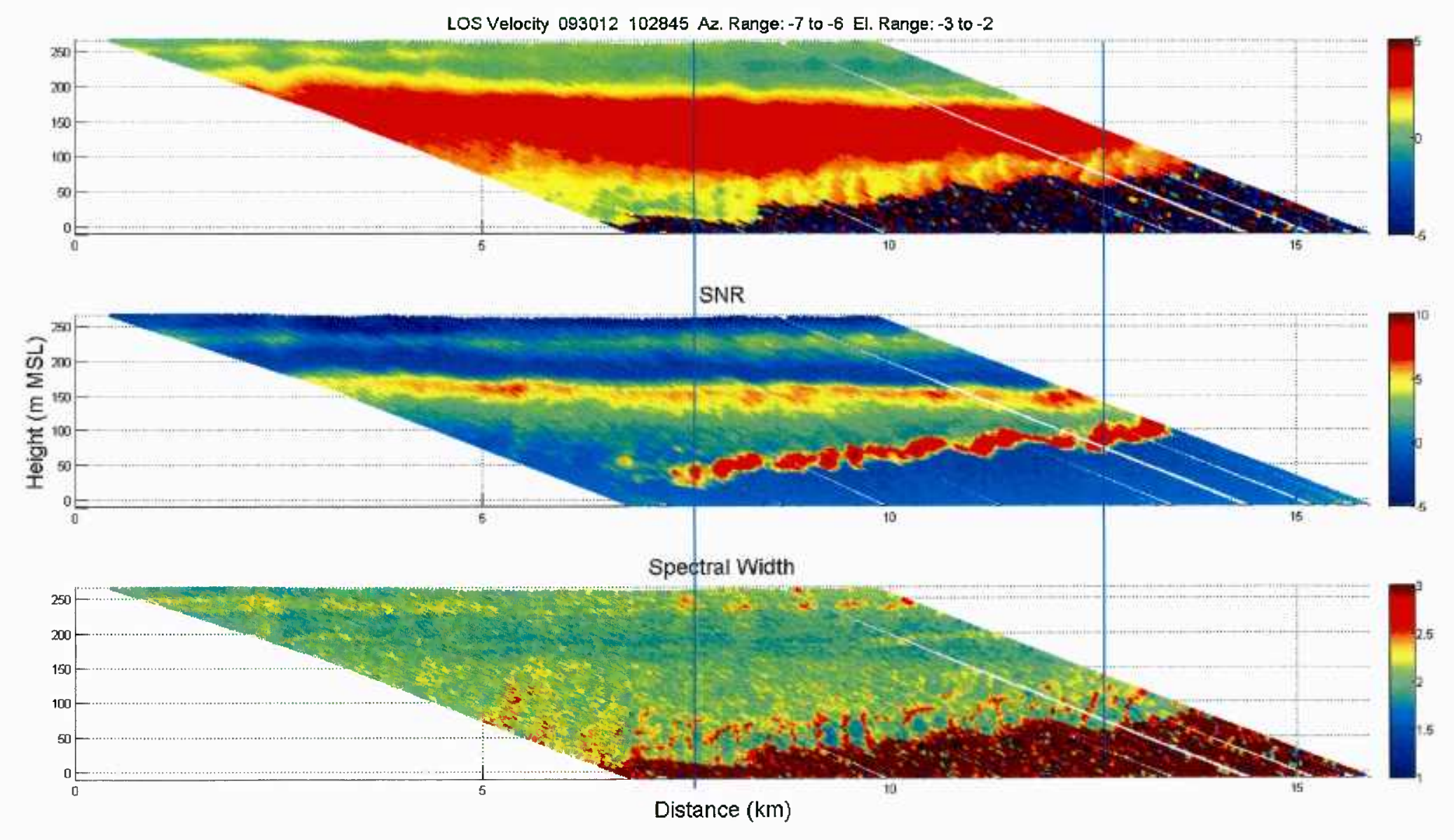




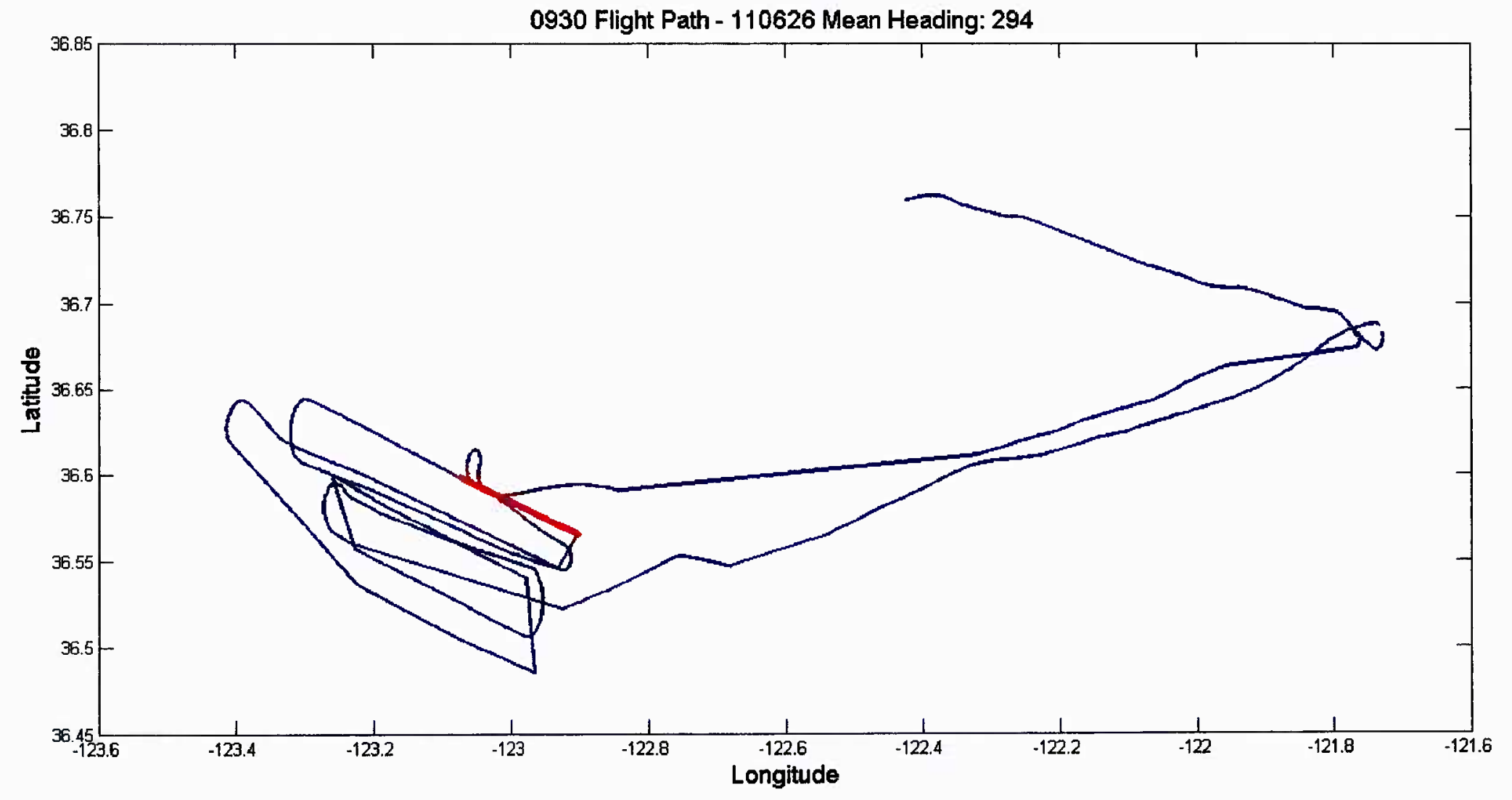




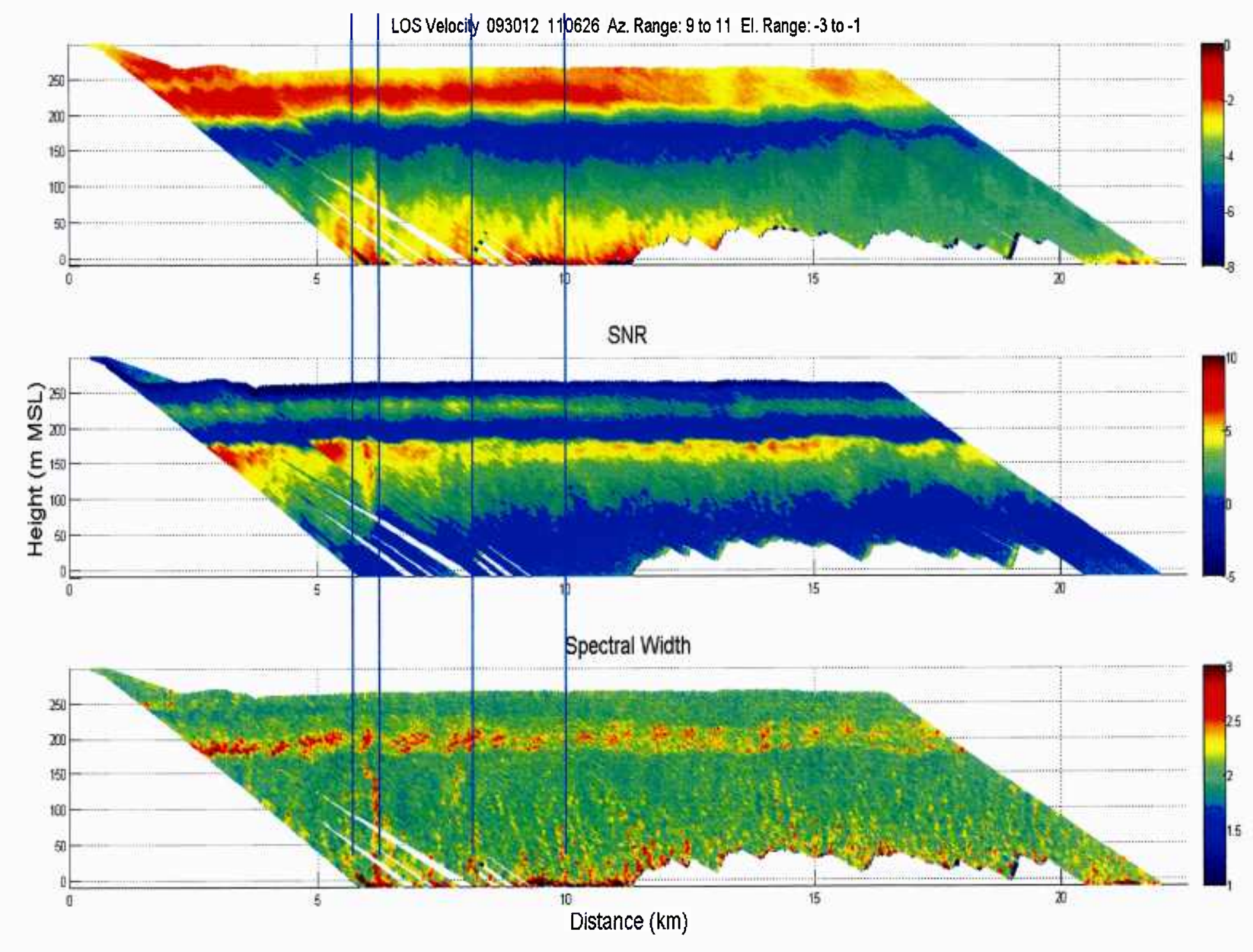




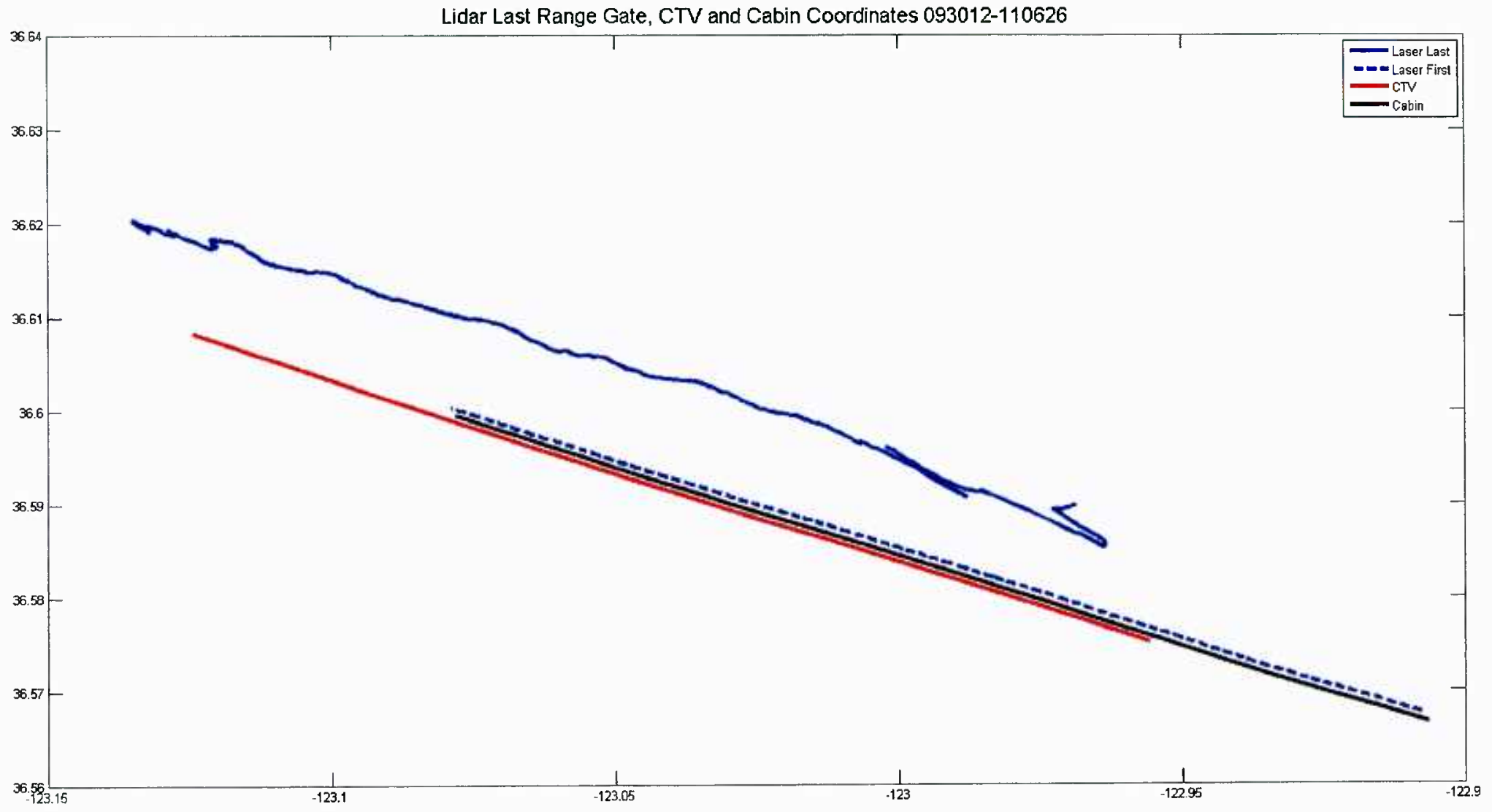


0930 Flight Path - 111126 Mean Heading: 294

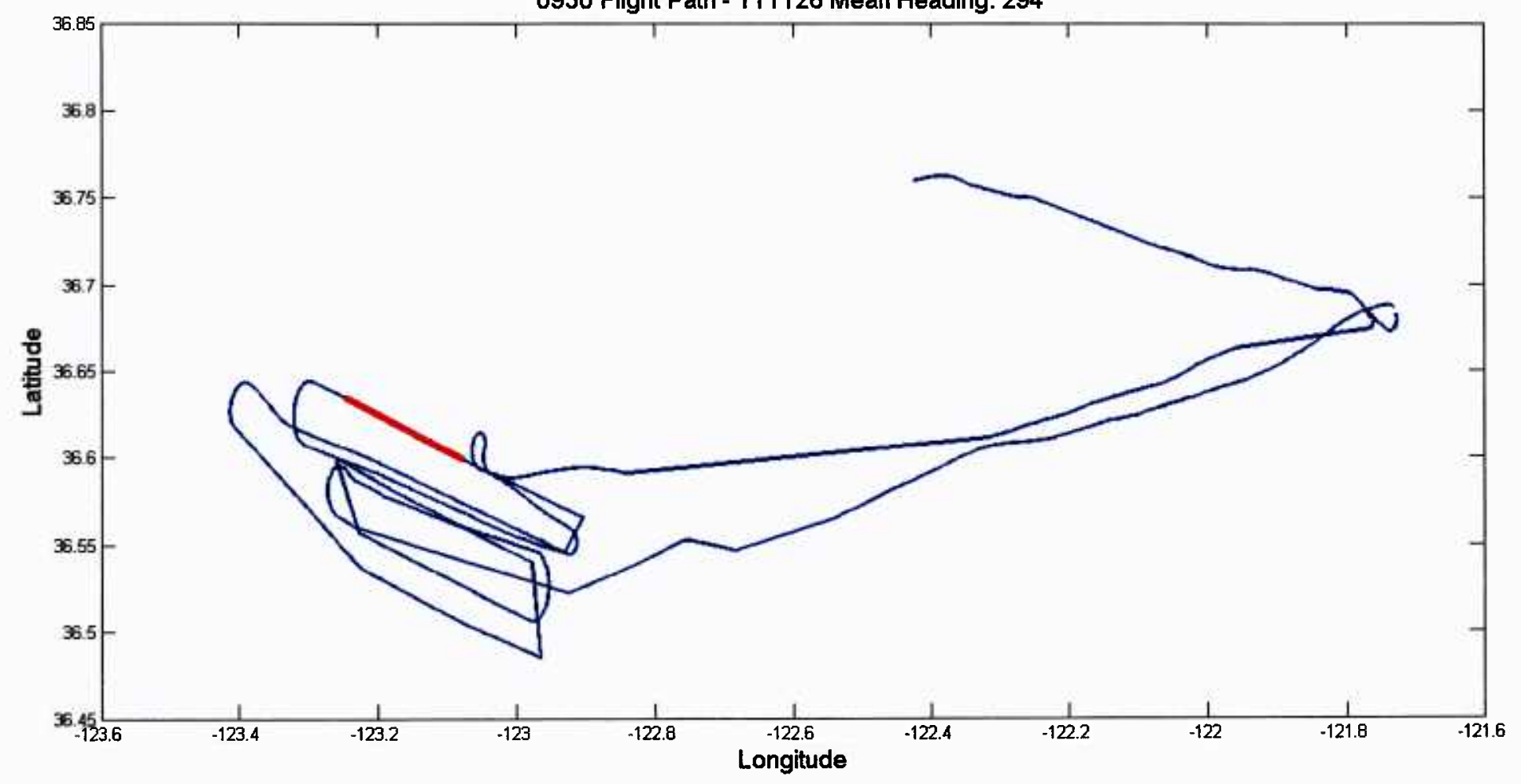


LOS Velocity 093012111126 Az. Range: 8 to 11 El. Range: -3 to -2

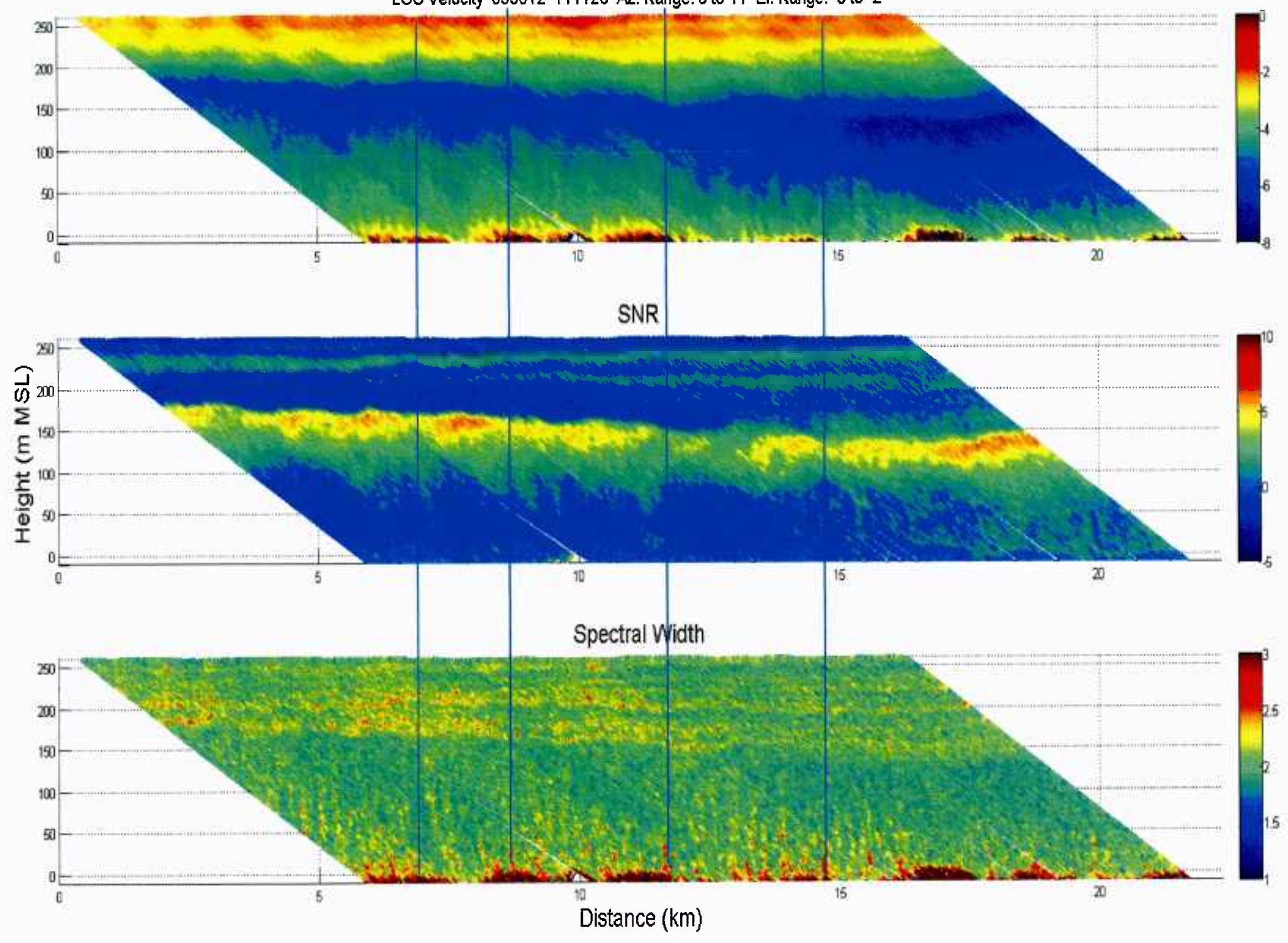




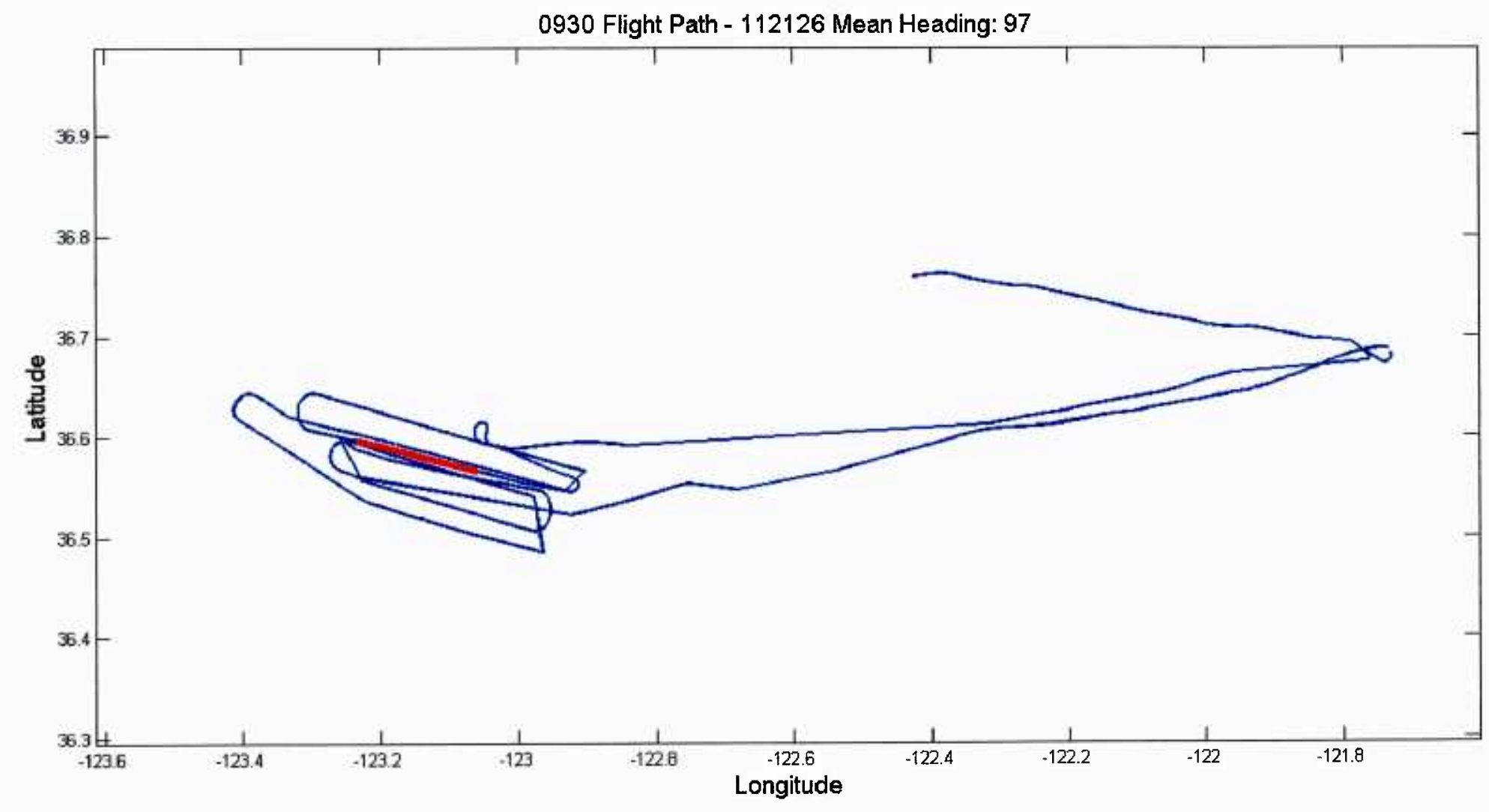




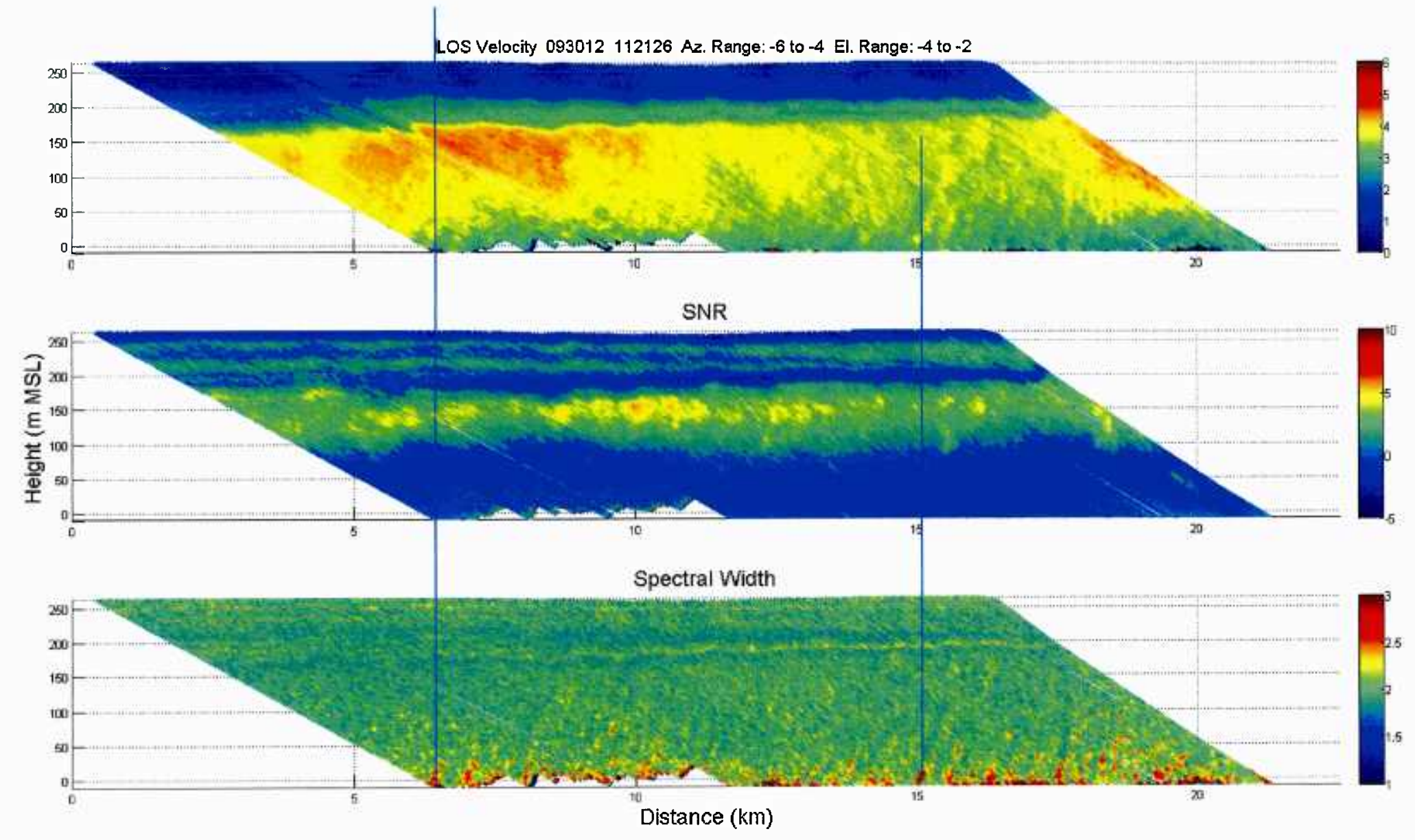


LOS Velocity 093012102845 Az. Range: -7 to -6 El. Range: -3 to -2

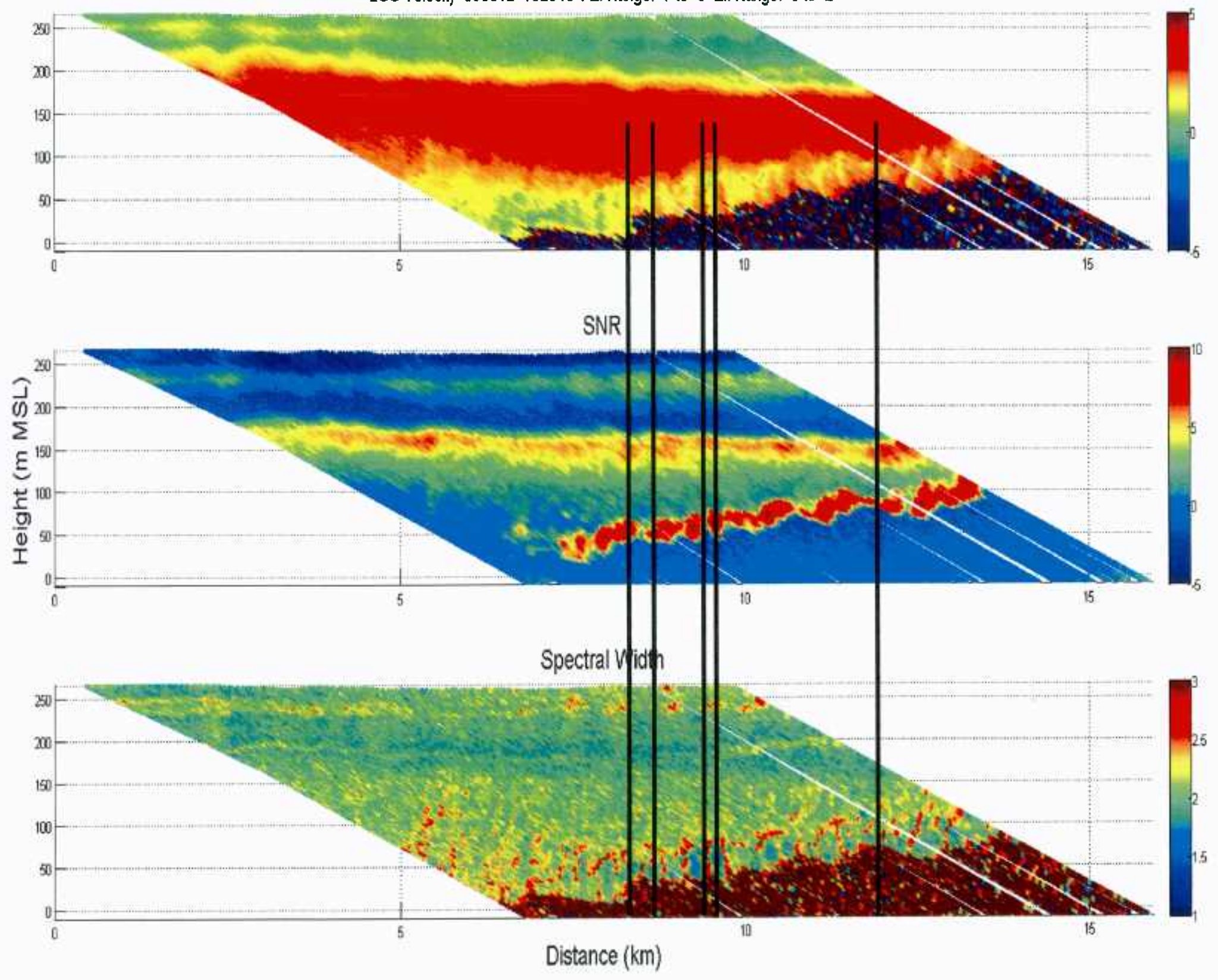




\section{Current Findings}

- Columns of "spectral broadening (SB)" seen only in zones of near surface convergence and inferred upward motion

- Not all columns terminate at elevated turbulence "blobs" or accumulation pockets.

- Number of SB columns per $1 \mathrm{~km}$ is the same as the number of convergence zones. However, the spacing between convergence zones varies. 


\section{Line density of rolls (per $10 \mathrm{~km}$ )}

\begin{tabular}{|l|l|l|}
\hline \multicolumn{1}{|c|}{ Flight Segment } & \multicolumn{1}{|c|}{ SB Columns } & $\begin{array}{c}\text { Horizontal } \\
\text { Convergence zones }\end{array}$ \\
\hline 1007 & 25 & 25 \\
\hline 1017 & 42 & 42 \\
\hline 1028 & 30 & 30 \\
\hline 1106 & 28 & 28 \\
\hline 1111 & 16 & 16 \\
\hline 1121 & 26 & 26 \\
\hline
\end{tabular}


CTV Primes 102845 TKE: 0.80198 WQ: -12.655 W-Theta: -18.7389 Skew: 0.048147
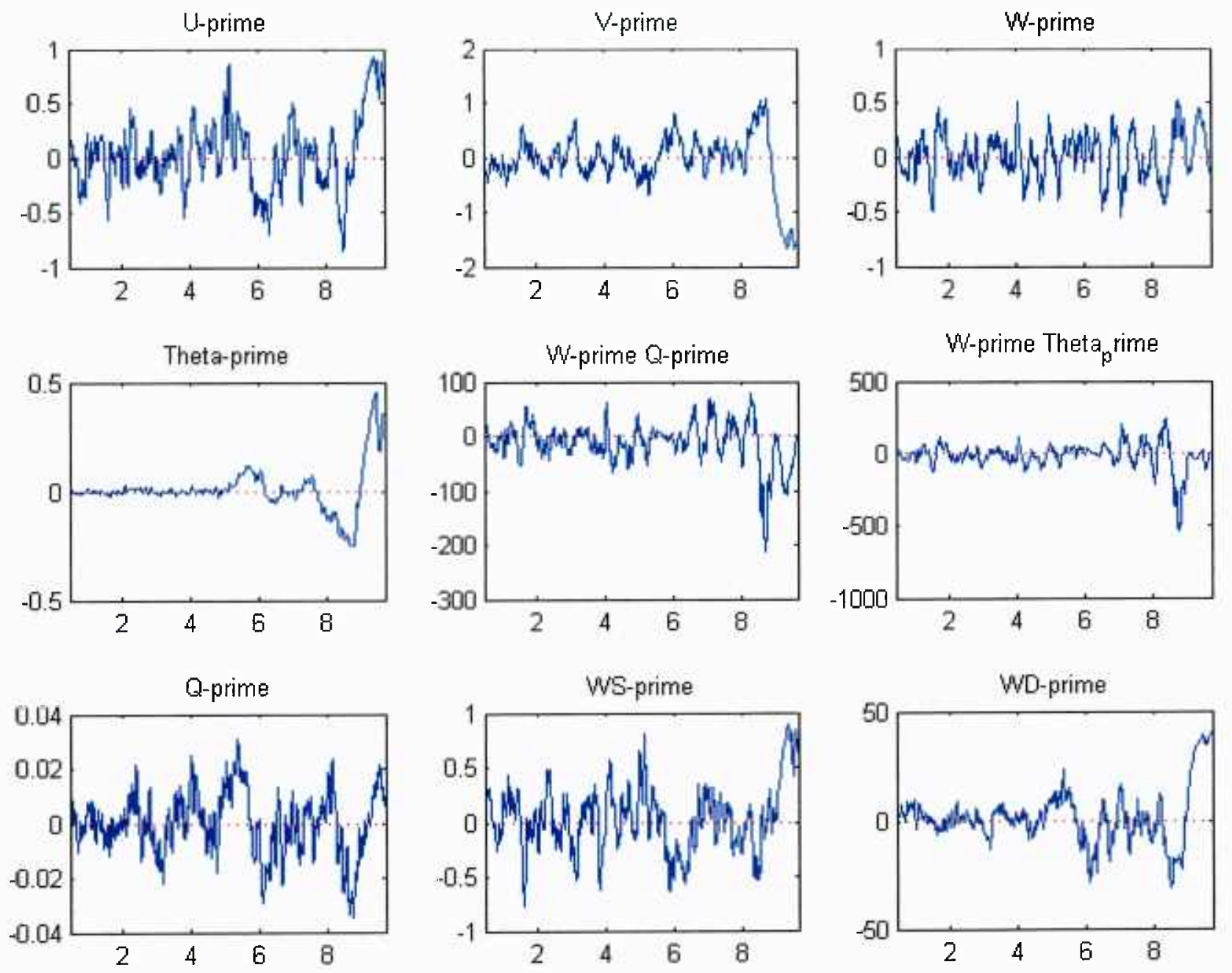

Data and cross products derived from the CTV observations (provided by Khelif (CCTI) taken during the case above. The horizontal axis units are $\mathrm{km}$ from the start of the data file. 


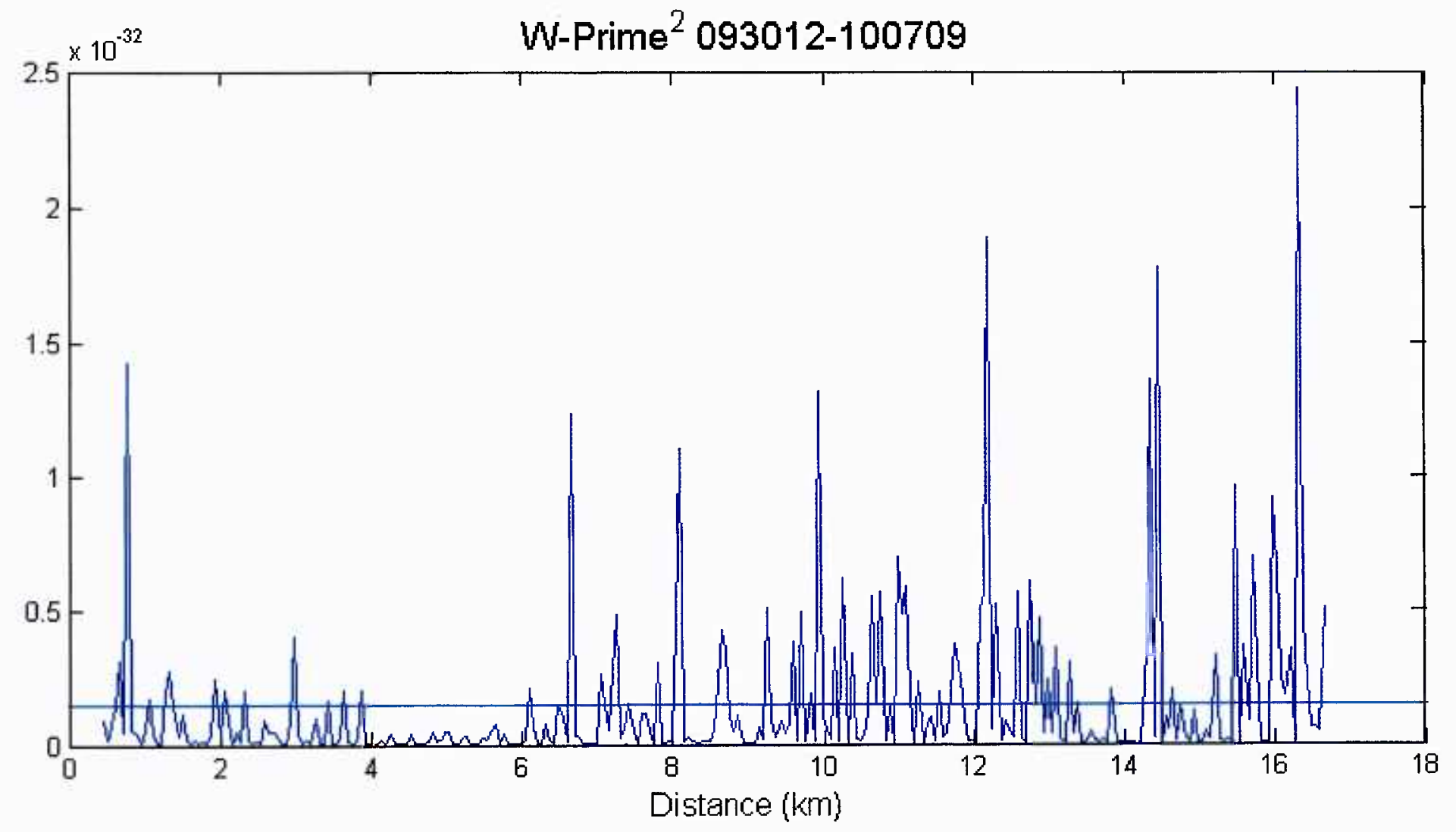




\section{Summary of segment statistics}

\begin{tabular}{|c|c|c|c|c|c|c|c|}
\hline $\begin{array}{l}\text { Flight } \\
\text { Segment }\end{array}$ & $\begin{array}{l}\text { TODWL } \\
\text { Altitude }\end{array}$ & $\begin{array}{l}\text { CTV } \\
\text { Altitude }\end{array}$ & Heading & TKE & $\begin{array}{l}\text { Sensible } \\
\text { Heat (W) }\end{array}$ & $\begin{array}{l}\text { Latent } \\
\text { Heat (W) }\end{array}$ & Skewness \\
\hline \multirow{2}{*}{1007} & \multirow[t]{2}{*}{284} & \multirow[t]{2}{*}{60} & \multirow[t]{2}{*}{94} & 19 & 8.55 & 3.43 & -.40 \\
\hline & & & & 1.92 & -1.28 & 15.15 & .90 \\
\hline \multirow{2}{*}{1028} & \multirow[t]{2}{*}{292} & \multirow[t]{2}{*}{25} & \multirow[t]{2}{*}{98} & .04 & .22 & .09 & -.18 \\
\hline & & & & .80 & -12.6 & -18.7 & .05 \\
\hline \multirow{2}{*}{1106} & \multirow[t]{2}{*}{286} & \multirow[t]{2}{*}{75} & \multirow[t]{2}{*}{294} & .05 & 3.02 & 1.21 & -.51 \\
\hline & & & & 1.1 & -3.36 & -1.19 & -.17 \\
\hline \multirow{2}{*}{1111} & \multirow[t]{2}{*}{290} & \multirow[t]{2}{*}{75} & \multirow[t]{2}{*}{293} & .24 & 1.98 & .80 & -.37 \\
\hline & & & & .29 & -.74 & .55 & .22 \\
\hline 1121 & 288 & climbing & 98 & .14 & -1.11 & -.44 & .90 \\
\hline
\end{tabular}




\section{Summary (Marine)}

- The combination of an airborne Doppler Wind Lidar and a Controlled Towed Platform holds promise of a transformation of how we investigate air/sea exchanges and construct flux parameterizations for use in numerical weather models.

- Interpretation of the TODWL derived spectral width is a primary focus of our current investigation.

- Presentation by Foster this afternoon will address the second focus area, that of adding a "shear instability driven rolls" term to the EDMF. 


\section{Rolls over land}

- Extension of the UPP (Marine) study of rolls contribution to the EDMF to investigations over land.

- Used to provide comparisons of the roll phenomena as measured by an Airborne Doppler Wind Lidar.

- Flights conducted along Salinas Valley and over the Dugway Proving Grounds, Utah. 
LOS Velocity $092512160205 \mathrm{Az}$. Range: 37.6 to 41.8 El. Range: -1 to 2.1
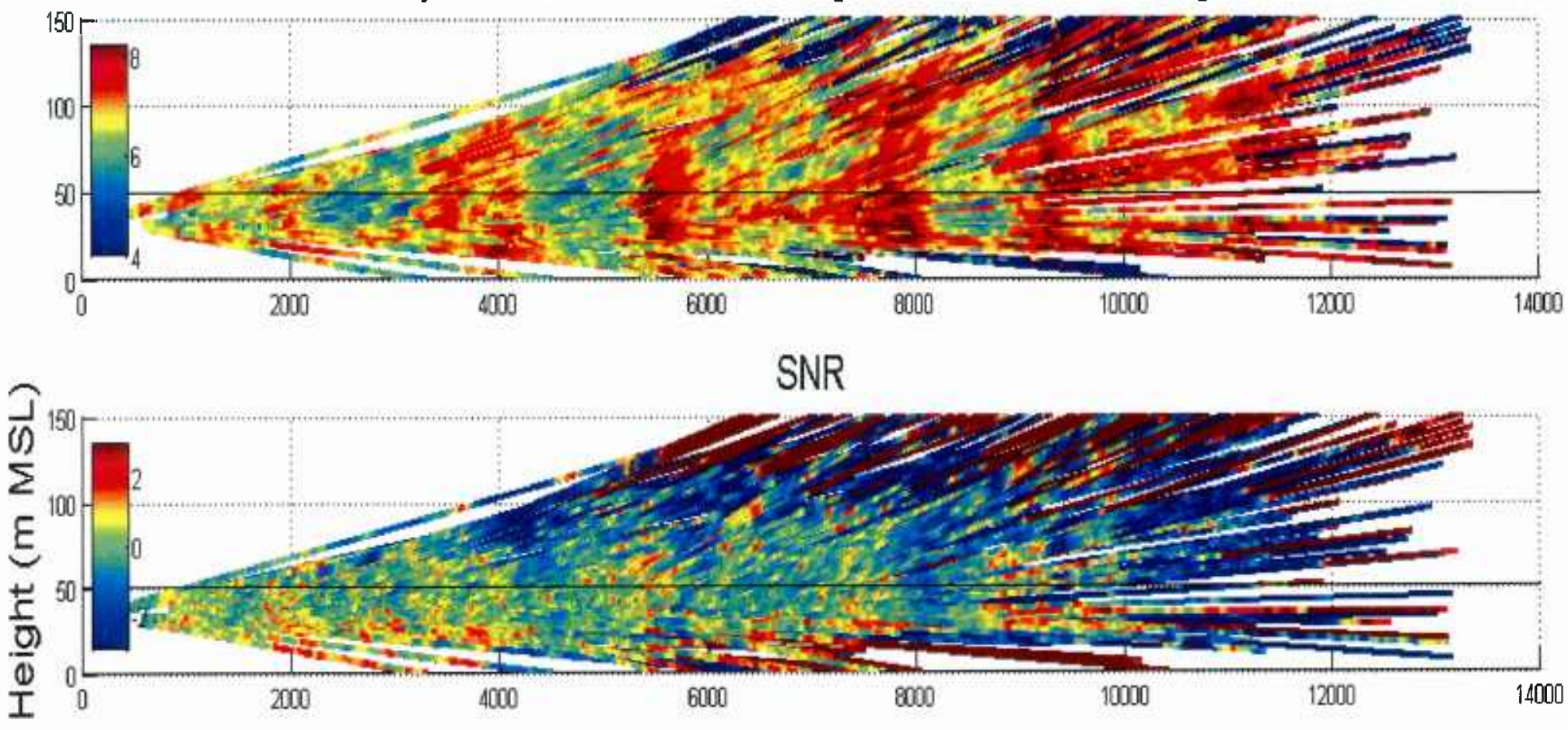

Spectral Width

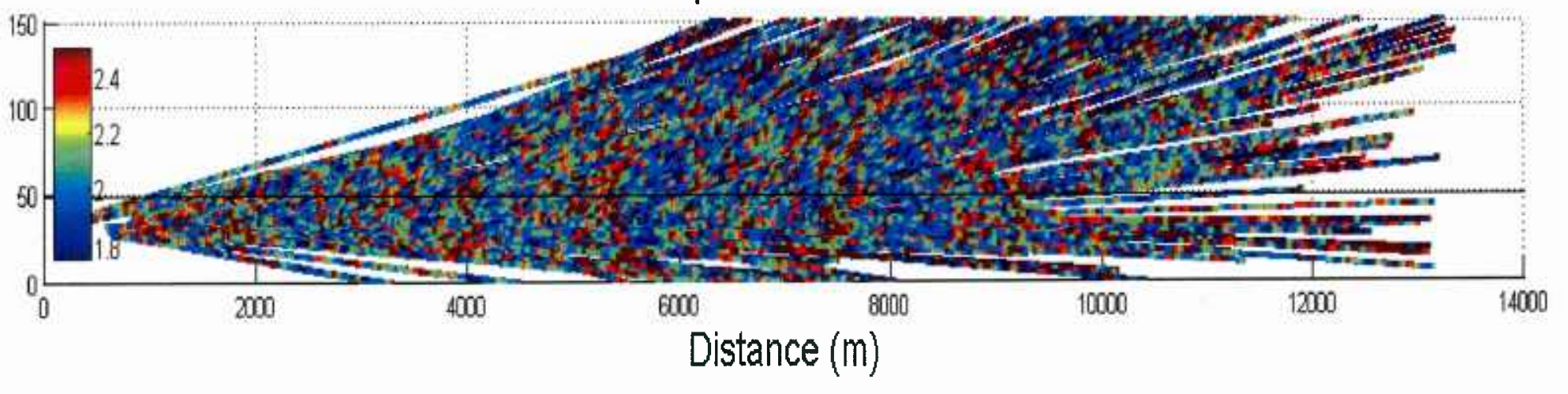


Longitude (degr.)
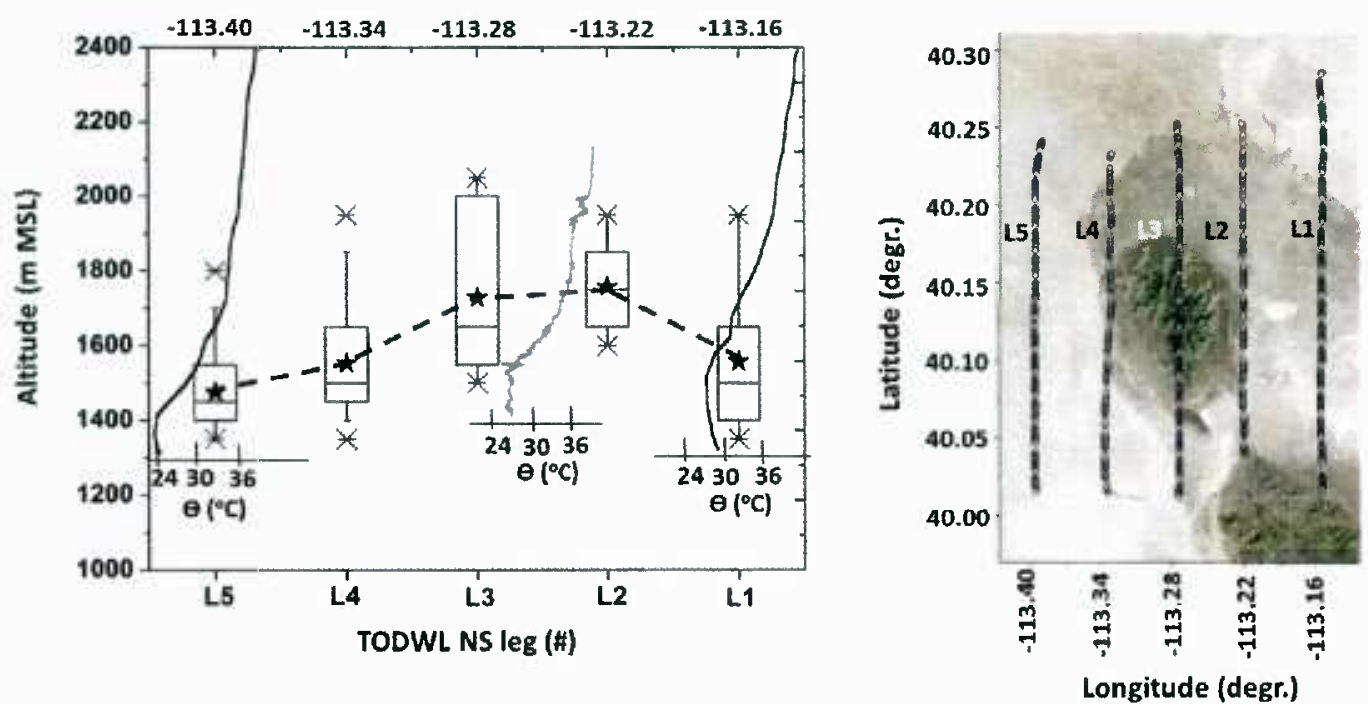

Box-and-whisker plot of the PBL heights derived from aerosol backscatter profiles along the north-south flight legs (b) performed during a morning TODWL mission between 1012 and 1052 MDT on 10 October 2012. The horizontal line in the box and the bottom and top line of the box show the median of the data, and the lower and upper quartiles (25\% and $75 \%$ ), respectively. The whiskers show the minimum and maximum values while the solid star is the mean value. Vertical potential temperature profiles obtained over the Playa and Sagebrush sites are shown on the western and eastern part of the domain. Also shown is the potential temperature profiles obtained from DATAHAWK (UAV) measurements located between TODWL legs L2 and L3. 

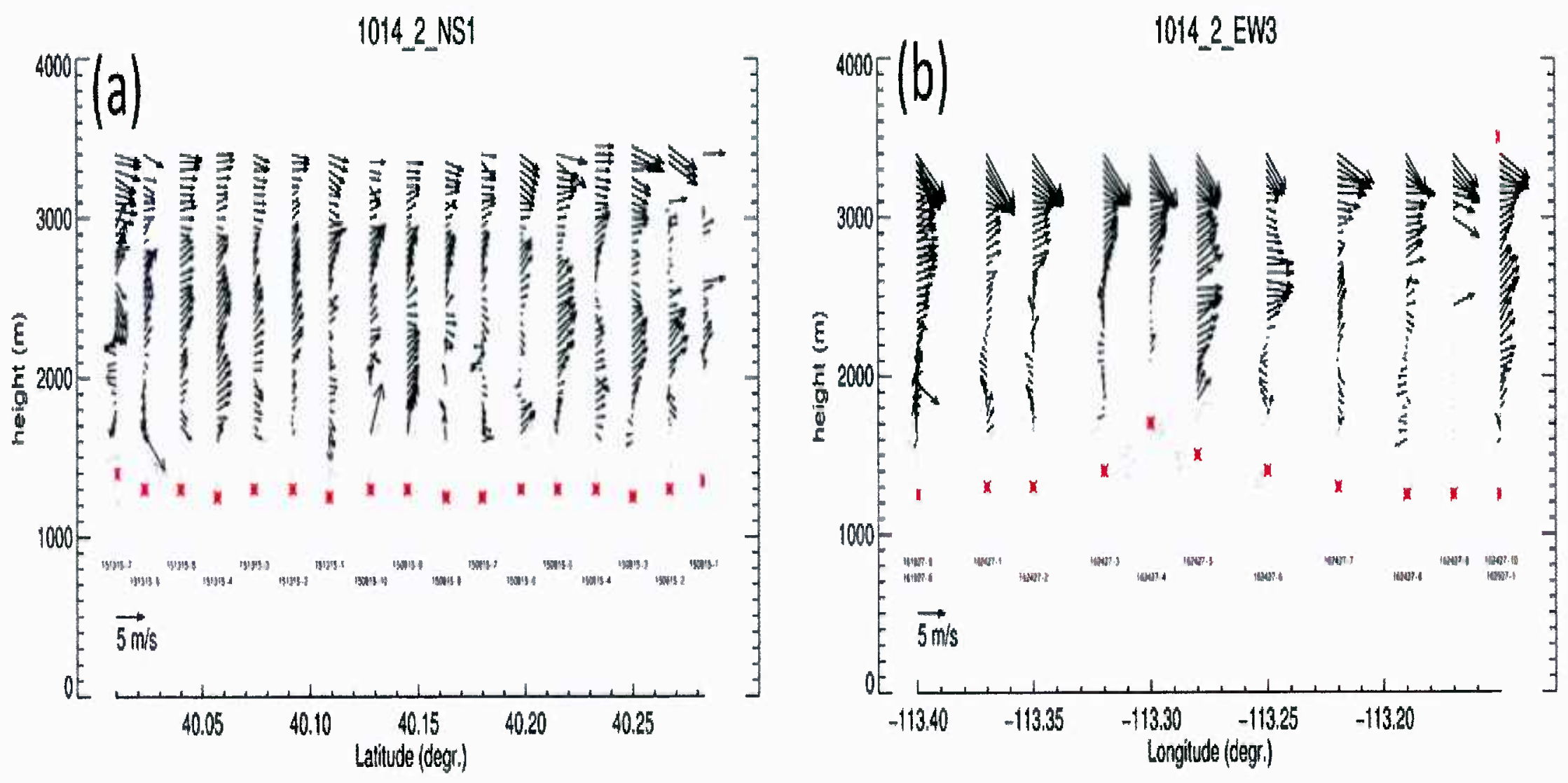

Vertical profiles of TODWL derived wind speed and direction along a northsouth flight leg east of Granite Peak (a) and an east-west flight leg over Granite Peak (b) on the afternoon of 14 October 2012. 


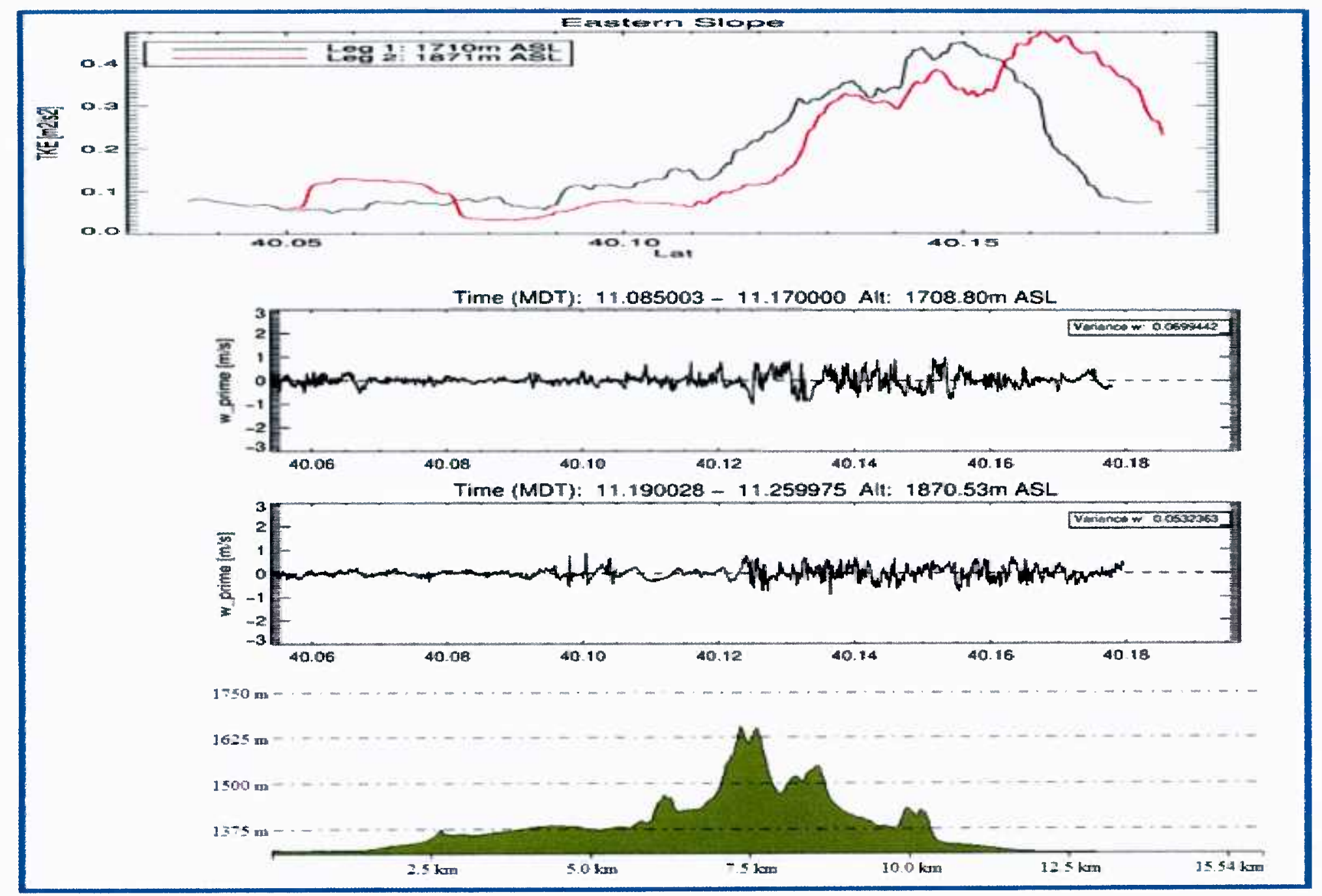

From top to bottom, horizontal profile of turbulence kinetic energy, vertical velocity vat two heights, and topography below a flight leg east of Granite Peak on 14 October 2012 


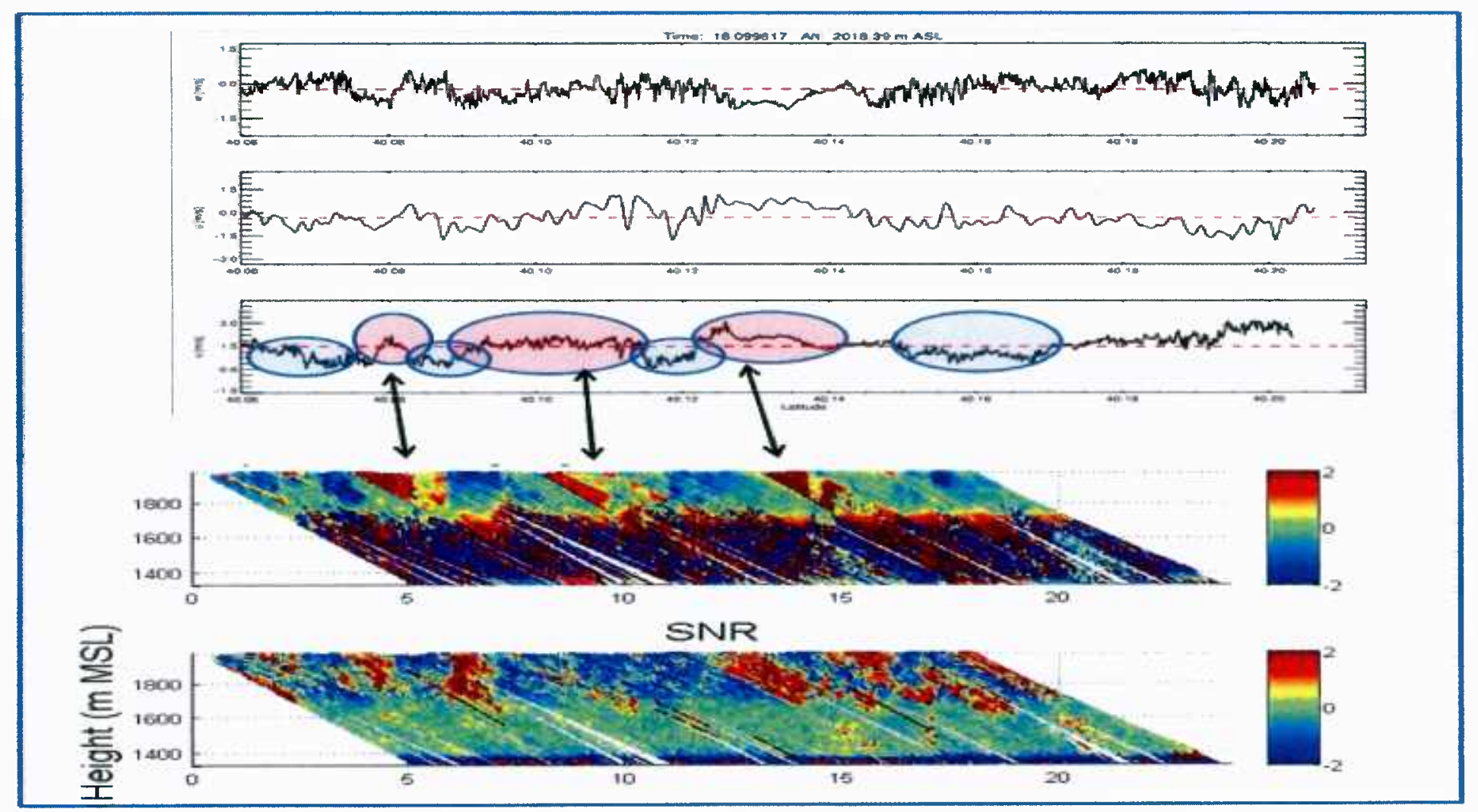

From top to bottom: $w, u$, and v -wind component along a flight leg east of Granite peak on 14 October 2012. The flight leg shown here is about $10 \mathrm{~km}$ further to the east than the flight leg shown in Fig. 3. Shown in the bottom two panels are the line of sight velocity and the signal-to-noise ratio of a forward stare on the same flight leg. In these panels, coherent turbulence structures are visible that align well with velocity fluctuations from the in-situ aircraft measurements. 


\section{Summary (land)}

- Both convective and shear driven rolls can be seen over land in the daytime.

- Salinas Valley exhibits convective rolls in the daytime and shear driven rolls at night (not discussed in this presentation).

- Deeper boundary layers at DPG exhibit rolls but are difficult to characterize in any detail. 

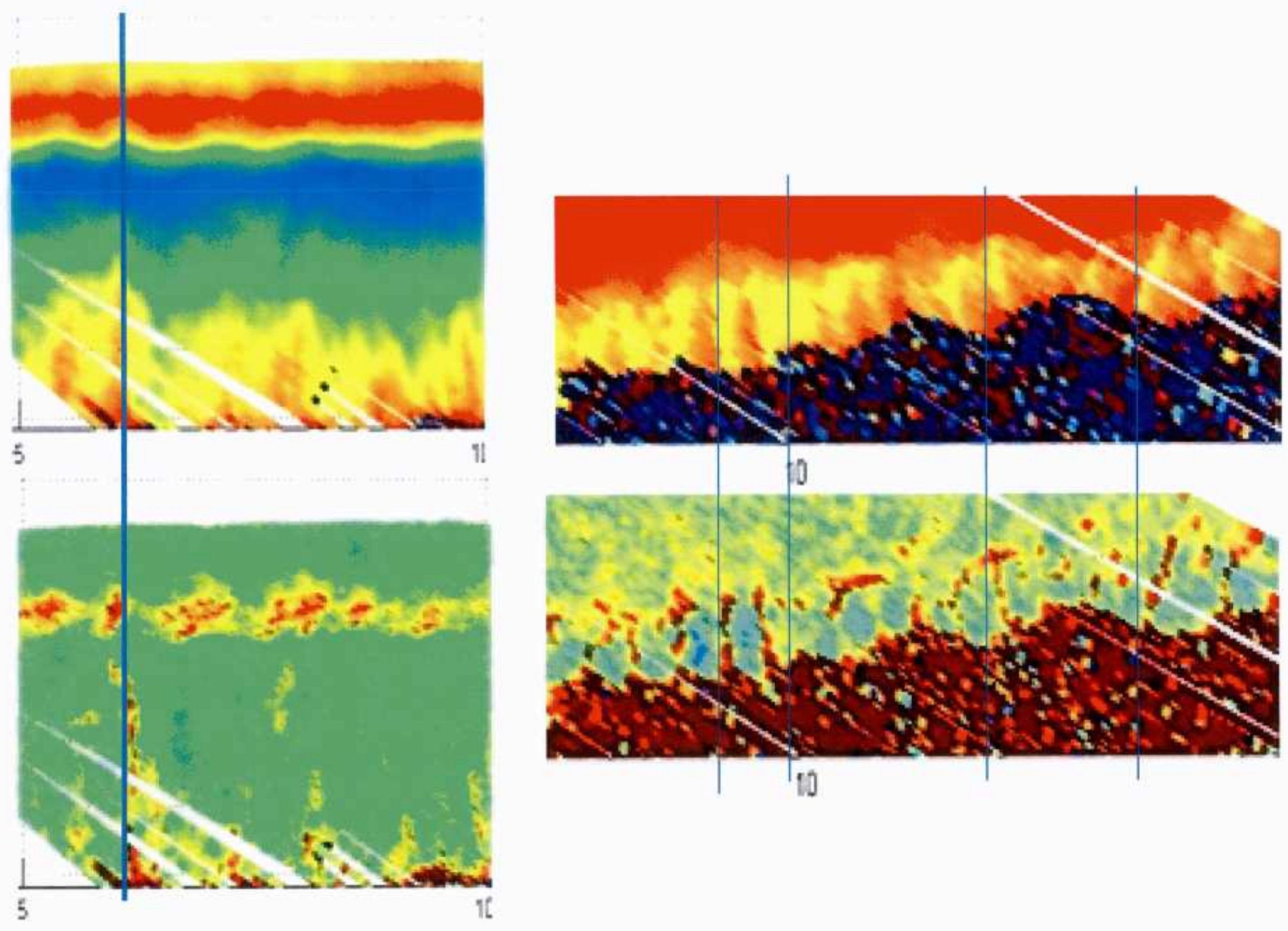


\section{Presentations and Students}

- Two graduate students supported at UVA. Focused upon the DPG data sets.

- Papers presented at multiple working groups, AGU 2013, SPIE 2014, AMS 2013, 2014.

- Paper to be published on the 9/30 case study on hold until sampling modeling is complete. 


\section{Research Plans}

- Complete DWL sampling model developed to understand the impact of various scales of turbulence and shear on spectral broadening.(Emmitt and $\mathrm{O}^{\prime}$ Handley)

- Reprocess the 9/30/12 data sets guided by input from the sampling model.(Emmitt and Godwin)

- Extend Foster model to cover the various modes of the $\mathrm{MBL}$ (Ri, shear, convective stability) (Foster)

- Conduct sensitivity experiments with a modified EDMF within the WRF and perhaps, the COAMPS. (de Wekker and Foster).

- Produce a lessons learned document and draft plan for an intensive TODWL/CTV investigation of non-convective rolls. Interact with the roll investigators (Mahrt, Ginis, ..) in the design. 


\section{CIRPAS Twin Otter with CTV below}

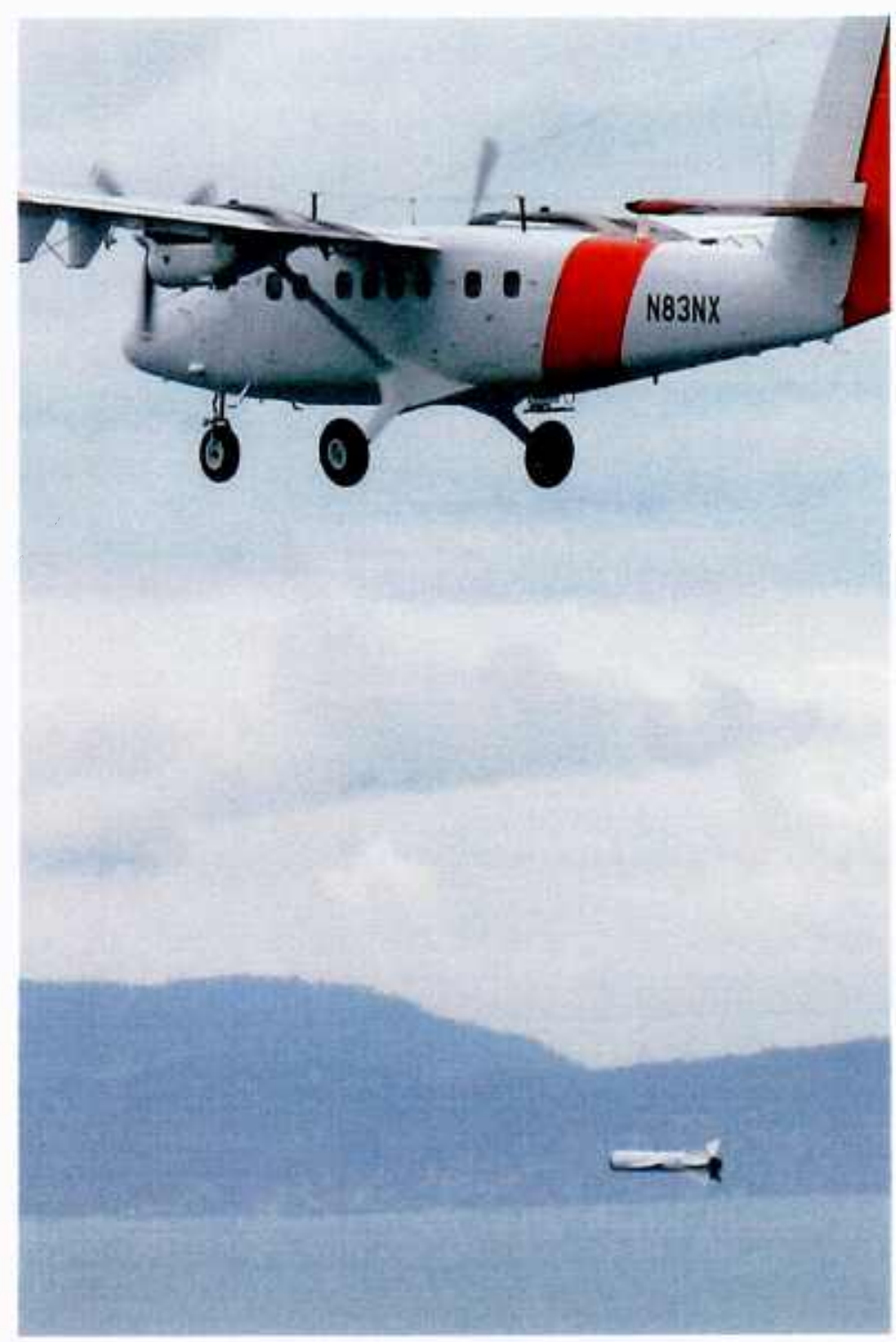

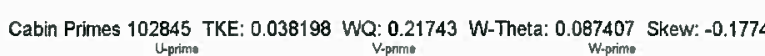

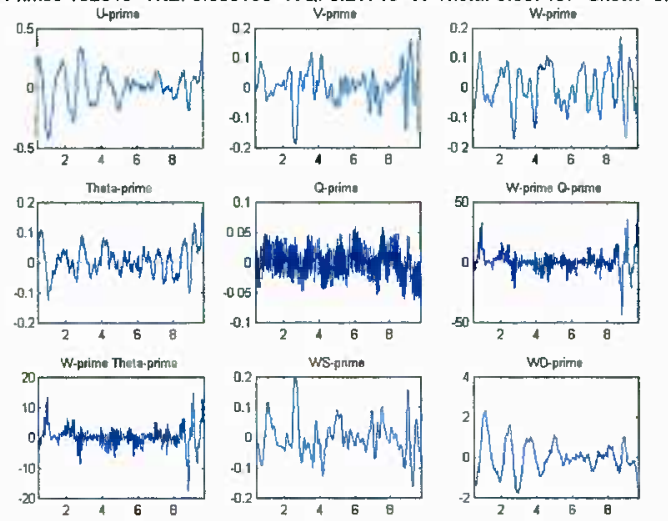

\section{Twin Otter}

Probe Data

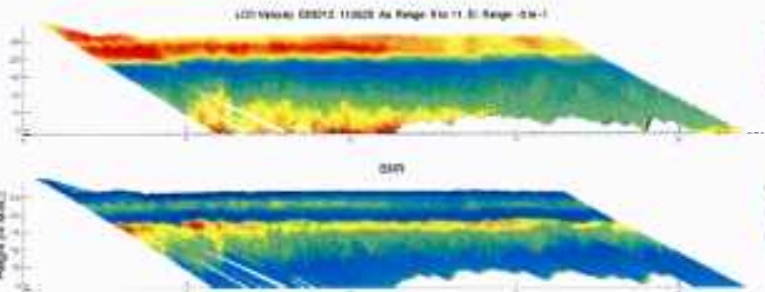

IODWL

Time/height Cross sections

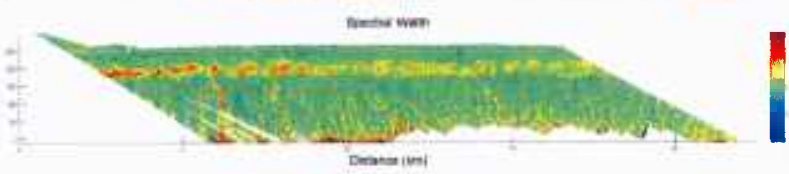

CTV Primes 102845 TKE: 0.80198 WQ: -12.655 W-Theta: -18.7389 Skew: 0.048147
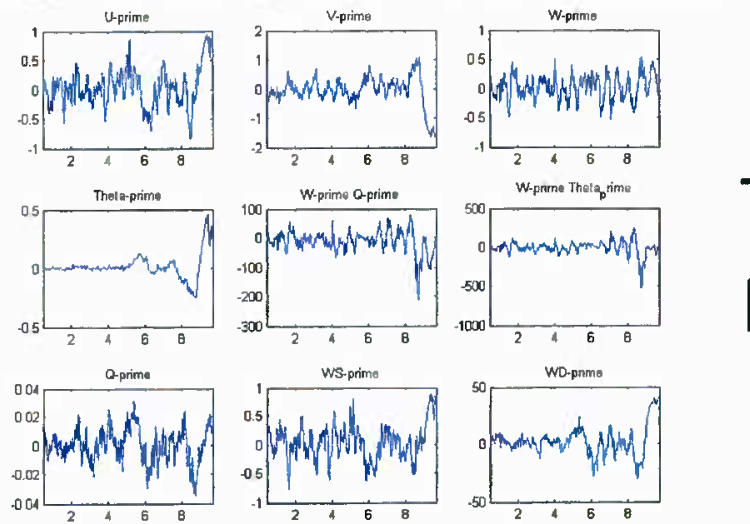

Towed Vehicle Flux Data*

* Derived from data provided by Khelif (UCl) 


\author{
Attachment 4 \\ EDMF in the Near-Neutrally Stratified Boundary Layer \\ presented at the DRI workshop 2014 \\ by R. Foster and G. D. Emmitt
}




\title{
EDMF in the Near-Neutrally Stratified Boundary Layer
}

\author{
Ralph Foster, APL UW \\ G. David Emmitt, SWA
}


Cold air flow over ice:

smaller-scale rolls,

near-neutral, possibly

slightly stable

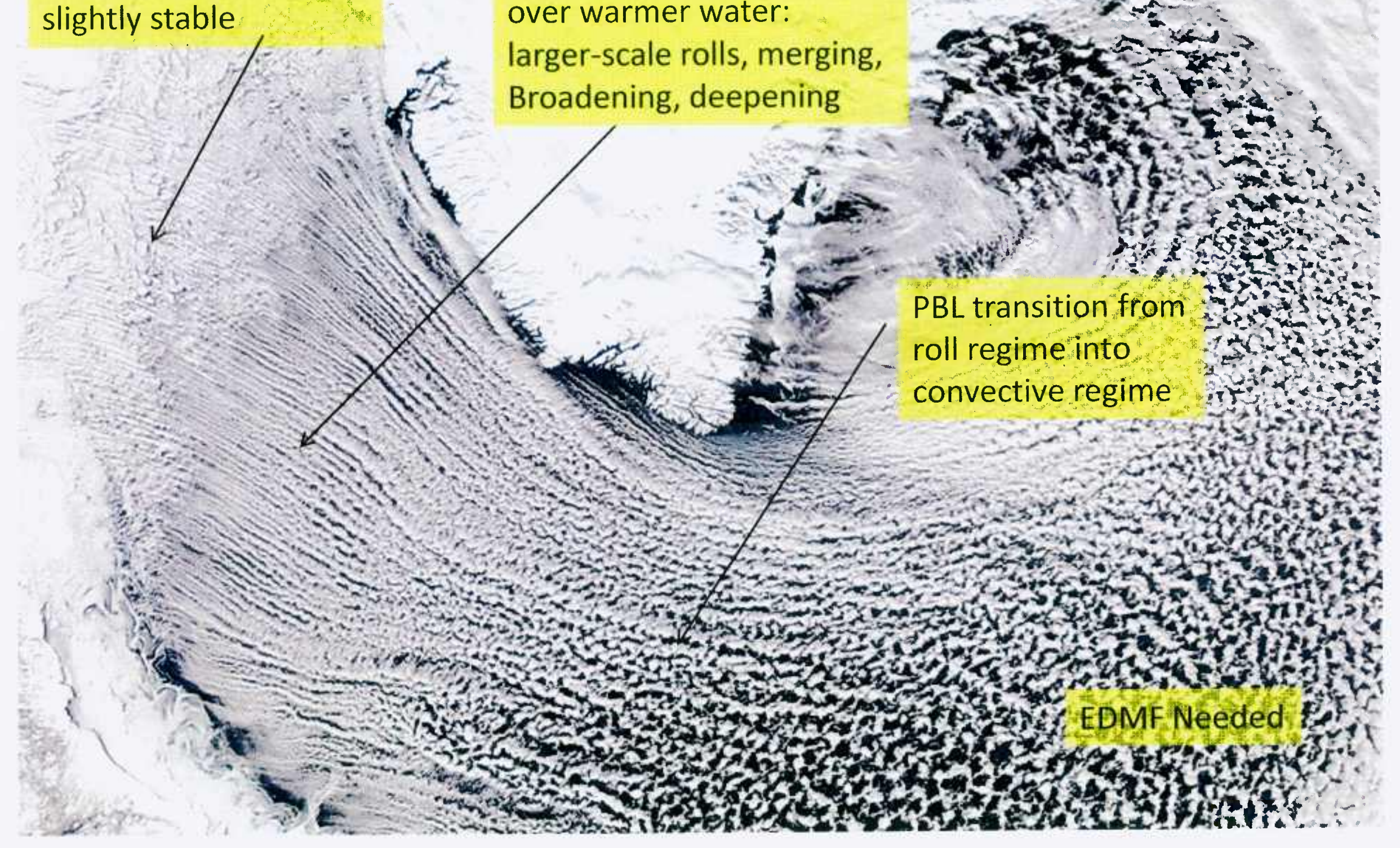




\section{EDMF}

- Method for estimating the non-gradient contribution to the PBL fluxes

- Current MF focus is on non-gradient contribution in low winds, primarily buoyancy production

- Assumes ED model correctly models PBLS with significant shear production

- Does EDMF need to capture the non-gradient fluxes due to roll OLE?

- Extension of MF contribution to near-neutral stratification 


\section{PBL Rolls}

- Very common

- Span the depth of the PBL

- Due to combined shear \& convective instability

$-U 10>\sim 5$ to $7 \mathrm{~m} / \mathrm{s}$

- Near-neutral to moderately unstable stratification

- Non-gradient diffusion transport

- Is this contribution important?

- Can we measure it?

- Can we parameterize it? 


\section{cllck}

JOURNAL OF (GEOPHYSICAL RESEARCH, VOL, 113, 017104, doi:10.1029/2017JDX)146-
Simulation and parameterization of the turbulent transport in the hurricane boundary layer by large eddies

Ping $\angle$ hul

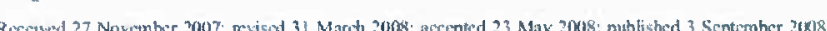

[1] Hurricane boundary layer (IIBL) processes. especially the strueture of the collerent lange eddy circulations (LIC $C$ ) and their induced vertical transport, are not well understood. This paper intreduecs a large eddy simulation (LES) tramework in a weath hindeasting mode developed from a mulliple scale nesed Weather kesearch and orecasing (WRH) model. Using the WRF - LLS, this study investigated the structure of the IIBL LLe's and the associated vertical transpon during the landiall of llurricanc han

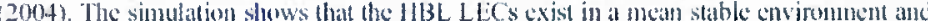

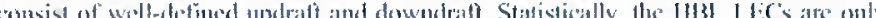

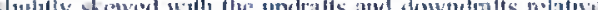

(c) Large eddy circulations and virtual potontial temperature (k) at the cross section in (a.3)

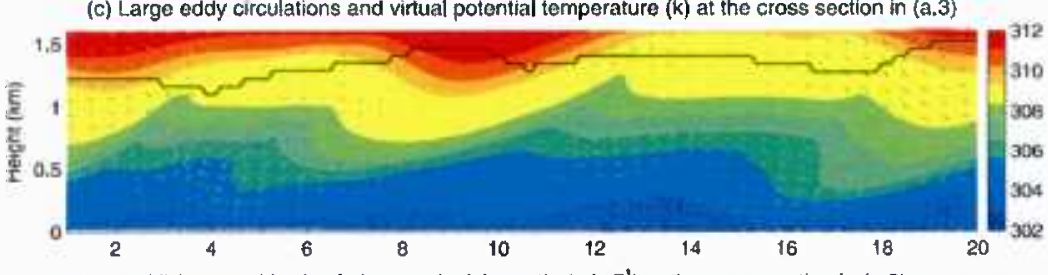

(d) Large eddy circulations and mixing ratio $\left(\mathrm{g} \mathrm{kg}^{-1}\right)$ at the cross section in (a.3)

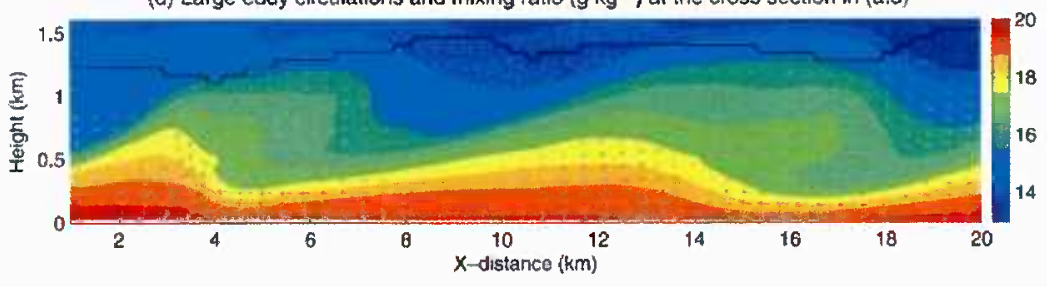

ZHU: HURRICANE BOUNDARY LAYER TURBULENT TRANSPORT Distance belween the cores of maximum and minimum winds $(\mathrm{km})$

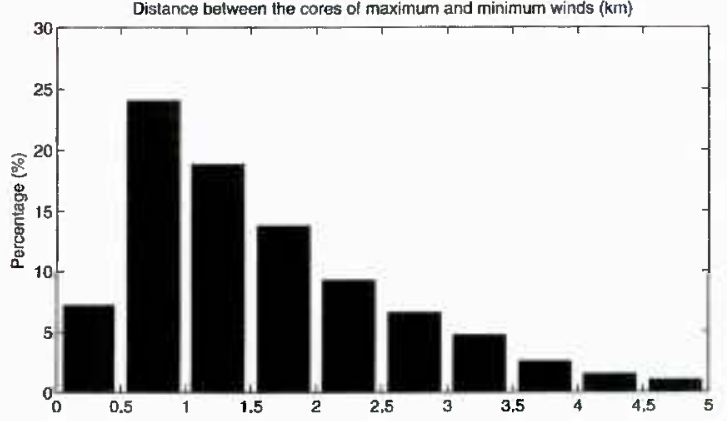

Figures. Histograin of the distance between the cores of maximun and minimum winds in the surface
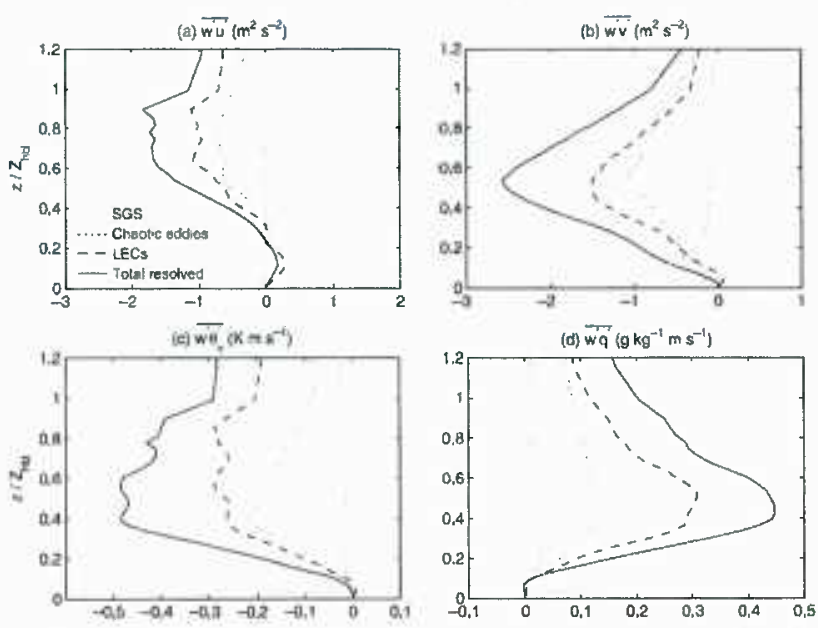

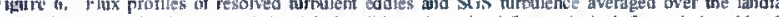

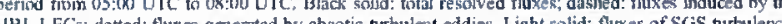
The teich ho been nomulized by the men

19710-4

ZHU: HURRKCANE BOUNDARY LAY LR TURHULENT TRANSPORT
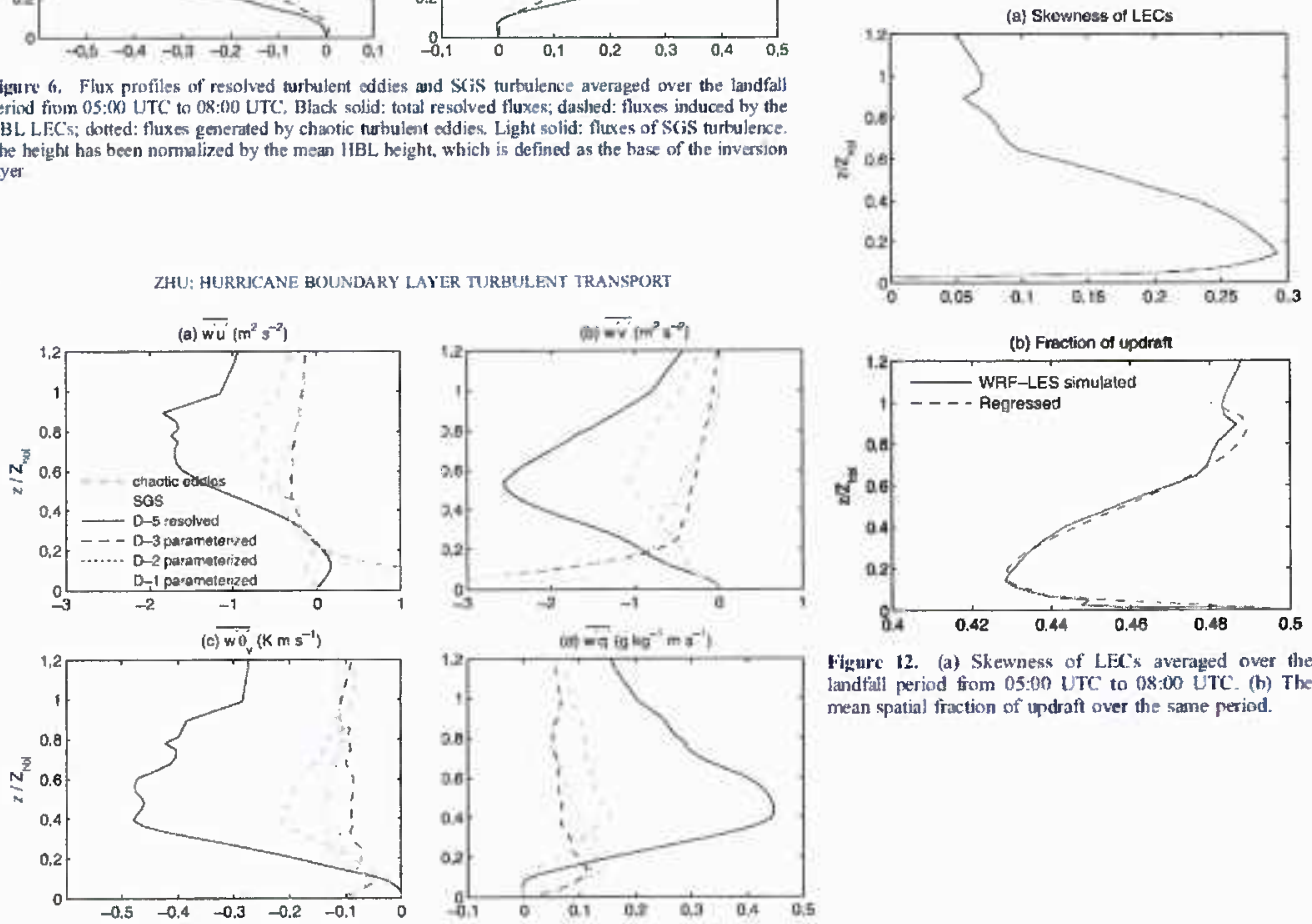

Hewre 12. (a) Skewness of LEC averaited over the

Vigure 9. The resolved and SCiS turbulant fluses in D.5 averaged aver the landfill period firm a and S(iS fluxes in D-5, respectively. The firght thick dashed profite indicates the contribution fom the resolved chaotic eddies only. The lieht solid, light dotted, and dart thished protites are the parameterizes

5-domain WRF "LES" (D5: 100 x 10 m) 


\section{Last UPP Meeting}

IT APPEARS THAT A PBL JET CAN INDUCE "STACKED" OLE

CO-LINEAR OLE TRIADS CAN GENERATE COMPLEX STRUCTURE

THERE IS A WEAKER, LARGER-SCALE, OBLIQUE ABOVE-JET MODE

Can it be energized by nonlinear triad mechanism?

Future work

Modify triad code for non-co-linear OLE

(2014: Done, preliminary look shows highly complex roll OLE) Include stratification and thermal wind effects on OLE

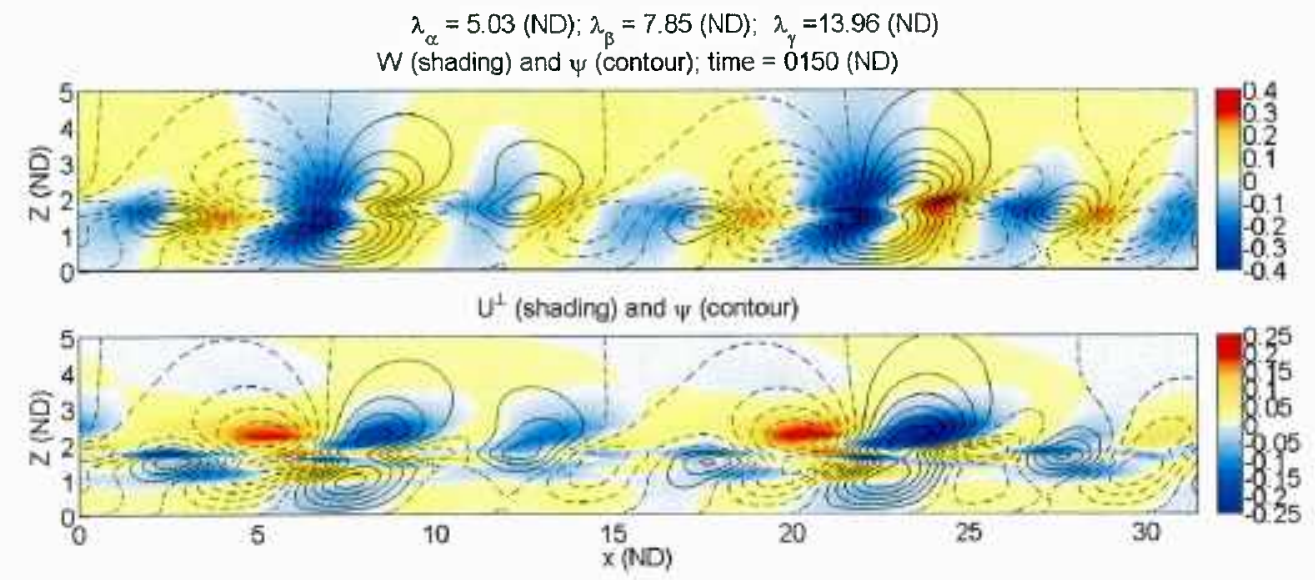

(2014: Done, untested)
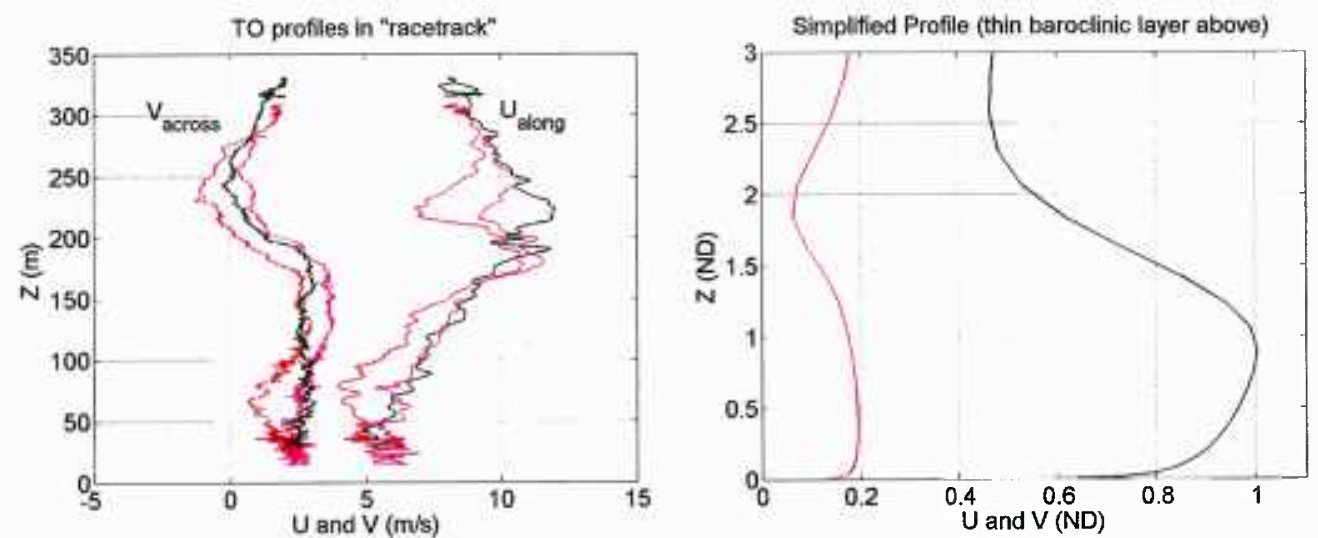


\section{Rolls in EDMF Framework}

- Simple MBL conditions

- Look at basic co-linear triads

- Simple MF statistics

- w' Skewness

- Updraft fraction $(\sigma)$

- Large-eddy mass flux $\left(\sigma(1-\sigma)\left(w_{u p}-w_{d n}\right)\right)$

- Compare with previous work (Zhu, 2007)

- Compare with Observations 


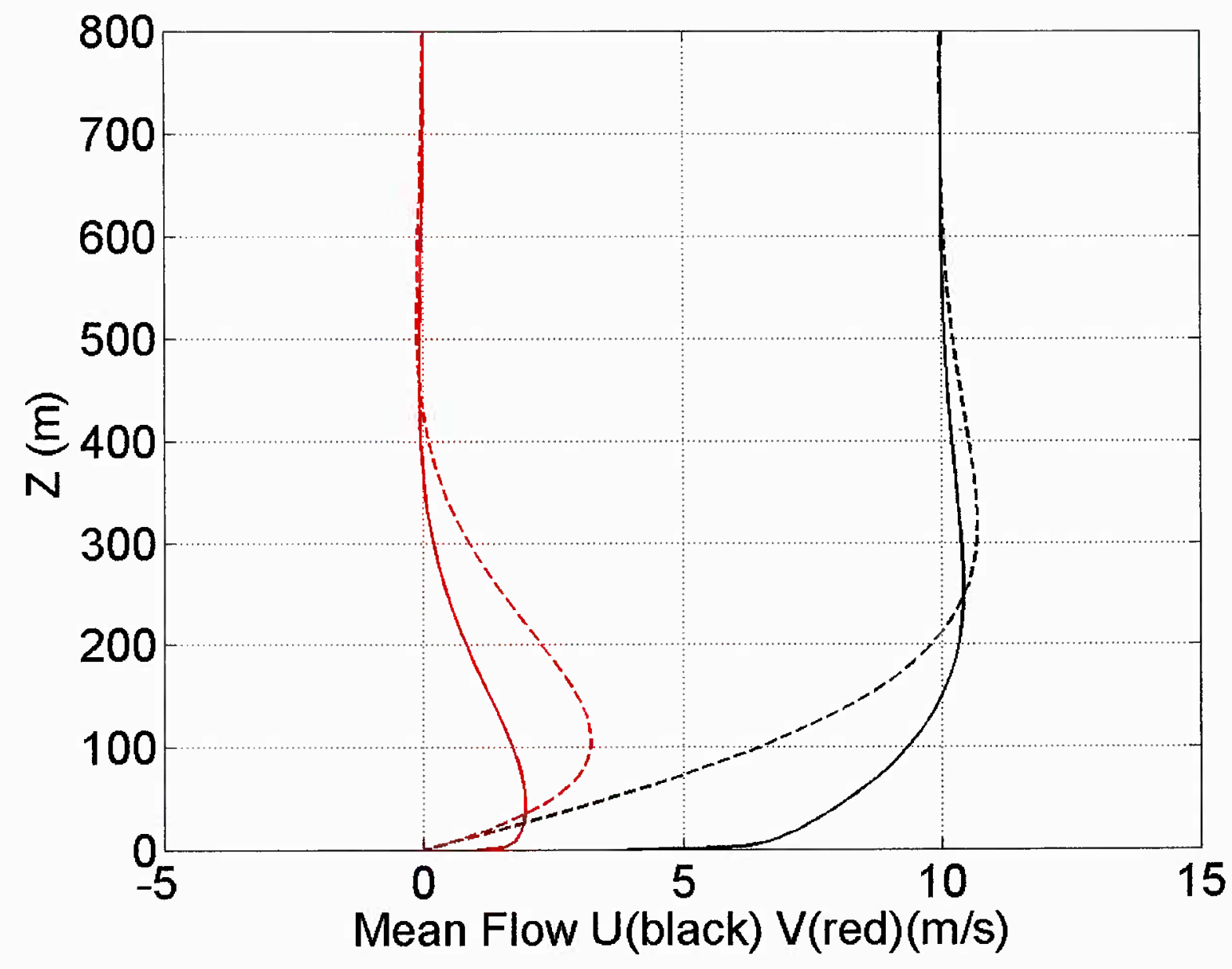

Basic PBL flow (Compared to pure Ekman) 


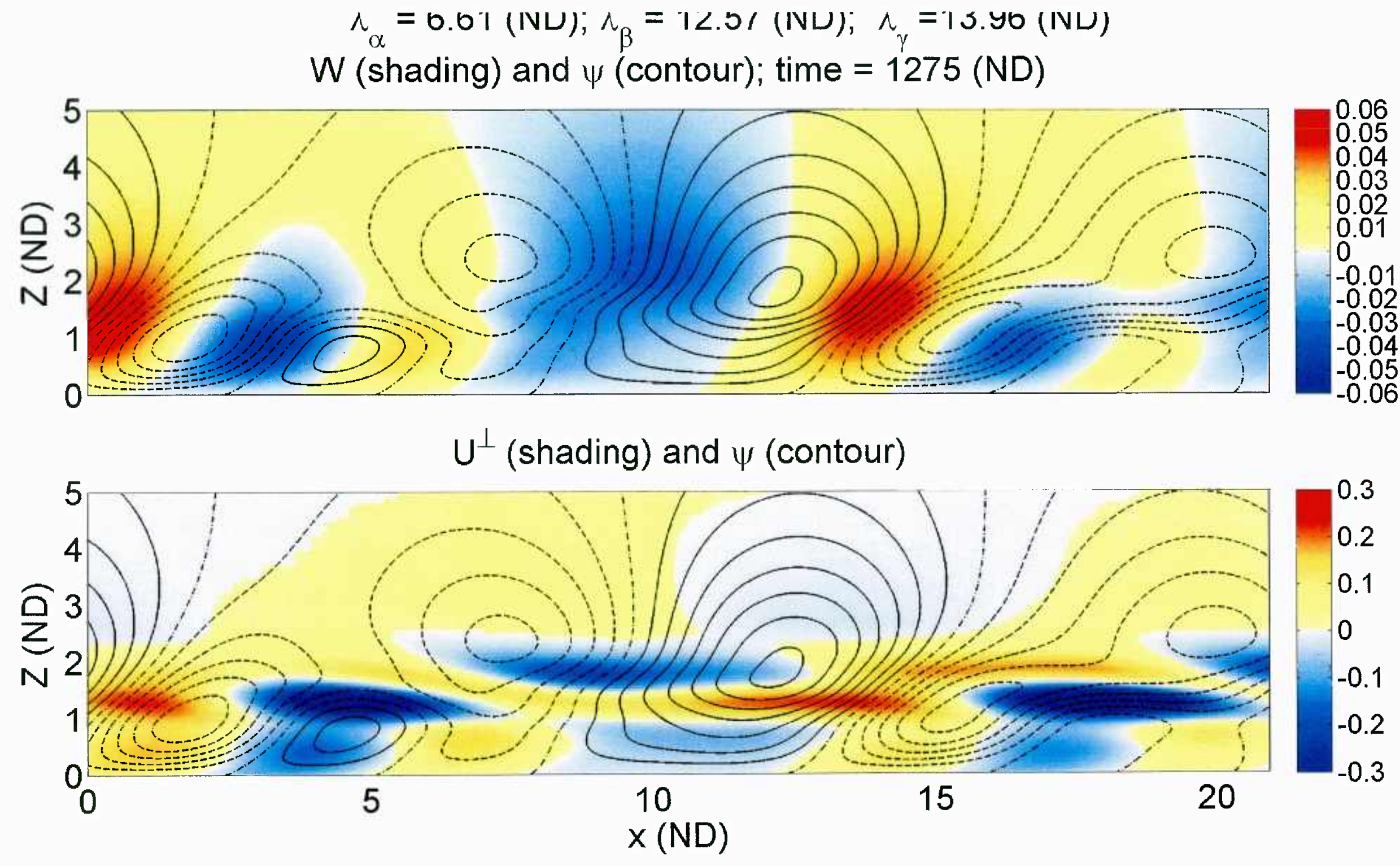



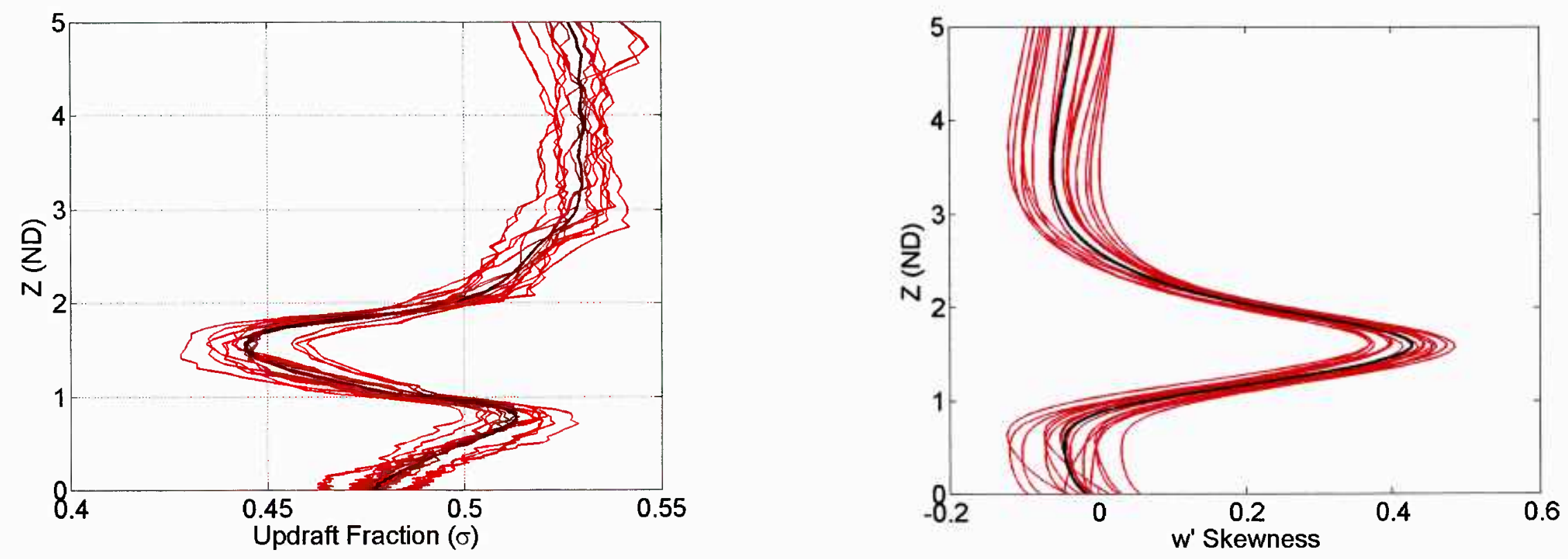

For this triad, statistics vary little with time 


$$
w^{\prime} v^{\prime}
$$
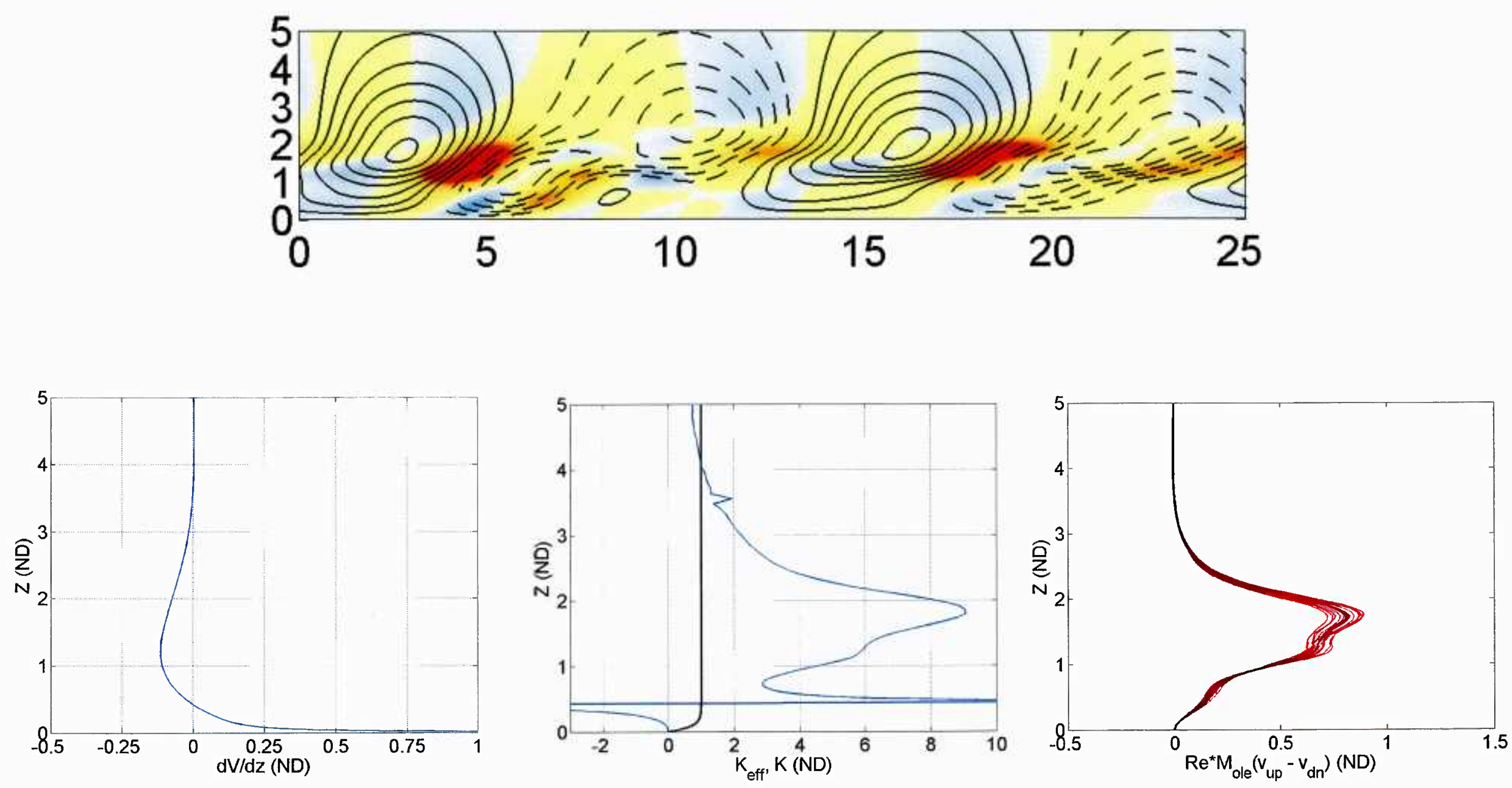


\section{Discussion}

- Idealized (nonlinear, triad interaction) roll OLE model produces results qualitatively similar to WRF"LES" of hurricane PBL LEC effects

- Similar LEC skewness and updraft fraction

- LEC contribution much larger than PBL parameterization

- Differences with Monterey Bay lidar observations

- Flux data suggested negative skewness near top of OLE

- Obs suggest OLE effect on fluxes not as large as modeled

- (10 to $30 \%$, not half or more)

- Lateral mixing missing in model?

- Direct OLE effect may overestimate contribution; "collection" of turbulent eddies may be more important

- Low-order truncation exaggerates fluxes 


\section{Low-Order Truncation Errors}

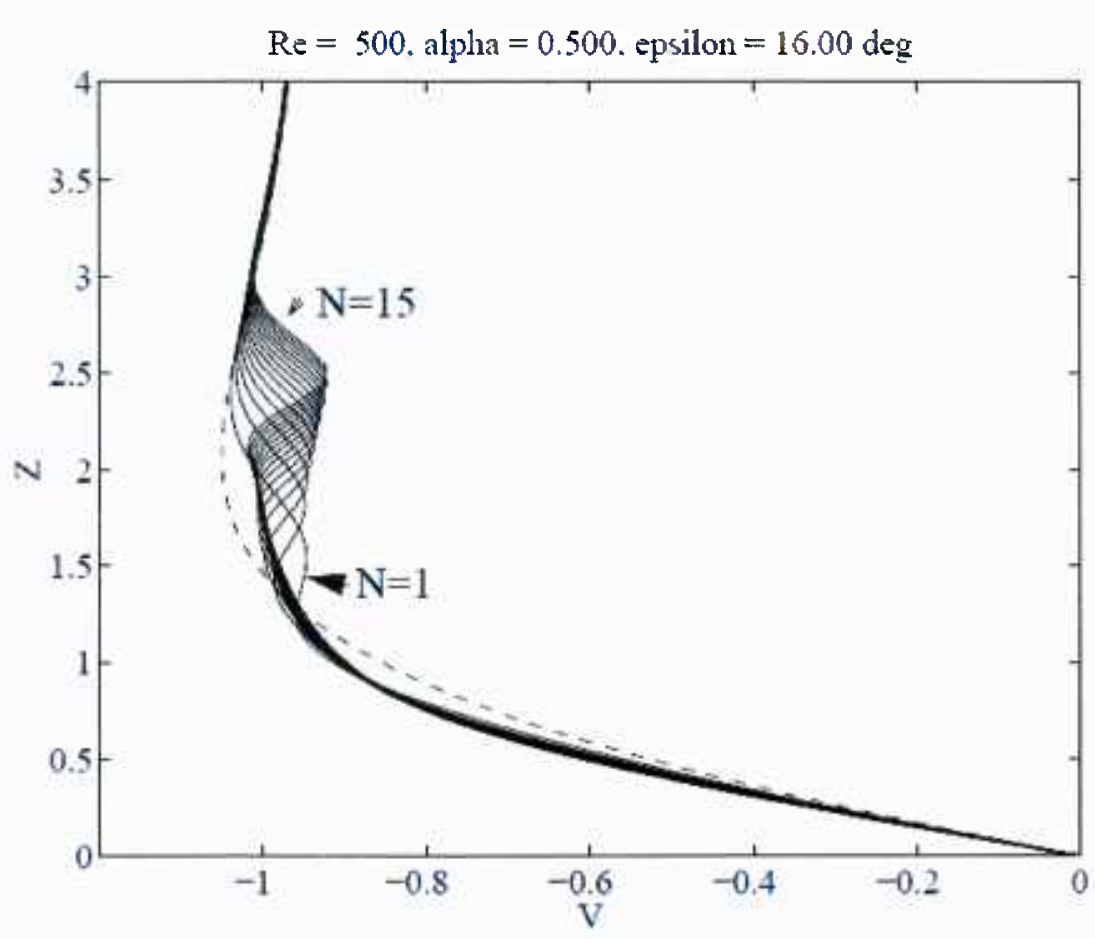

Mean-flow Modification

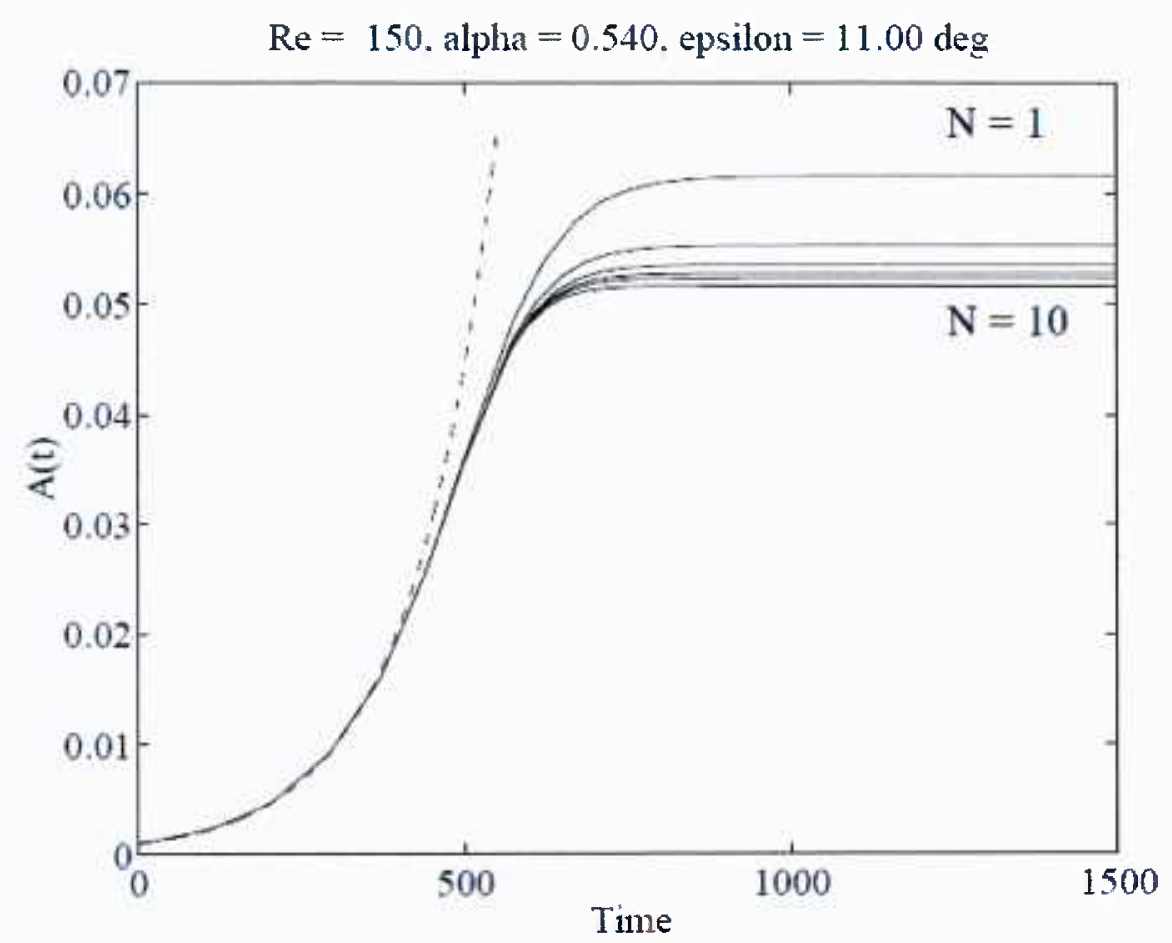

Amplitude Estimation

Low-order truncation problems:

- Over-estimated amplitude

- "S-shaped" MF modification 


\section{Standard Non-Linear Single-Wave PBL Roll Model}

Table 5.1 Contributions to the nonlinear perturbation up to the fifth Landau Coefficient

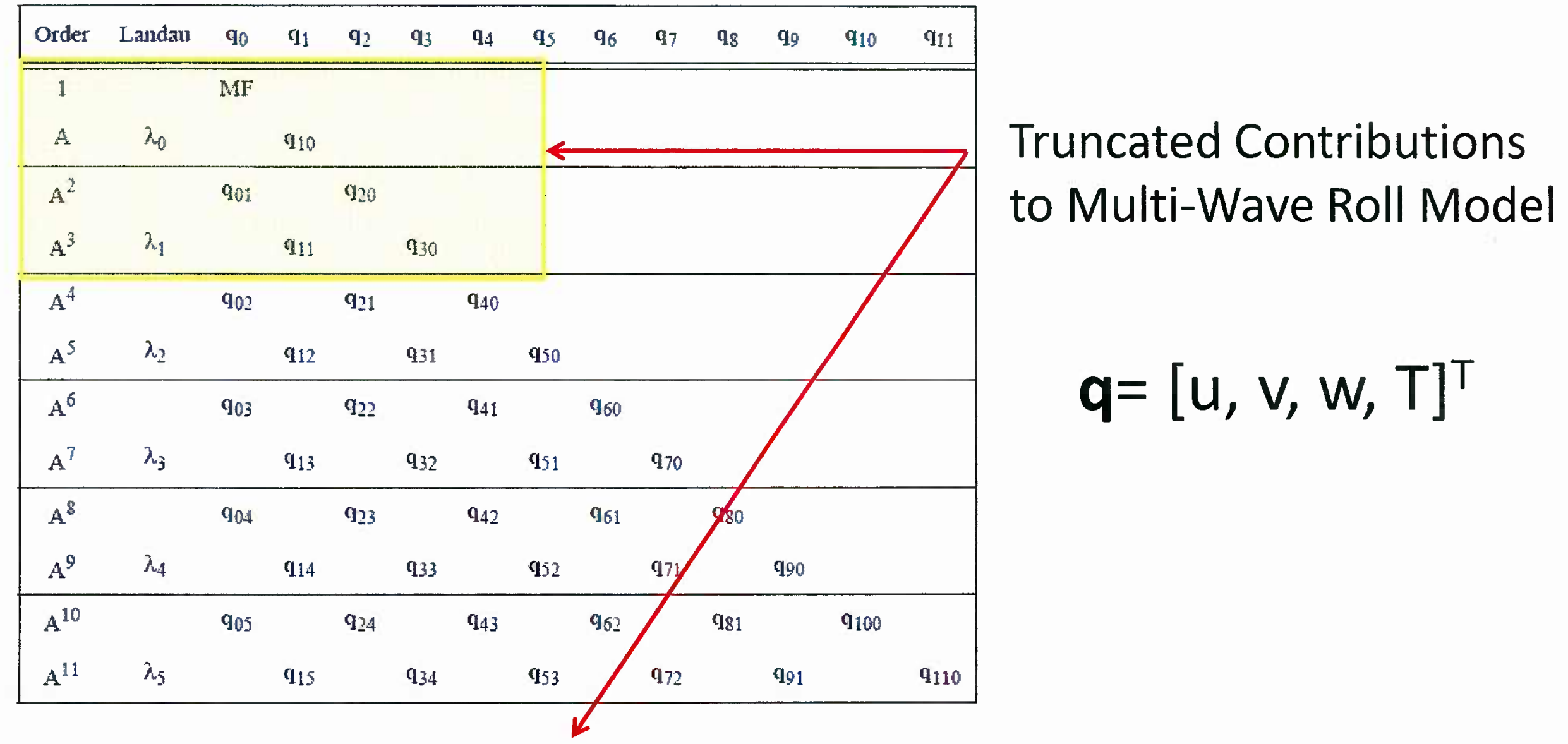

To $1^{\text {st }}$ Nonlinear Landau Term:
$0+A^{2} q_{01}$
$A q_{10}+0+A^{3} q_{11}$
$0+A^{2} q_{20}$
$0+0+A^{3} q_{30}$

(mean flow modification)

(fundamental wavelength)

( $1^{\text {st }}$ harmonic)

( $2^{\text {nd }}$ harmonic) 


\section{Triad Interaction Model}

$$
\begin{aligned}
q_{\alpha}= & A q_{0, \alpha}+B C q_{1, \alpha} e^{i \phi}+A\left[A^{2} q_{2, \alpha}+B^{2} q_{3, \alpha}+C^{2} q_{4, \alpha}\right]+ \\
& A^{2} q_{20, \alpha}+A^{3} q_{30, \alpha} \\
q_{\beta}= & B q_{0, \beta}+A C q_{1, \beta} e^{-i \phi}+B\left[A^{2} q_{2, \beta}+B^{2} q_{3, \beta}+C^{2} q_{4, \beta}\right]+ \\
& B^{2} q_{20, \beta}+B^{3} q_{30, \beta} \\
q_{\gamma}= & C q_{0, \gamma}+A B q_{1, \nu} e^{-i \phi}+C\left[A^{2} q_{2, \gamma}+B^{2} q_{3, \nu}+C^{2} q_{4, \gamma}\right]+ \\
& C^{2} q_{20, \nu}+C^{3} q_{30, \gamma} \\
&
\end{aligned}
$$

: contributions from single-wave theory; e.g. $q_{2, \alpha}=q_{11, \alpha}$.

- BLUE: new wave-wave \& wave-mean flow interaction contributions.

- RED: Low-order phase-coupling terms.

- Also: mean-flow modifications due to each wave. 

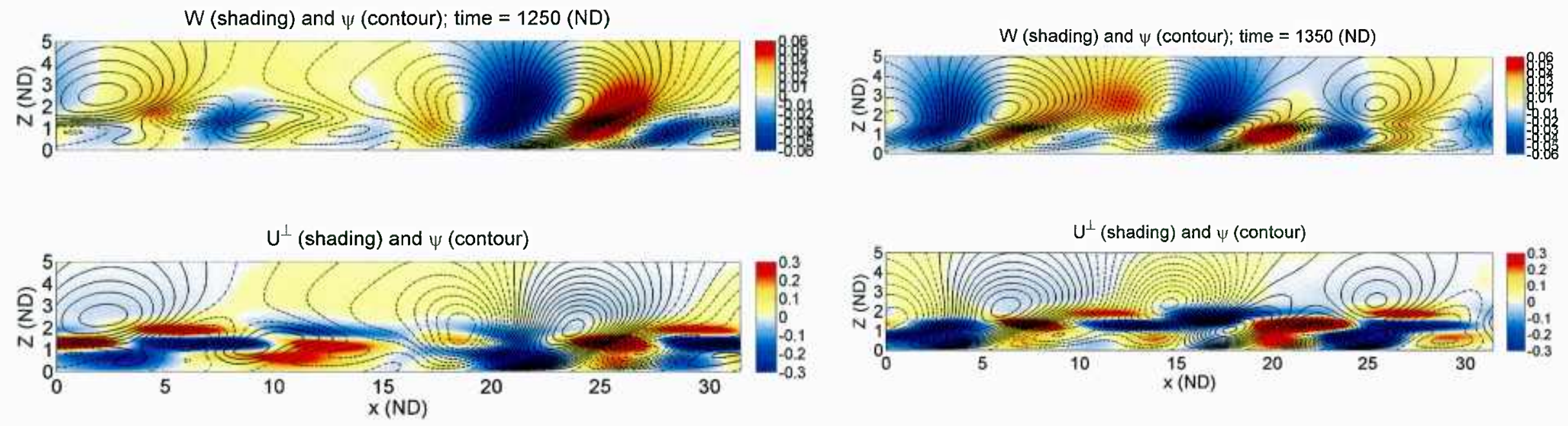

Similar triad generates different OLE effect

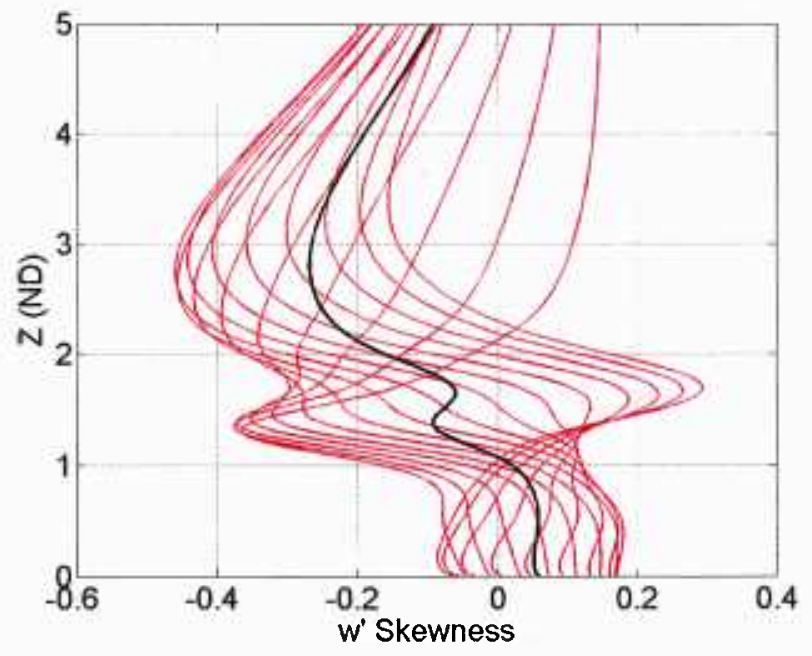

More similar to Obs,

Less similar to WRF-"LES"

- For this triad, statistics do vary with time

- Hurricane is very high shear, ideal for roll OLE, strongly forced modes.

- Monterey Bay had more variable conditions \& layered PBL structure. 


\section{What Do We Need From Observations?}

- Need to constrain parameter space

- PBL profiles throughout roll prospecting region

- For given mean flow $(U, V, T, q)$, what are the characteristics of the rolls? (wavelength(s), orientation, strength)

- Can we characterize in terms of $\mathrm{Ri}, \mathrm{Re}, . .$. ?

- Effects of rolls on fluxes:

- Fluxes and flux statistics at multiple levels

- Sfc, mid-PBL, Upper levels

- Separate local from LEC flux contributions 


\section{Next Steps}

- Investigate stratification effects \& 3-D effects

- Use observations to correct model

- Implement simple roll MF addition to EDMF model 
Attachment 5

Investigation of coastal zone complex boundary circulations and their potential impact on energy transport

presented at SPIE Defense and Security Conference in Amsterdam 2014 by G. D. Emmitt, K. Godwin and R. Foster. 


\section{Investigation of coastal zone complex boundary circulations and their potential impact on energy transport}

G. D. Emmitt and K. Godwin

Simpson Weather Associates, Inc.

R. Foster

University of Washington 


\section{Objectives}

- Investigate and characterize the presence of rolls (OLEs) within and at the lateral boundaries of stratocumulus topped Marine Boundary Layers (MBLs).

- Study the potential impact on the development and implementation of the Eddy Diffusivity and mass Flux (EDMF) parameterization into weather forecast models.

- Make the case for adding an MF term unique to rolls generated by both convective and shear instabilities. 


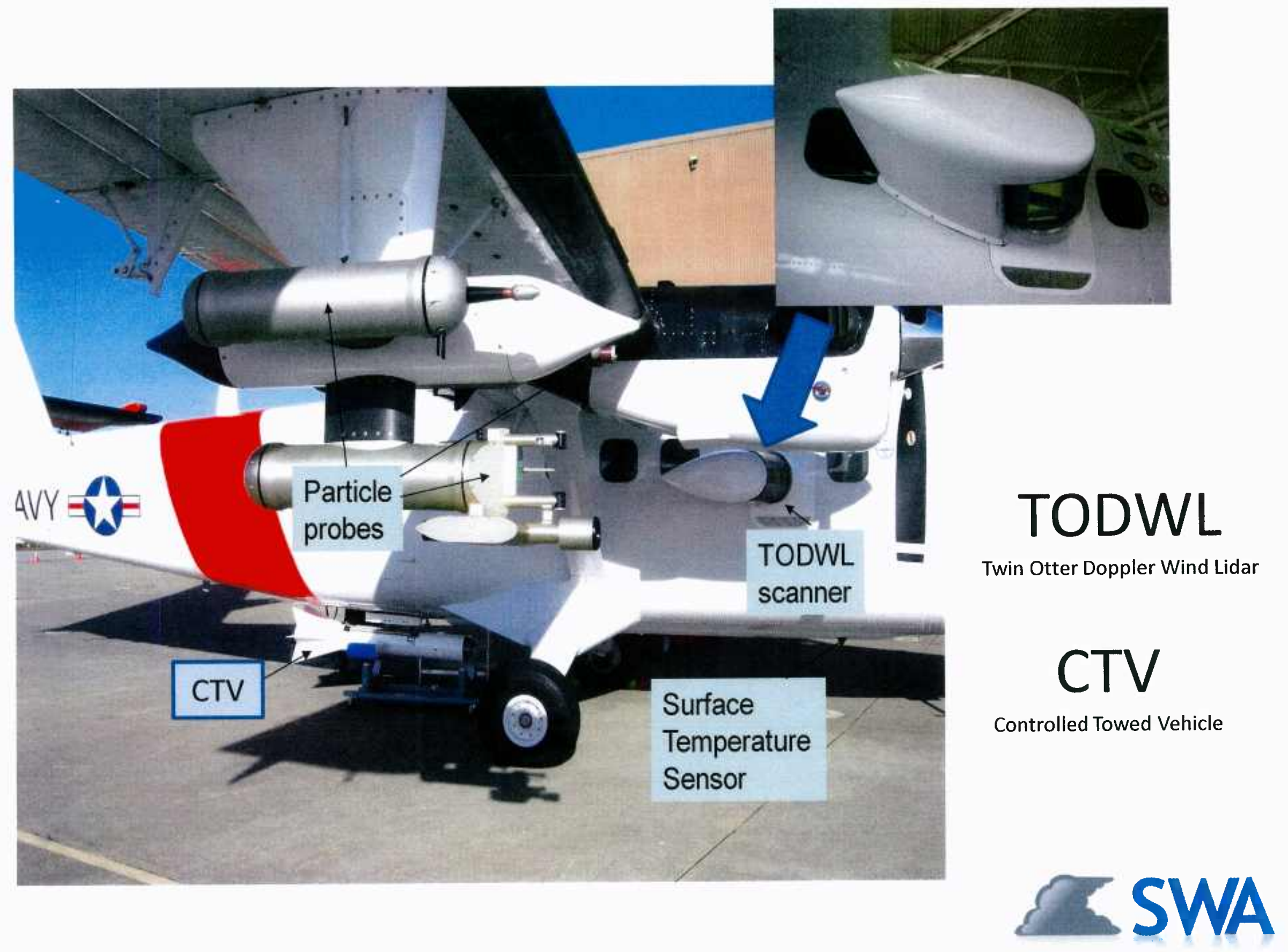




\section{TODWL data description}

\begin{tabular}{|l|l|l|}
\hline \multicolumn{1}{|c|}{ Attribute } & Performance Metric & \multicolumn{1}{c|}{ Comments } \\
\hline $\begin{array}{l}\text { LOS resolution (applies } \\
\text { to vertical profiles of } \\
\text { 3D winds as well) }\end{array}$ & $50 \mathrm{~m}$ & $\begin{array}{l}\text { Range resolution to hard } \\
\text { targets (ground or dense } \\
\text { cloud) can be better than } \\
10 \text { meters. }\end{array}$ \\
\hline U,V,W resolution & $<10 \mathrm{~cm} / \mathrm{s}$ & $\begin{array}{l}<5 \mathrm{~cm} / \mathrm{s} \text { for stationary } \\
\text { groundbased operations }\end{array}$ \\
\hline Maximum range & $6-30 \mathrm{~km}$ & $\begin{array}{l}\text { Very dependent upon } \\
\text { aerosols }\end{array}$ \\
\hline $\begin{array}{l}\text { Time to complete full } \\
\text { step stare conical scan } \\
\text { for wind profiles }\end{array}$ & $\sim 20 \mathrm{sec}$ & $\begin{array}{l}12 \text { point step stare with } \\
.5 \text { second dwells }\end{array}$ \\
\hline $\begin{array}{l}\text { Sampling frequency } \\
\text { Samp }\end{array}$ & $100 \mathrm{~Hz}$ & $\begin{array}{l}\text { Integration of several } \\
\text { shots is typical to } \\
\text { improve range } \\
\text { performance }\end{array}$ \\
\hline
\end{tabular}




\section{Data summary for September/October UPP field campaign with TODWL}

- Three quality flights with the DWL

- One quality co-flight with the CTV (9/30).

- Two 5 hour ferry flights between Monterey, CA and Salt Lake City, Utah. (Ruby Mountain waves)

- Seven 4.5 hour flights over DPG, Utah during the MATERHORN

- Co-funded by ONR and ARO

- 3500 vertical profiles used to validate WRF models

- 14 low level flights dedicated to prospecting for OLEs in the vicinity of flux towers. 
CIRPAS Twin Otter with

\section{CTV below}

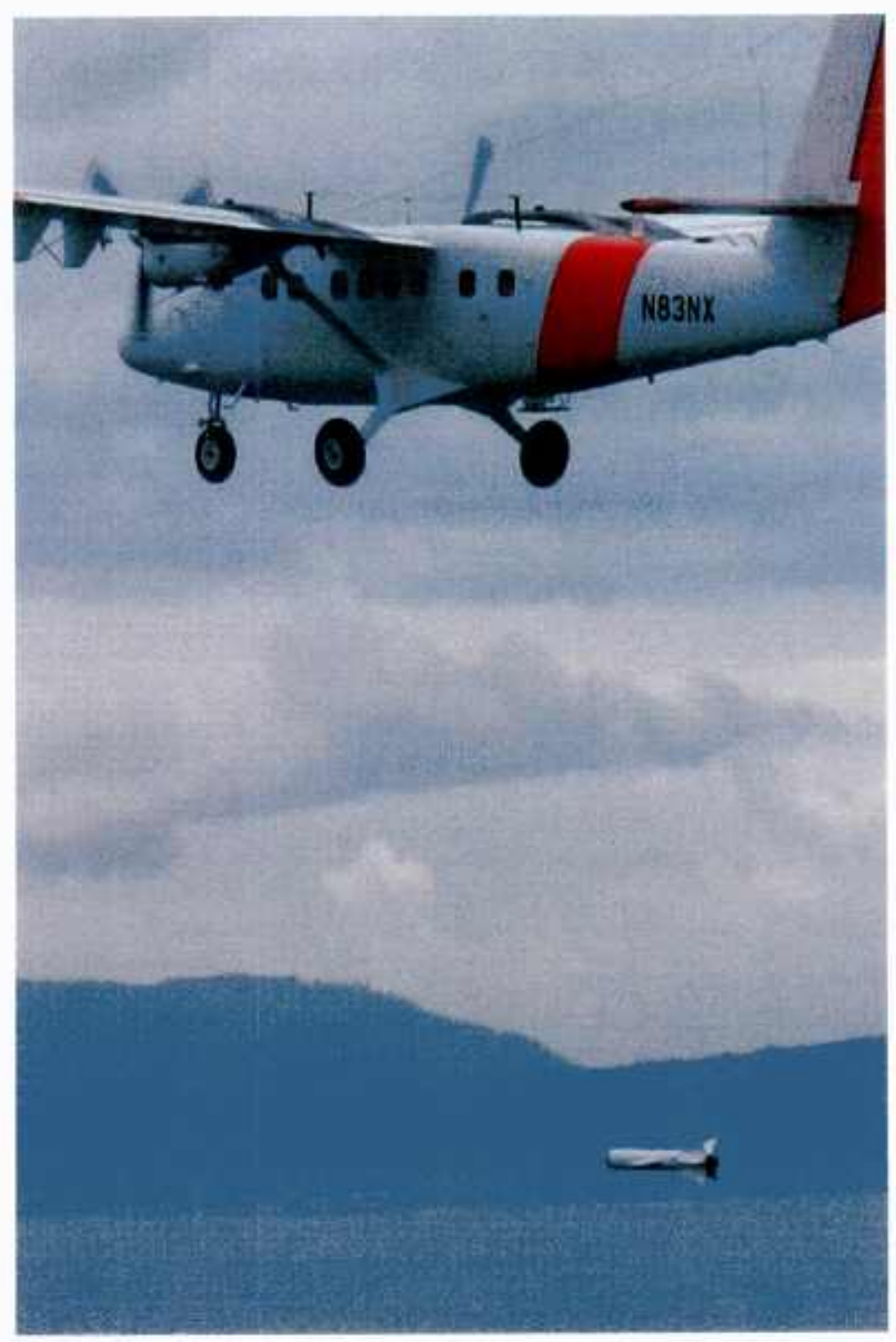

Cabin Primes 102845 TKE: 0.038198 WQ: 0.21743 W-Theta: 0.087407 Skew: -0.1774

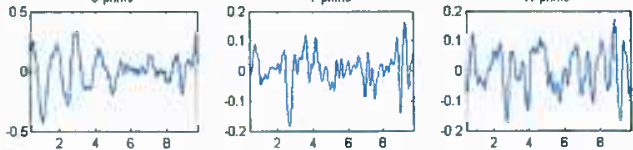

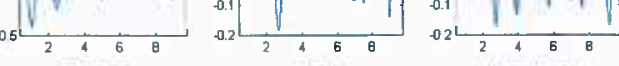

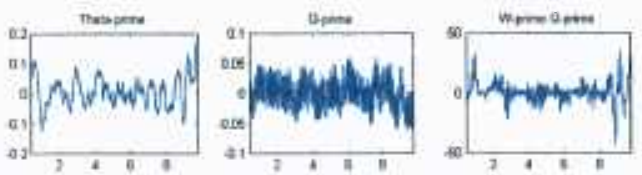

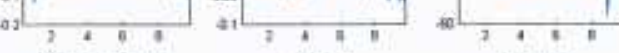

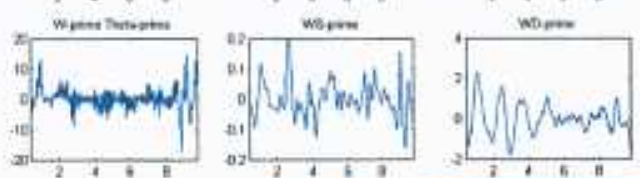

Twin Otter

Probe Data

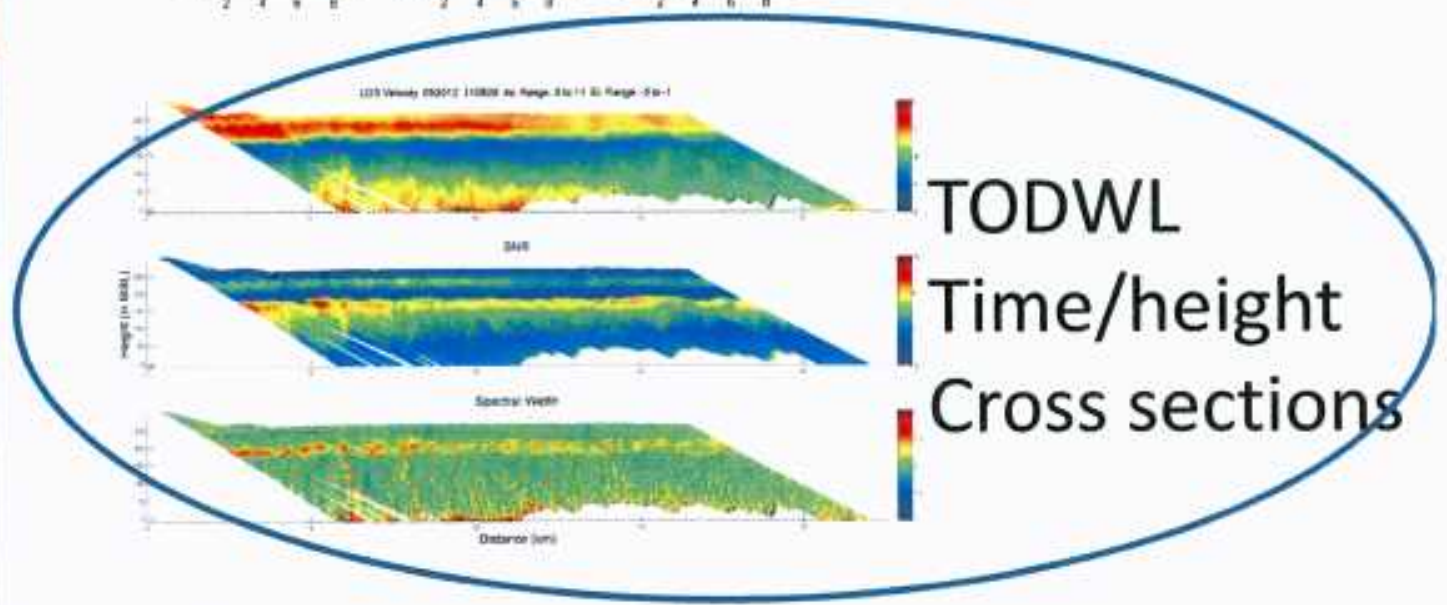

CTV Primes 102845 TKE, 0.80196 WQ -12.655 W-Theta: -18.7389 Skew 0.048147

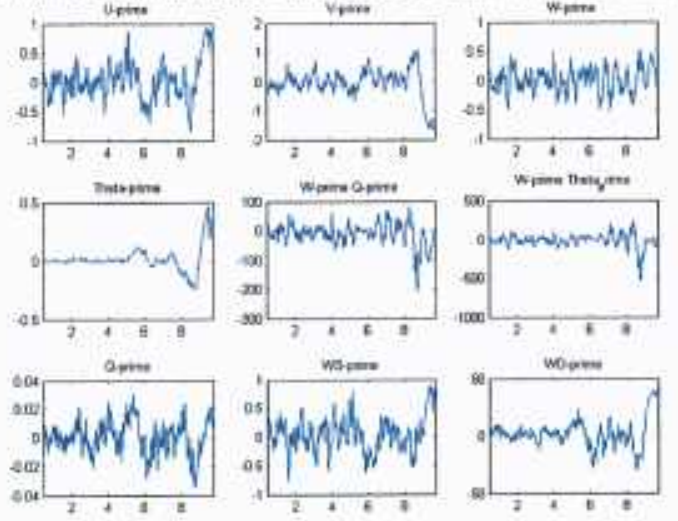

Towed Vehicle Flux Data*

* Derived from data provided by Khelif (UCI) 


\section{Structure prospecting with DWL}

- Feature prospecting uses a very shallow angle below the horizon ( -1 -3 degrees for a 300m flight altitude).

- Results in $2 \mathrm{~m}$ vertical resolution and $50 \mathrm{~m}$ horizontal resolution with $\sim 40$ meter sliding sample.

- It takes 33 seconds to profile 100 meters below the aircraft. 


\section{TODWL prospecting geometries $(9 / 30 / 12)$}

$300 \mathrm{~m}$

-3 degrees elevation angle $(\tan =.052)$

$6 \mathrm{~km}$

\begin{tabular}{|l|l|}
\hline \multicolumn{1}{|c|}{ Metric } & \multicolumn{1}{c|}{ Value } \\
\hline Twin Otter flight altitude & $300 \mathrm{~m} \mathrm{MSL}$ \\
\hline Scan configuration & Straight ahead and down $1-3^{\circ}$ \\
\hline Range gate length & $50 \mathrm{~m}$ \\
\hline Twin Otter ground speed & $50-60 \mathrm{~m} / \mathrm{s}$ \\
\hline Shot frequency & $160 /$ second \\
\hline Shot integration (data granule) & $100(\sim 40$ meters forward motion) \\
\hline Vertical increment between granules & $\sim 2 \mathrm{~m}$ \\
\hline Time to sample $100 \mathrm{~m}$ vertical & $\sim 33$ seconds \\
\hline
\end{tabular}




\section{Idealized rolls}

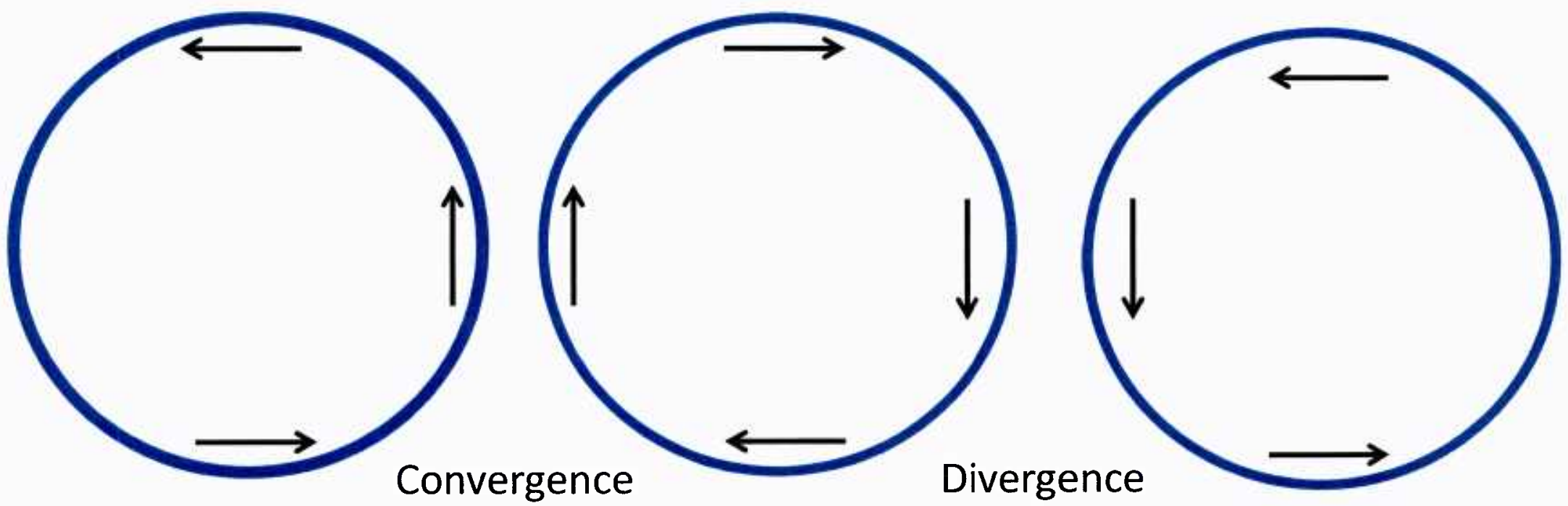




\section{Spectral analyses of TODWL data}

The TODWL is a 2 micron, eyesafe Coherent detection lidar. The returning Signal is heterodyned with a local optical Oscillator and then digitized $(200 \mathrm{MHz})$. An FFT is used to process the resulting Time series with $50 \mathrm{~m}$ line-of-sight Resolution. In homogeneous flows, a single Spectral feature (top figure) is identified as the frequency representation of the radial wind speed.

When probing a turbulent and/or highly Sheared environment, the spectral Feature is broadened. It is this broadening That we desire to use for estimating Turbulence on scales of $25-100$ meters With multipulse integrations over 50 - 200
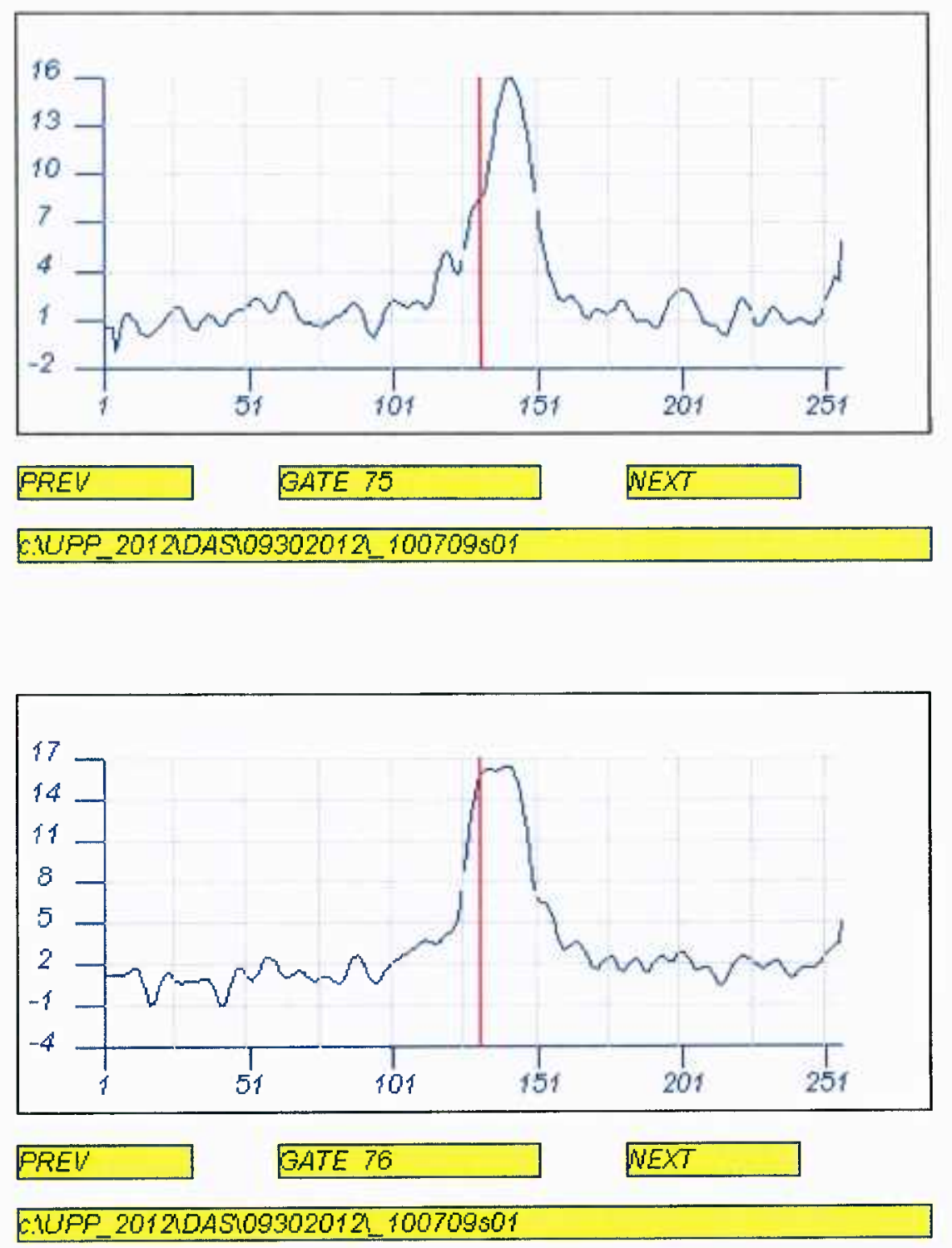


\section{9/30/12 case study}

- Processed lidar data in search of organized aerosol/wind structures below the Twin Otter flight path

- Processed Twin Otter instrument data for time series of $u, v, w, q$, and $\theta$.

- Processed CTV data for $u, v, w, q$ and $\theta$.

- Match up times and then features from the TODWL and CABIN data sets near flight level.

- Match up times and features from TODWL and CTV at CTV cruise levels. 

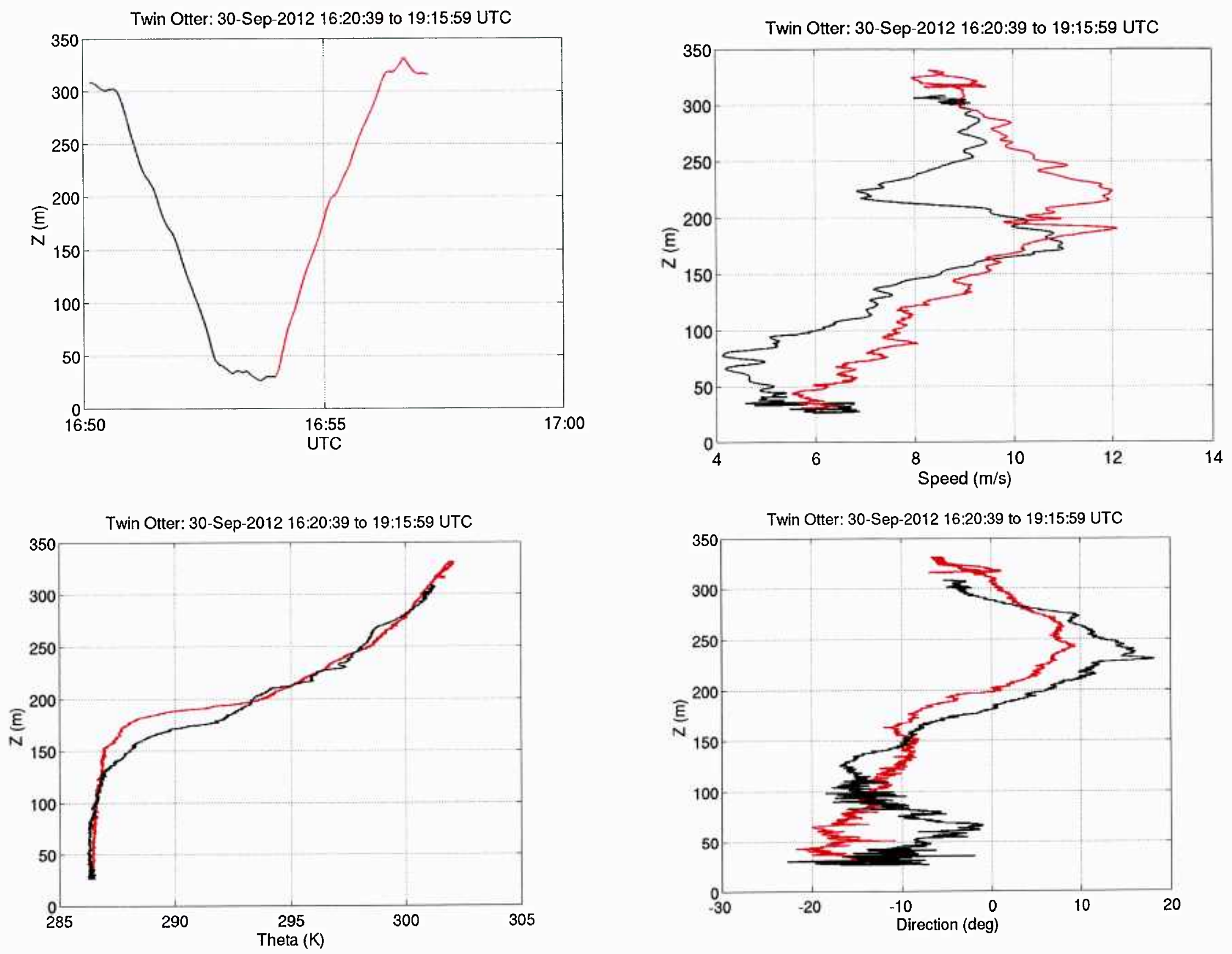


\section{Flight path}

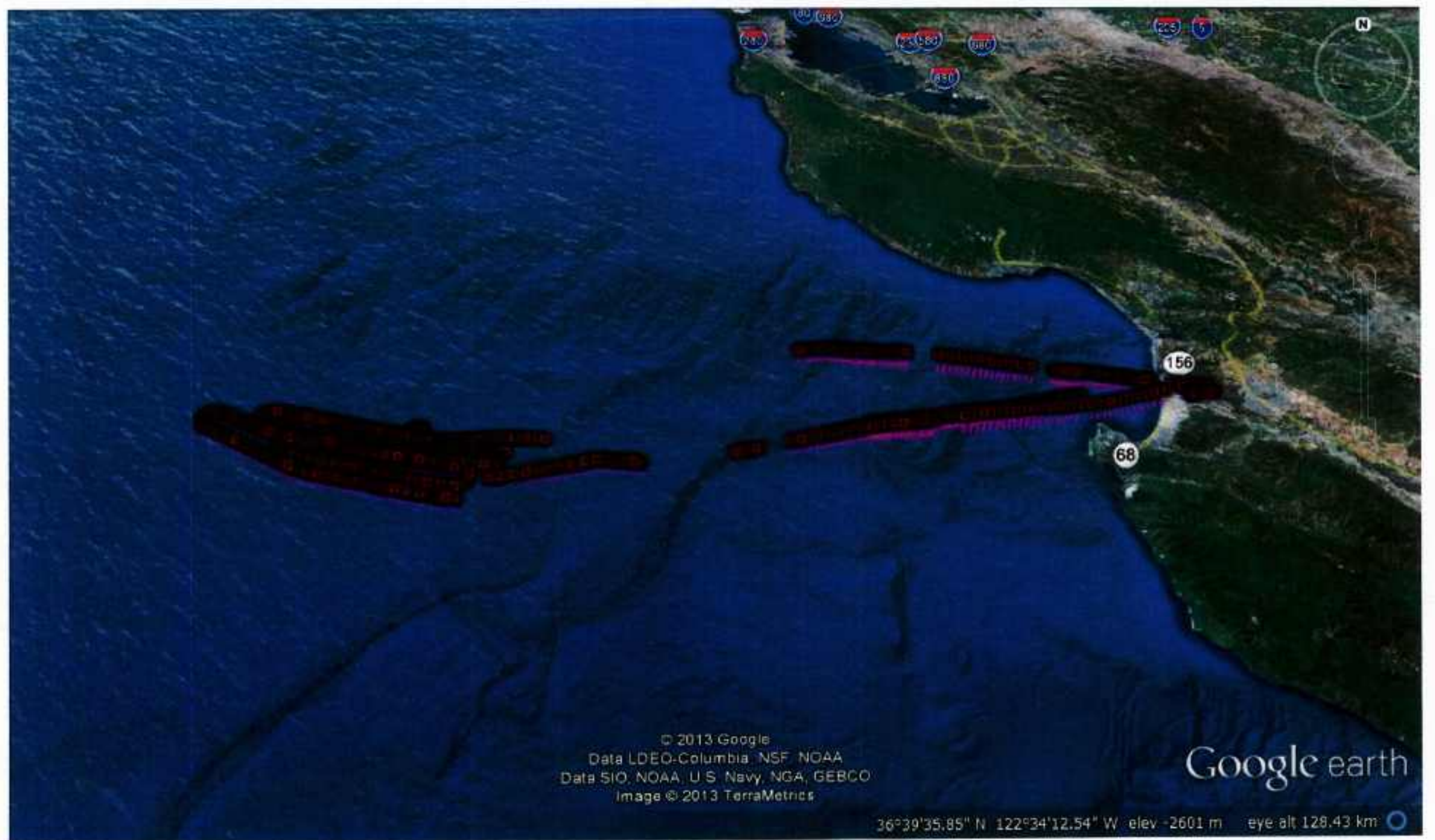




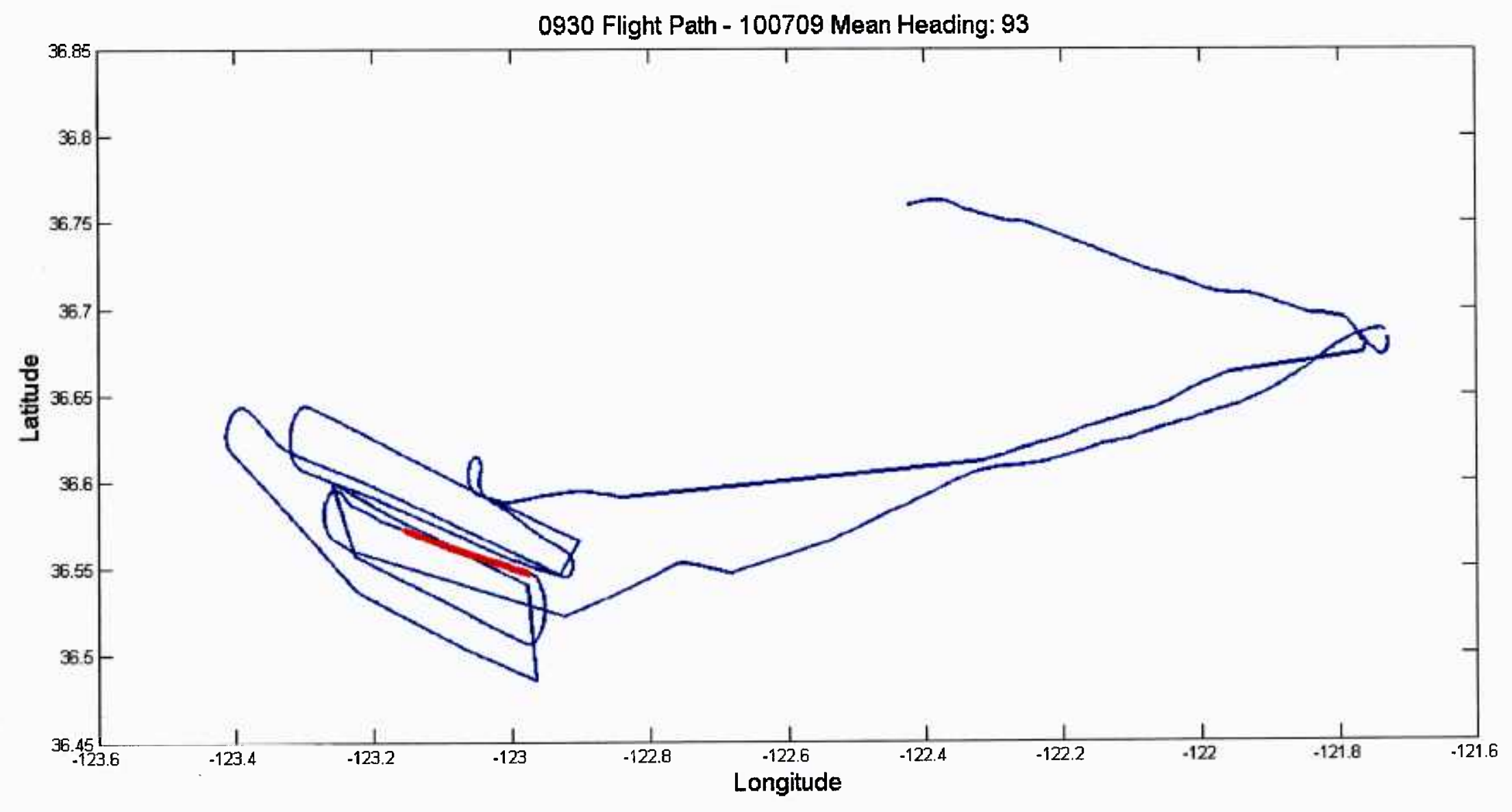




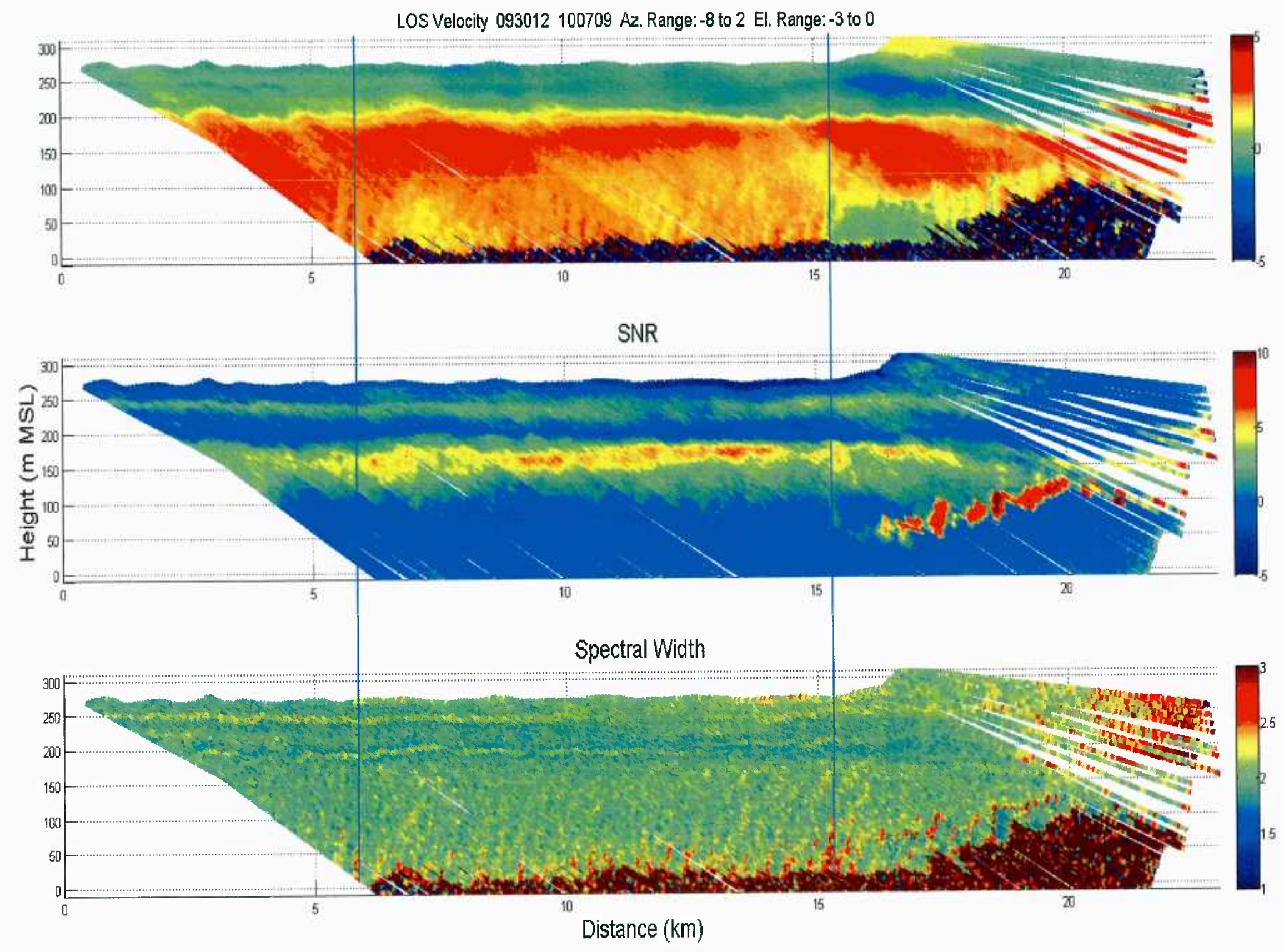




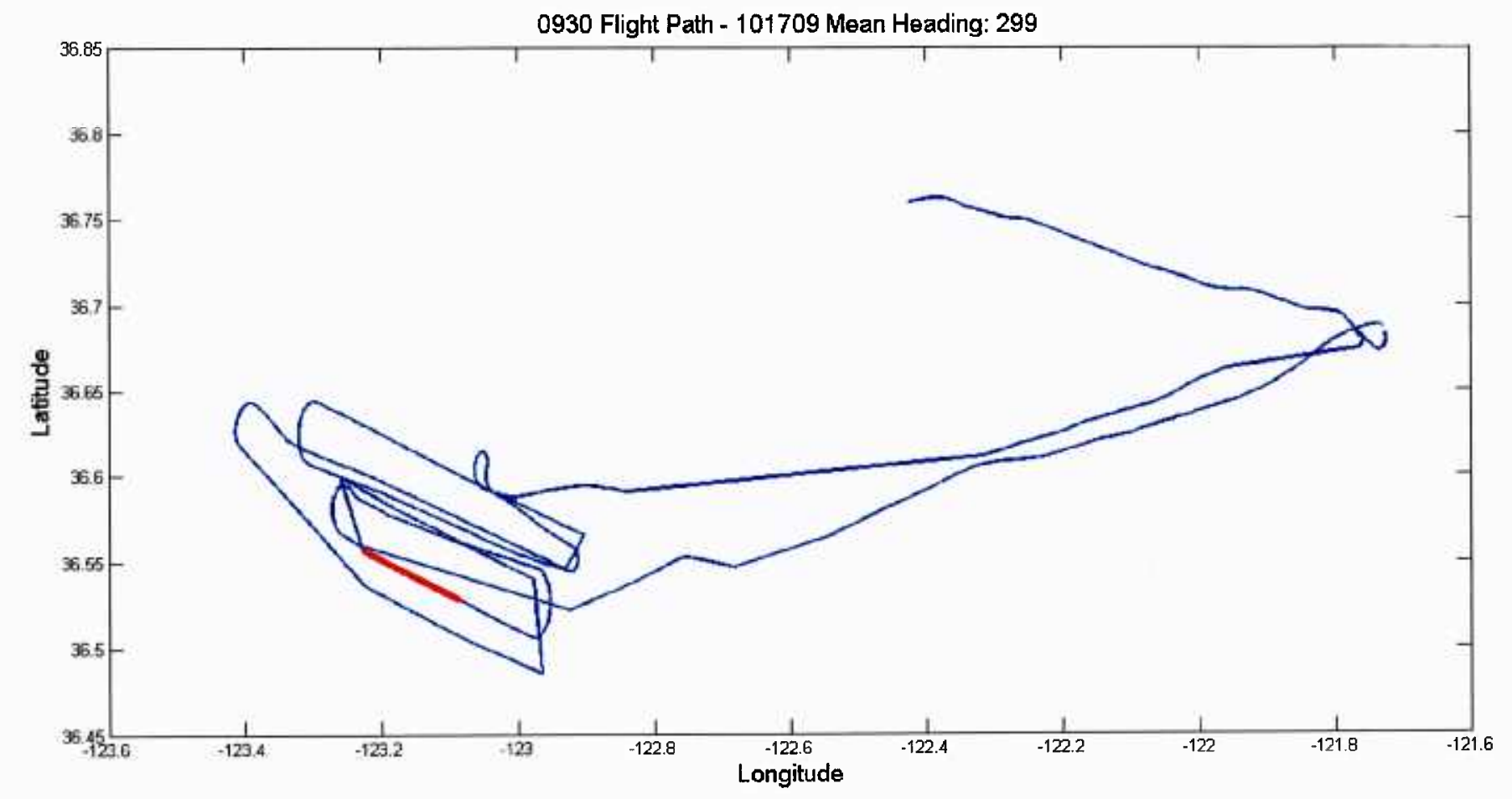


LOS Velocity 093012101709 Az. Range: 13.2 to 15.5 El. Range: -3.3 to -2.5

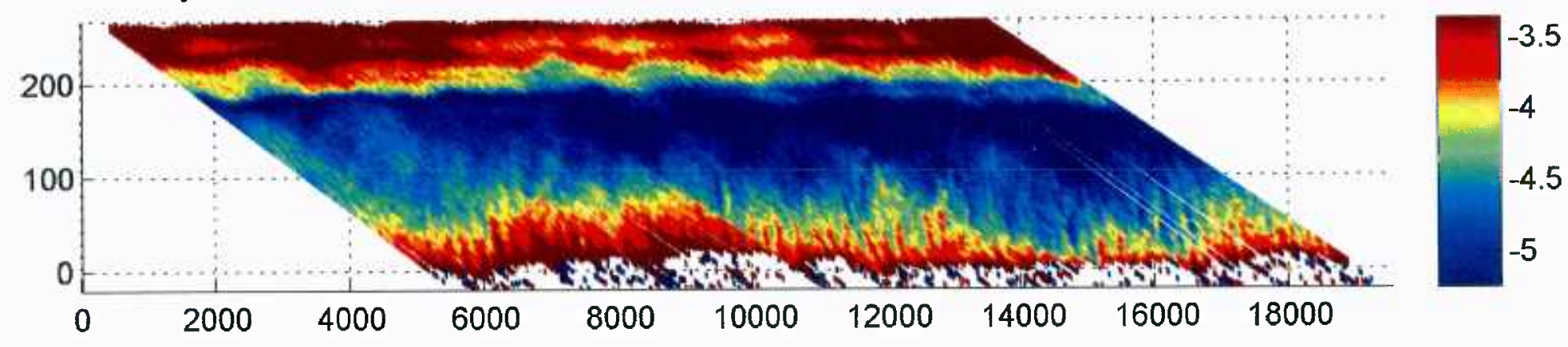

SNR

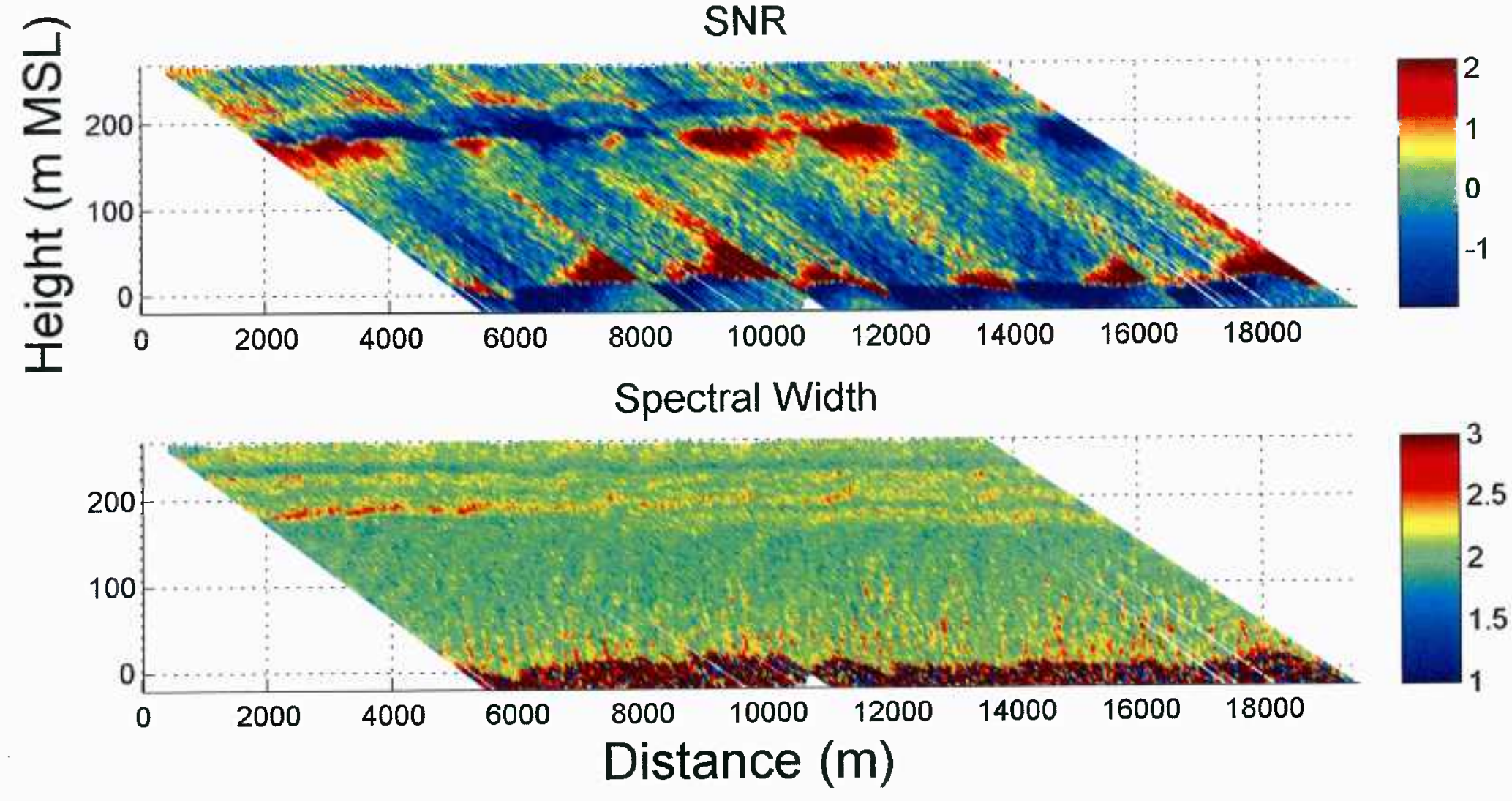


0930 Flight Path - 110626 Mean Heading: 294

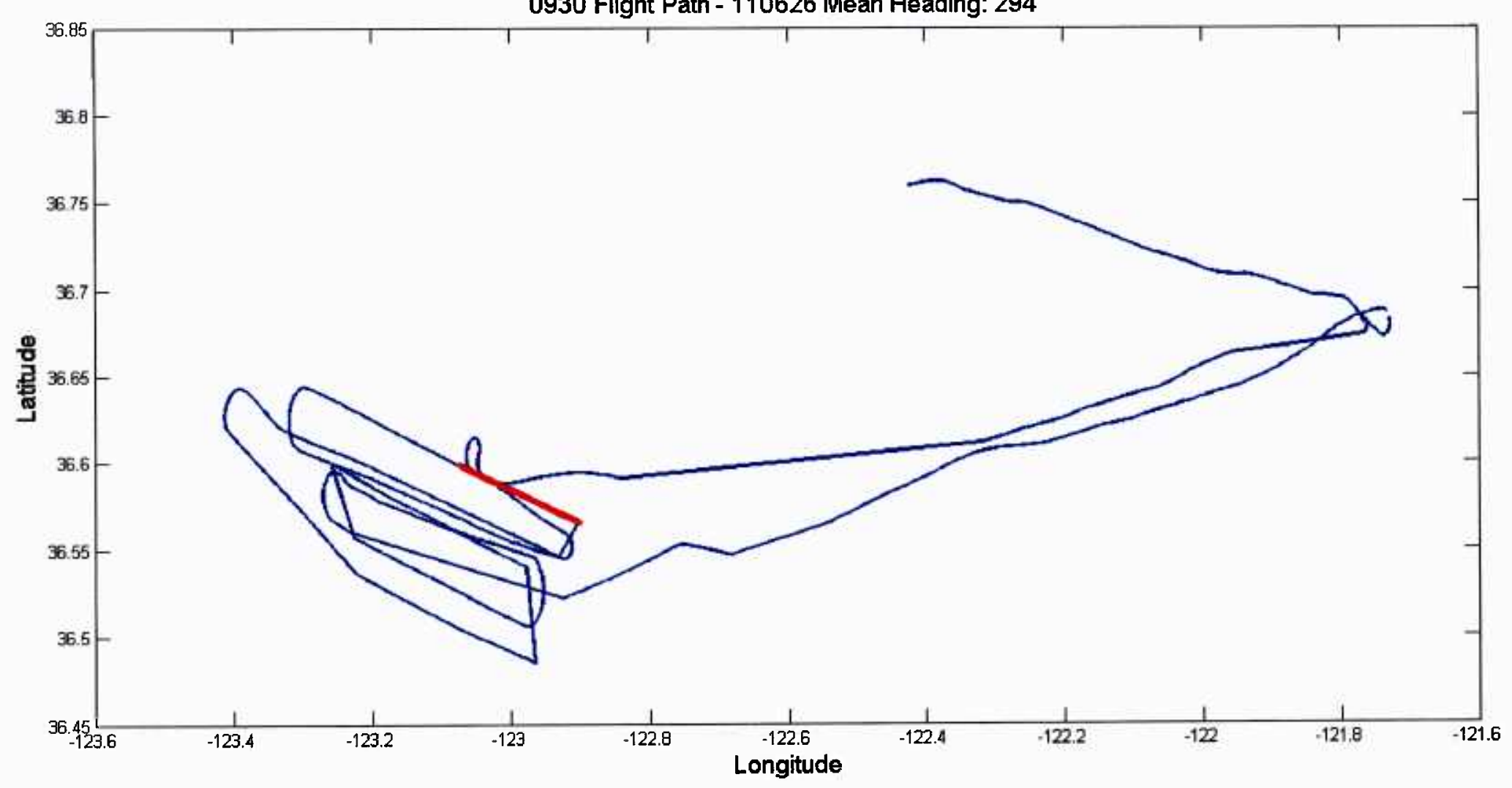




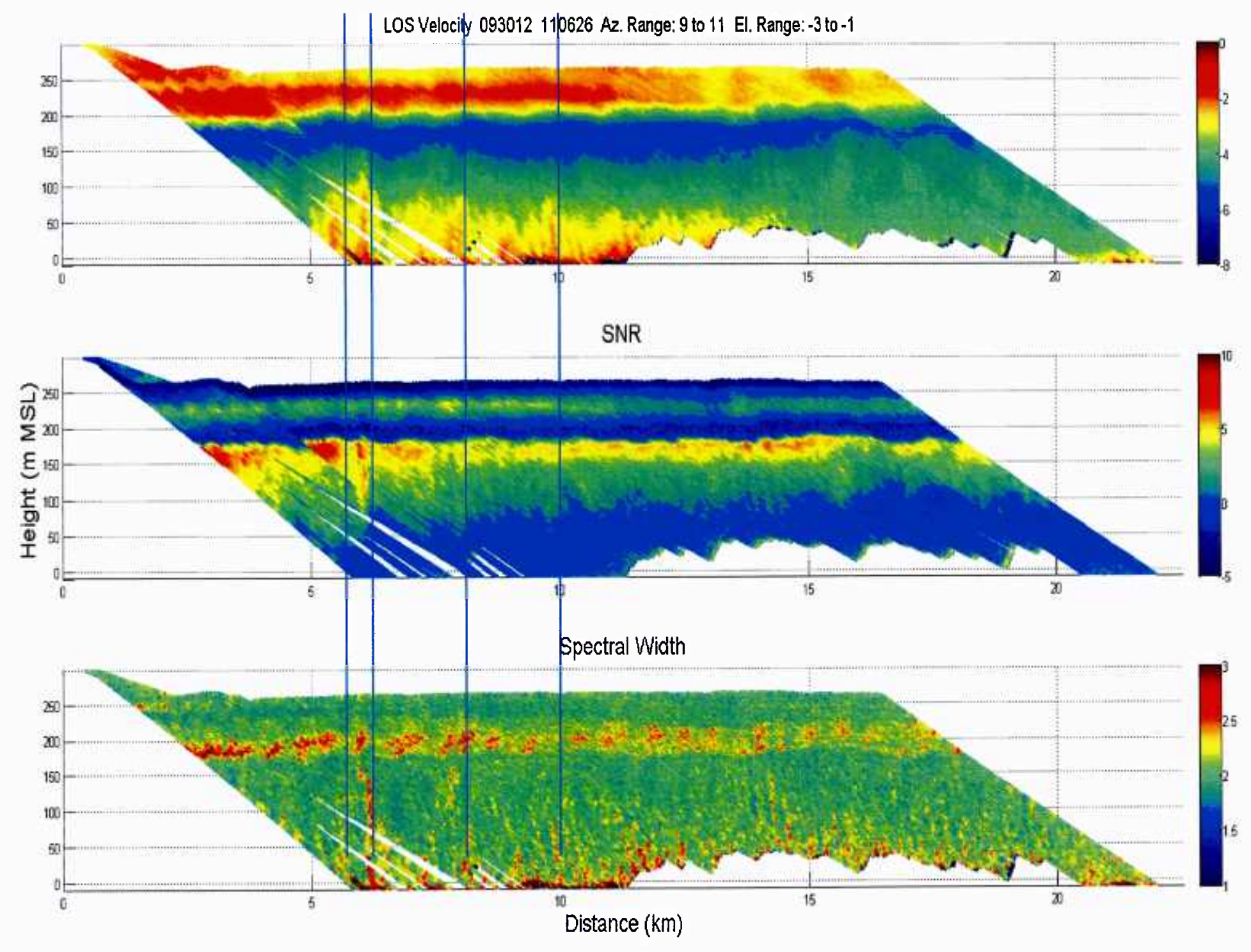




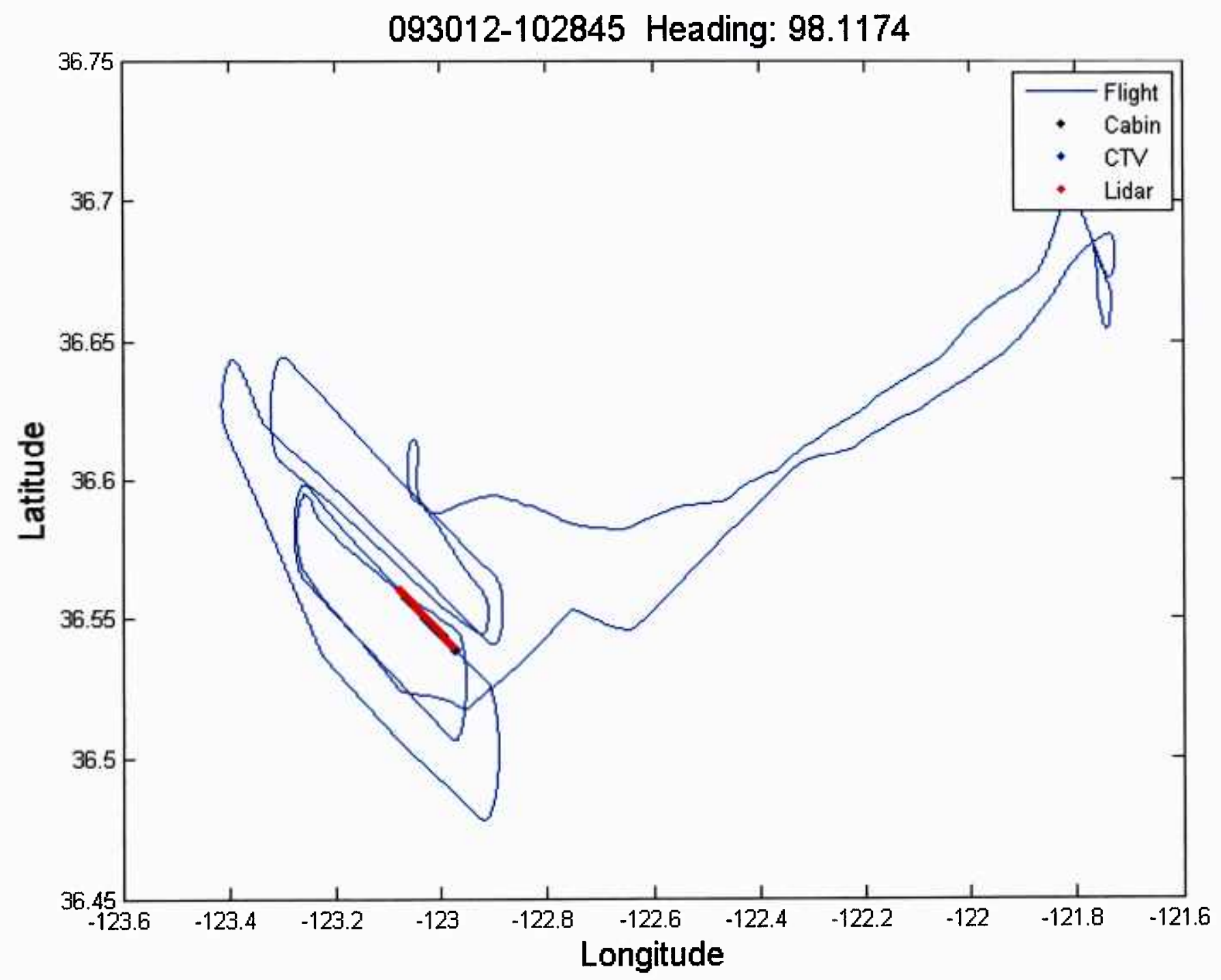




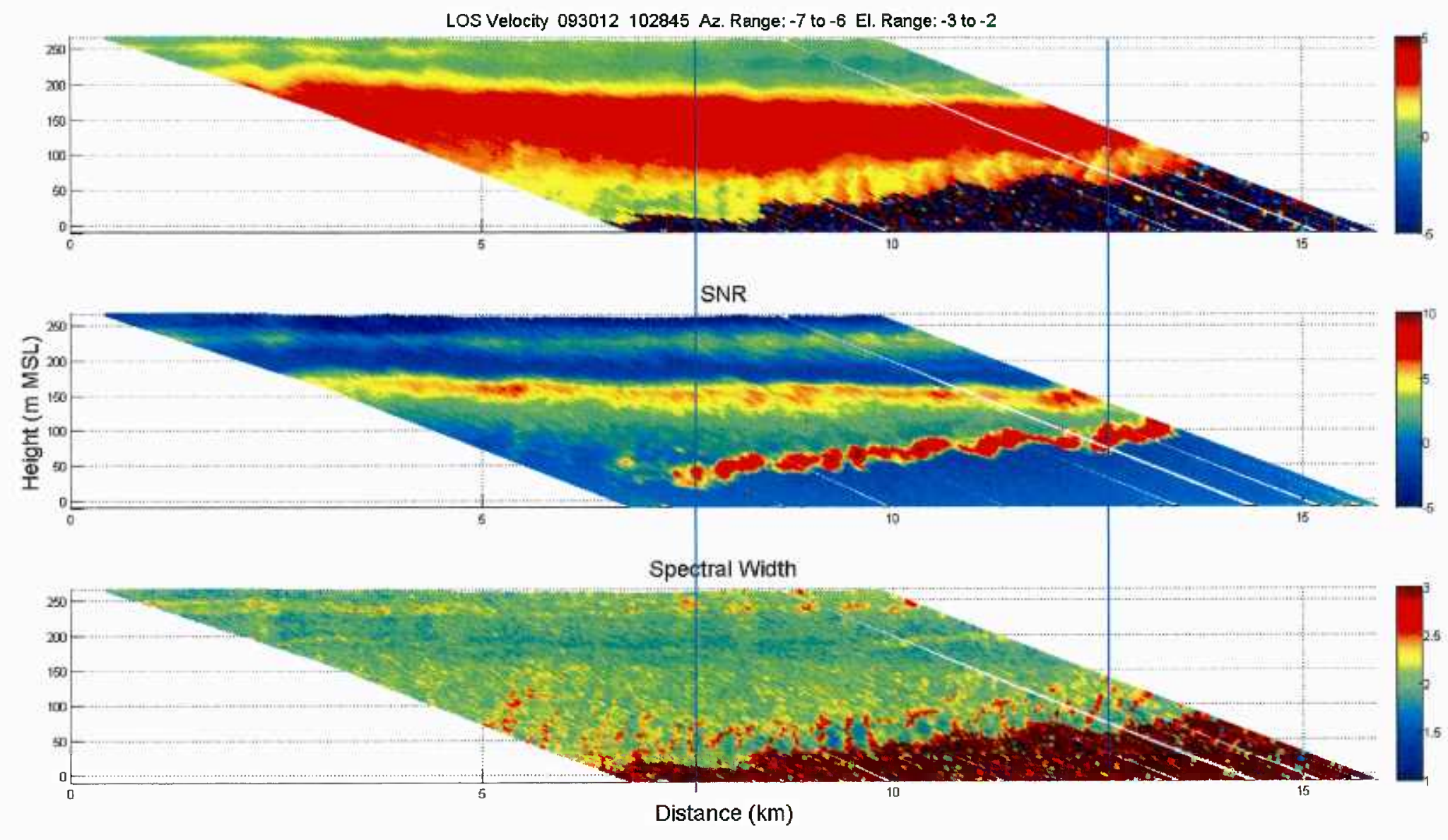



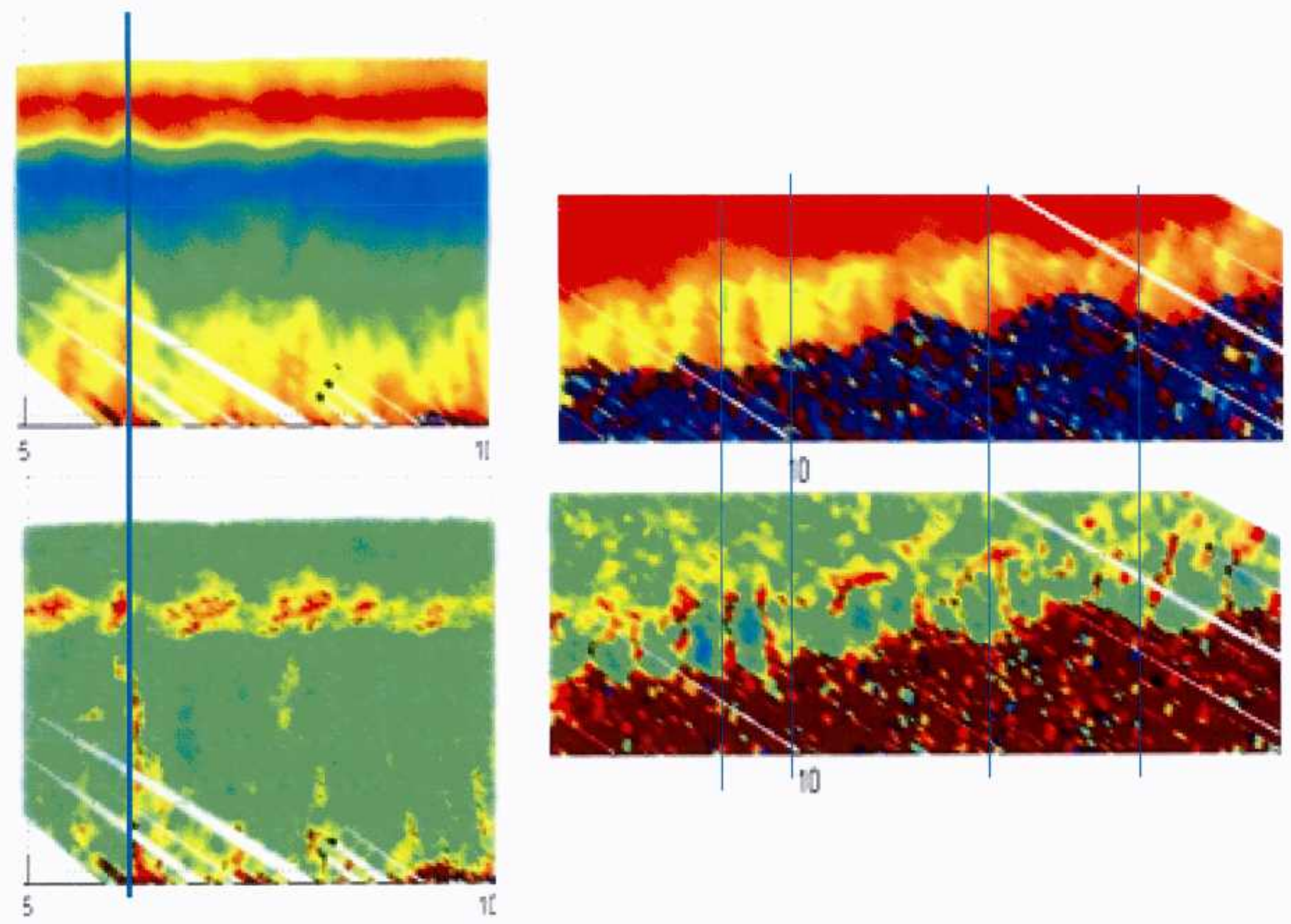


\section{Current Findings}

- Columns of "spectral broadening (SB)" of the DWL return are seen only in zones of near surface convergence and inferred upward motion

- Not all columns terminate at elevated turbulence "blobs" or accumulation pockets.

- Number of SB columns per $1 \mathrm{~km}$ is the same as the number of convergence zones. However, the spacing between convergence zones varies greatly. 


\section{Line density of rolls (per $10 \mathrm{~km}$ )}

\begin{tabular}{|l|l|l|}
\hline \multicolumn{1}{|c|}{ Flight Segment } & SB Columns & $\begin{array}{c}\text { Horizontal } \\
\text { Convergence zones }\end{array}$ \\
\hline 1007 & 25 & 25 \\
\hline 1017 & 42 & 42 \\
\hline 1028 & 30 & 30 \\
\hline 1106 & 28 & 28 \\
\hline 1111 & 16 & 16 \\
\hline 1121 & 26 & 26 \\
\hline
\end{tabular}




\section{Summary}

- The combination of an Airborne Doppler Wind Lidar and a Controlled Towed Platform holds promise of a transformation of how we investigate air/sea exchanges and construct flux parameterizations for use in numerical weather models.

- Interpretation of the TODWL derived spectral width is a primary focus of our current investigation.

- We are now focused on adding a "convective/shear instability driven rolls" terms to the EDMF. 
Attachment 6

Triad Interaction Model and its role in modifying the EDMF parameterization to include contributions from non-gradient fluxes due to rolls.

Sub report

R. Foster 


\title{
Triad Interaction Model and its role in modifying the EDMF parameterization to include contributions from non-gradient fluxes due to rolls.
}

\author{
Ralph Foster
}

An important part of our project is to use the Doppler wind lidar (DWL) data to guide in the development of a parameterization of roll OLE contributions to the PBL fluxes. The target for this parameterization is the eddy diffusivity/Mass flux (EDMF) PBL parameterization. As currently implemented, the EDMF parameterizes the non-gradient fluxes that are induced by convective plumes using a mass flux scheme. The plume contribution parameterization is based LES of shear-free convection. However, when shear is important, and even into the very near-neutral stratification regime, the dominant form of non-gradient fluxes is due to roll OLE, which are much more challenging to study and parameterize using LES.

For example, an EDMF model must be capable of capturing complex PBL transitions such as in off-ice flow in high latitudes. The PBL is slightly stable over pack ice, yet rolls are observed in this regime. Over water, that flow gains significant surface buoyancy flux and the rolls strengthen, broaden and deepen. Farther off-shore, they experience an up-scale transition and ultimately break down into $0(25-50 \mathrm{~km})$ convection. At present, the EDMF parameterizes the small-scale, largely shear-driven small-scale turbulence with the ED part and the convective regime after the rolls break down. However, in the near neutral stable and the moderately unstable regimes where rolls are present, the EDMF model has no mechanism for parameterizing their non-gradient contribution to the PBL fluxes.

Our strategy is to use the DWL observations to calibrate and validate a general model for roll OLE that can be used to develop a roll parameterization for the EDMF. Roll OLE, which are often mischaracterized as either convective rolls or shear rolls are in general due to a combined shear and convective instability that reaches a quasi-equilibrium state in which finite amplitude rolls are maintained in a slightly modified mean state. This mechanism is well-established in the literature, most recently for the hurricane boundary layer by Foster (2005), Zhu (2008) and Nakanishi and Niino (2012). However, both our DWL observations and the numerical modeling indicate that single-mode rolls, while capturing the basic OLE flow, are insufficient to describe the variability in the PBL.

As previously reported, the general, nonlinear "single-mode" model described in Foster (2005) has been expanded to capture the nonlinear energy transfer among resonant triads of PBL modes. Resonant triads are the fundamental building blocks of the nonlinear interactions between fluid motions at different scales. Energy transferred from motions of different spatial scales into or out of a particular mode comes from modes whose wave vectors form a triangle with the wave vector for the mode in question (Fig. 1). The standard single-mode nonlinear stability analysis (e.g. Foster. 2005) will thus omit these "wave-wave interaction" pathways by which energy can flow from the dominant mode into more slowly-growing modes. Our first effort worked on the much simpler case in which the triad modes are all colinear. 
In this year, we significantly expanded the model to include the nonlinear interactions between non-colinear triads. The quasi-equilibrium solutions continue to change with time, but through a limited flow regime. And at any particular time, the solutions vary spatially. The solution space is complex, but so far the results are realistic and appear to agree with simpler models (e.g. Dubos et al., 2008). A snapshot of a particular solution is shown in Figs. 2 and 3. The dominant roll OLE are oriented about $19^{\circ}$ from the down-wind direction. The triad includes a smaller-scale mode oriented about $17^{\circ}$ from the dominant mode and a larger-scale mode about $46^{\circ}$ from the dominant mode. The overturning circulation induced by the roll OLE is best seen in the $x-z$ cross-sections taken at different down-roll positions (Fig. 2). The variability in the overturning circulation strength and shape is evident, which can be seen most clearly in the vertical velocity. The along-roll velocity also varies in strength along the rolls. Fig. 3 shows the horizontal perturbation wind vectors at near the surface and in the mid-PBL. near the surface, the along-roll component dominates. In the mid-PBL, the overturning circulation dominates. The roll circulation is clearly three-dimensional and varies in both time and space. Efforts in this year will focus on understanding the non-colinear triad interactions in this simple case. This study is an important advance in PBL roll theory and is worthy of publication. Once the new (and more complex) mathematics is more carefully checked and better understood, it will be applied to the DWL observations.

Zhu (2008) proposed that roll OLE fluxes could be parameterized using the mass-flux paradigm. A key difference is that standard mass flux modeling assumes that the vertical velocity is highly skewed with a small updraft fraction. For roll OLE, the vertical velocity is only slightly skewed and the updraft fraction is closer to $50 \%$. For a single roll OLE situation, the skewness, updraft fraction and mass flux, $(1-\sigma)\left(w_{-} u p-w_{-} d n\right)$, are all well behaved and similar to the calculations in Zhu (2008) (Fig. 4 and 5). As shown, OLE roll fluxes are inconsistent with eddy-diffusivity modeling. However, the mass flux parameterization is relatively wellbehaved.

In support of the application to the EDMF, we applied the colinear triad interaction model to the OLE observations over Monterey Bay. Previously, we made a case that the mean PBL structure was likely due to advection of over-land PBL air over the thin marine layer in the bay. The mean flow indicated an elevated PBL jet at the intersection between the air masses. The observations showed a likely "stacked-OLE" configuration in which OLE were separately generated in each layer and interacted across the jet. The triad model showed greater and lesser interaction between the layers above and below the jet that varied in spatially and temporally, which was consistent with the observations (Fig. 6). Note the change in the Skewness profiles above the level of the mid-PBL jet.

In this case, consistent with the DWL data, Twin Otter fluxes and towed platform fluxes, the OLE-induced skewness is much more complex. Understanding and modeling correctly this process will be a focus in the upcoming year. In particular, we will need to implement the non-colinear roll OLE model and apply it to the Monterey PBL conditions.

Joao Teixeira's research group at JPL has provided us with an implementation of the EDMF PBL model that we can use to experiment with implementing the OLE MF contribution. 
Figure 1: Typical non-colinear roll OLE triad for simple PBL mean flow. Contours show the instability growth rate. Dominant mode is labeled $B$. Sub-modes are $A$ and $C$. Construction shows that $A=B+C$ as required.

Figure 2: Cross-sections in the $x-z$ plane at two locations along the dominant roll mode direction (mode $B$ from Fig. 1). Upper panels color shading show vertical velocity. Lower panels color shading shows along-mode $B$ OLE perturbation velocity. Vectors show the overturning circulation $(U, W)$ perpendicular to the mode $B$ OLE axes.

Figure 3: Horizontal cross sections $(x-y)$ through the vertical velocity. Left panel is nearer the surface and right panel is at the mid-PBL. Vectors show the along-across horizontal velocities. Near the surface, the along-mode $\mathrm{B}$ component dominates. In the mid-PBL, the overturning component begins to dominate. The secondary circulation due to rolls is three-dimensional.

Figure 4: Upper panel pair: Snapshot of colinear roll OLE triad solution for a simple PBL mean flow. Upper shows vertical velocity and overturning stream function. Lower shows along-roll perturbation velocity. Lower left panel: updraft fraction. Lower right panel: vertical velocity skewness.

Figure 5: Example across-roll momentum flux. Upper panel, wu velocity product with overturning streamfunction contoured. Lower left: effective eddy viscosity needed if these fluxes are modeled using the eddy diffusivity approach. Lower right, momentum flux modeled using mass flux approach.

Figure 6: Upper panels: two snap shots of the vertical velocity for the nonlinear, colinear triad model for a mean flow profile similar to the DWL observations over Monterey Bay, 2012. Lower left: mean flow profile used to generate the solution show in the upper panels. Lower right: vertical velocity skewness from the triad model. Note that the skewness can be either positive or negative near the surface, which is consistent with the observations.

\section{References:}

Foster RC 2005: Why rolls are prevalent in the hurricane boundary layer, J Atmos. Sci, 62, 2647-2661.

Dubos, T, C. Barthlott, and P. Drobinski, 2008: Emergence and Secondary Instability of Ekman Layer Rolls. J. Atmos. Sci., 65, 2326-2342.

Nakanishi Mikio and Hiroshi Niino, 2012: Large-Eddy Simulation of Roll Vortices in a Hurricane Boundary Layer. J. Atmos. Sci., 69, 3558-3575.

Zhu, P., 2008: Simulation and Parameterization of the Turbulent Transport in the Hurricane Boundary Layer by Large Eddies. J. Geophys. Res., 113, D17104 


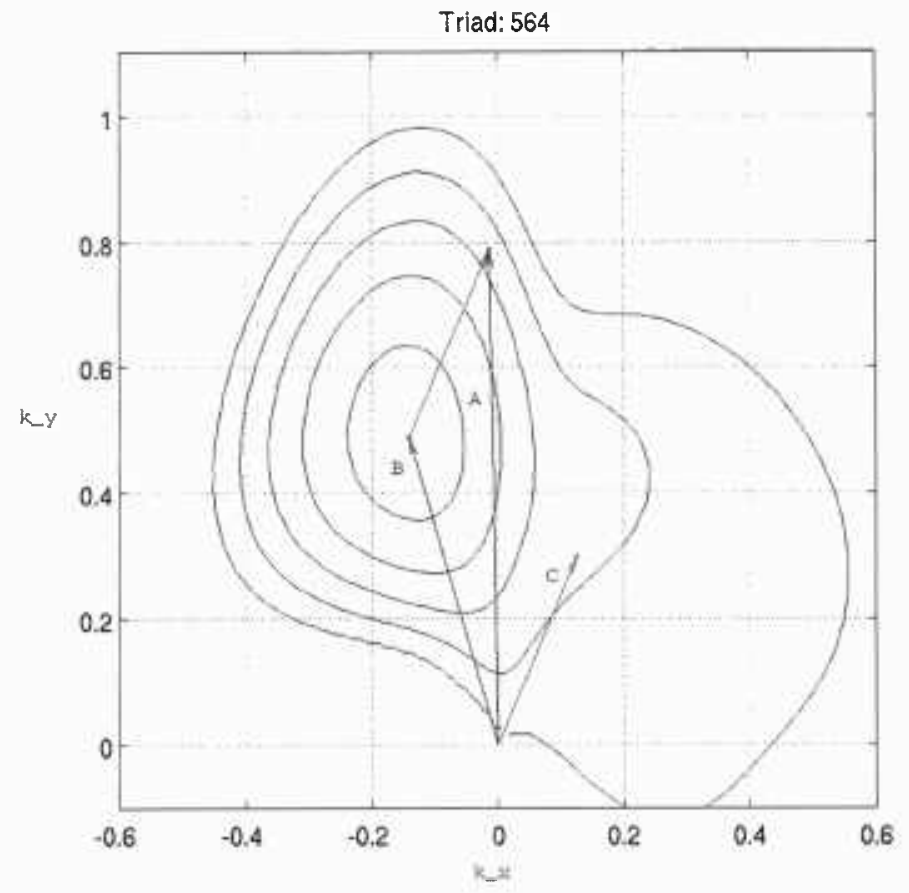

Figure 1 


$$
A-A
$$
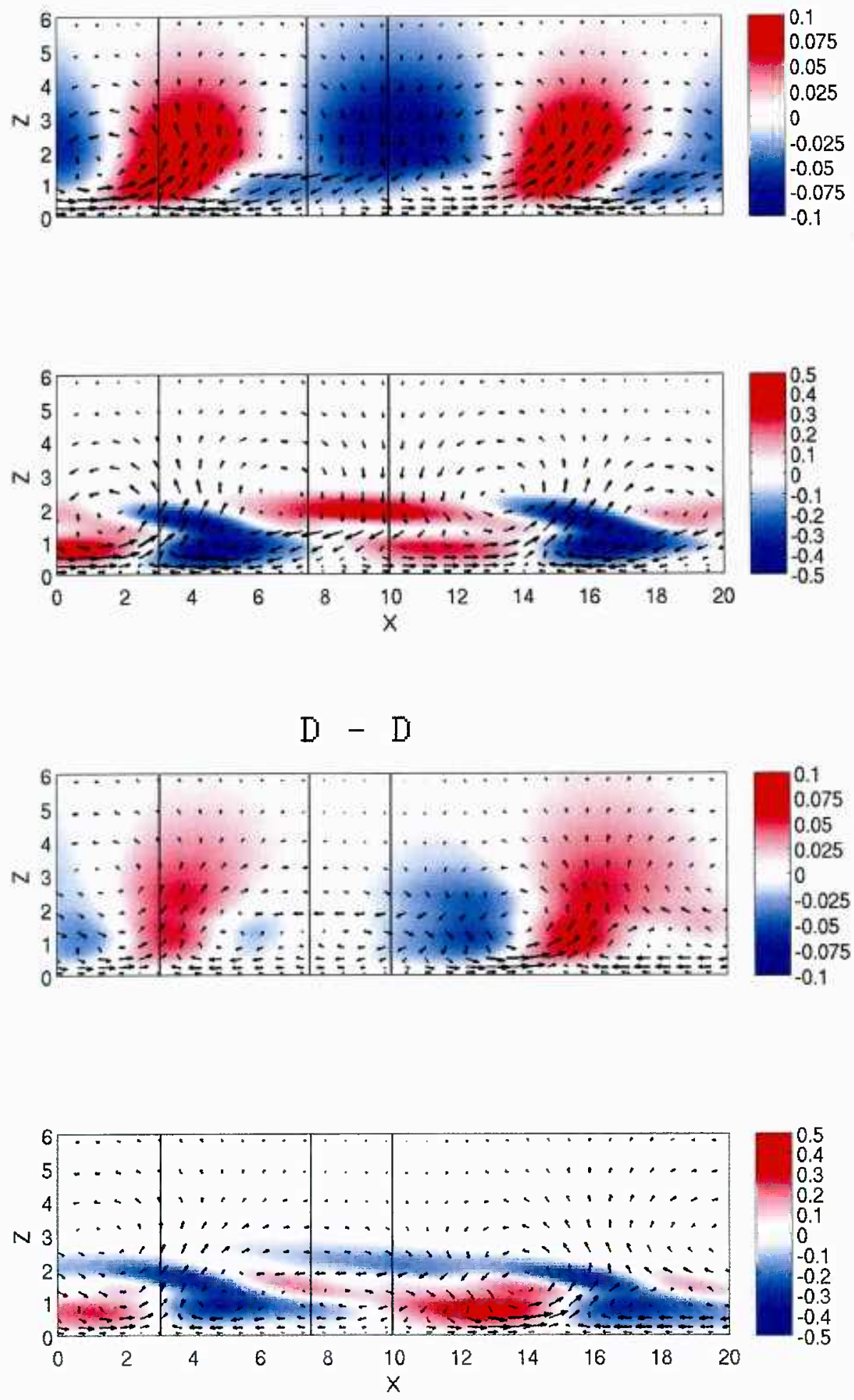

Figure 2 

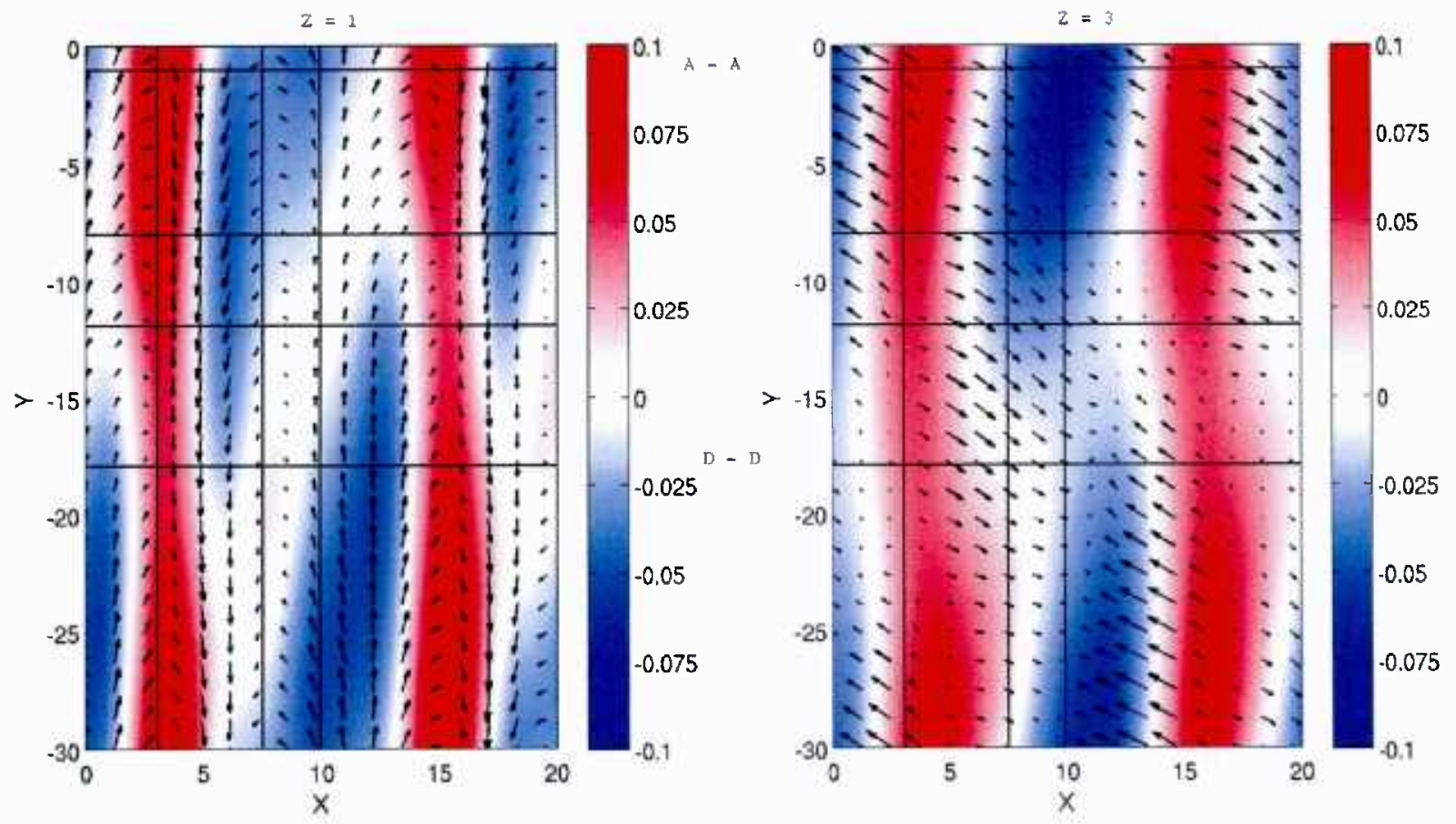

Figure 3 

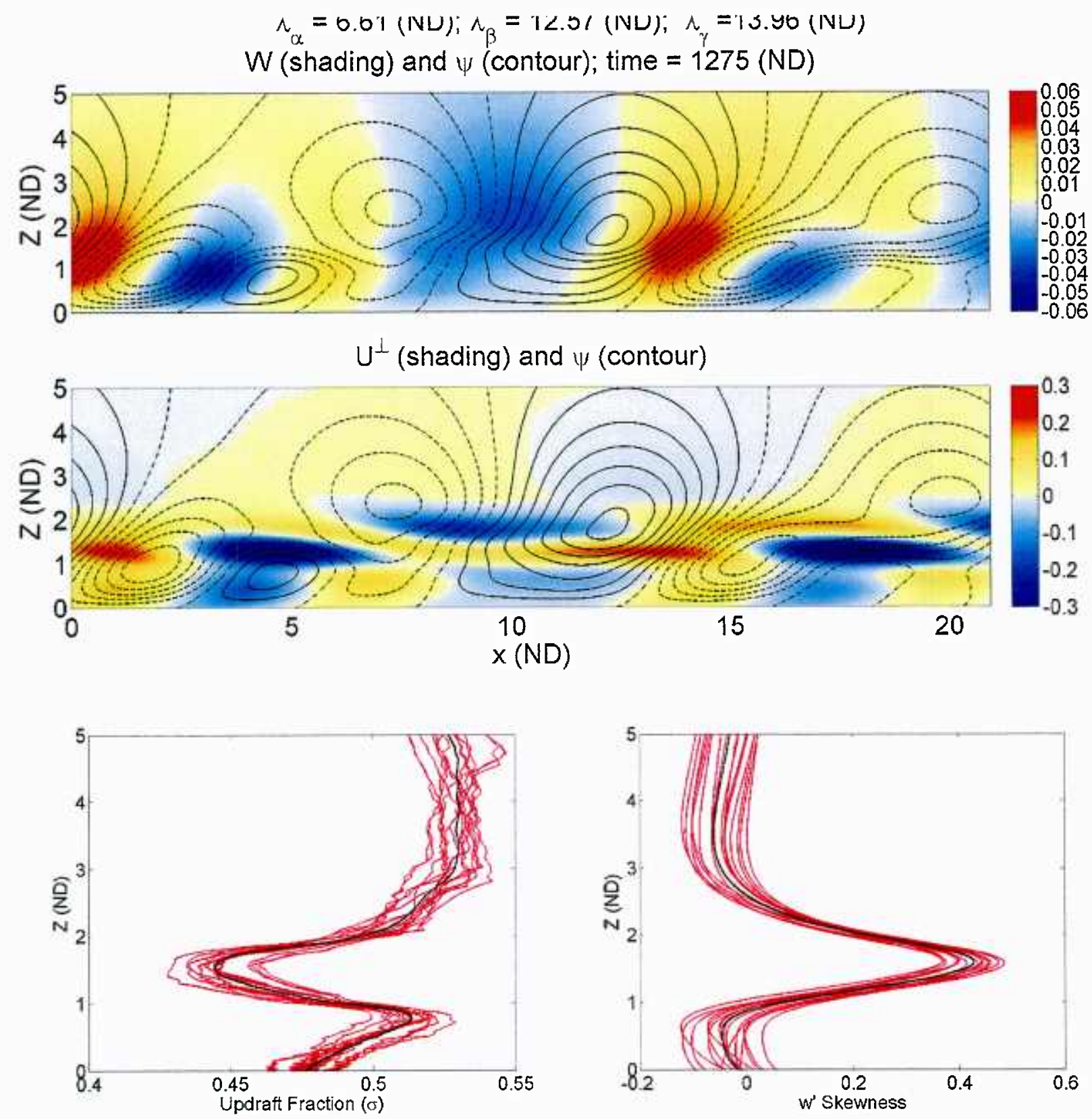

Figure 4 

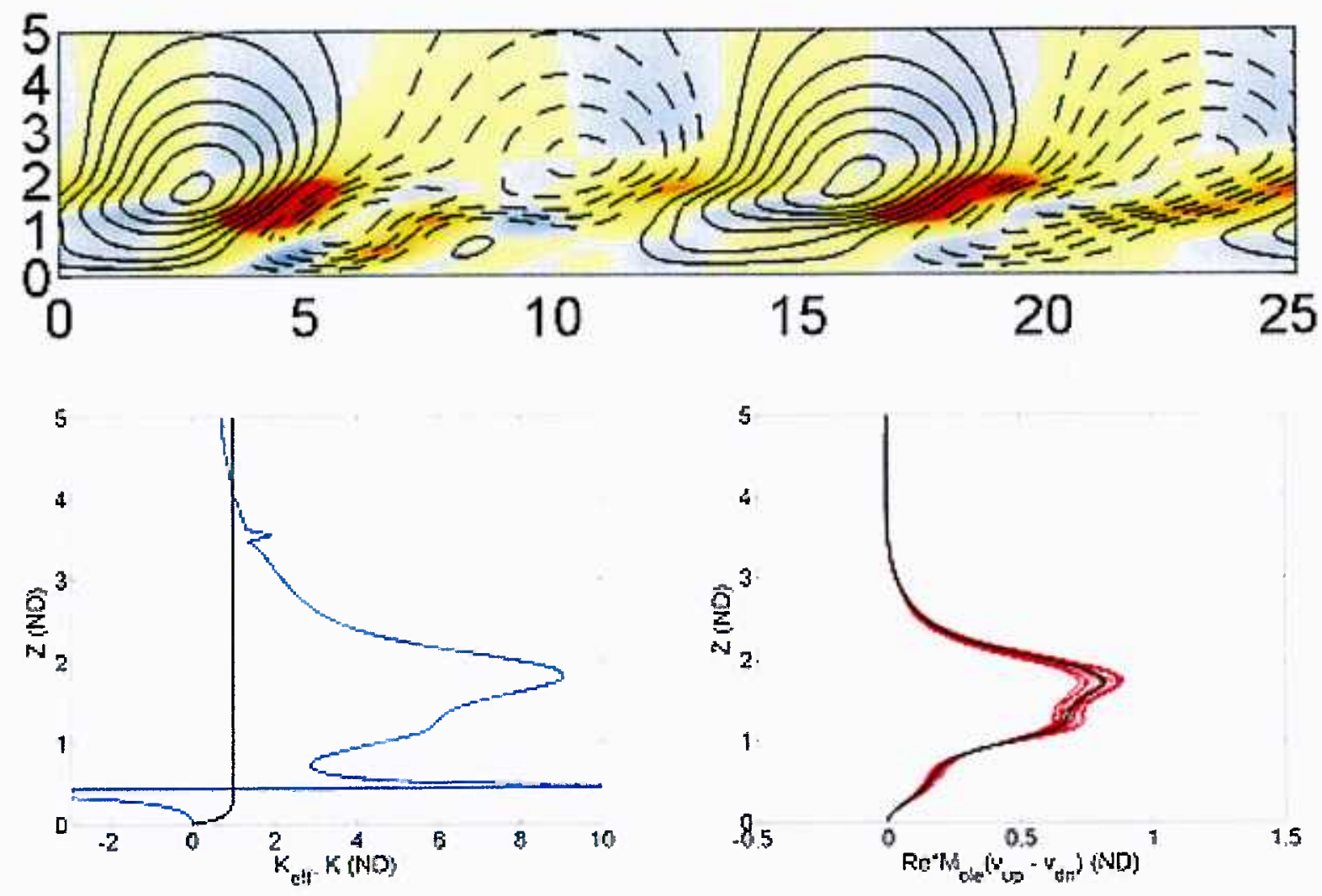

Figure 5 


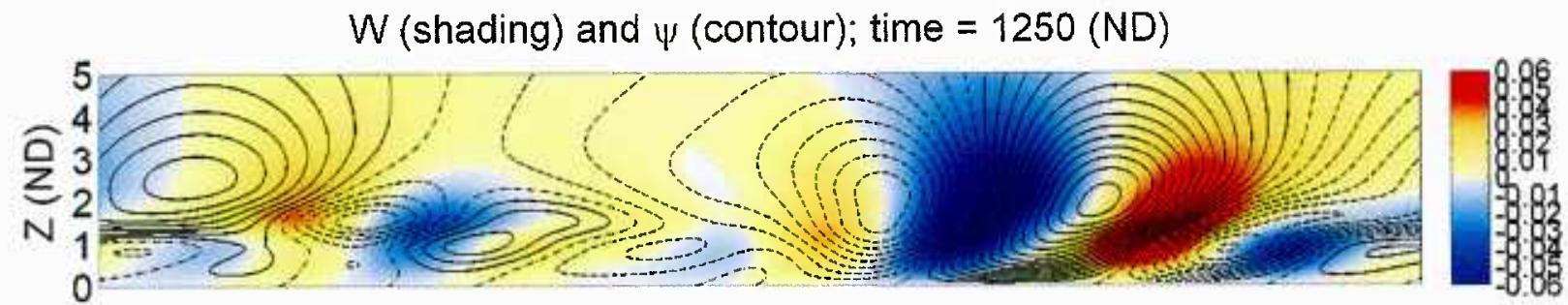

$W($ shading) and $\psi$ (contour); time $=1350$ (ND)
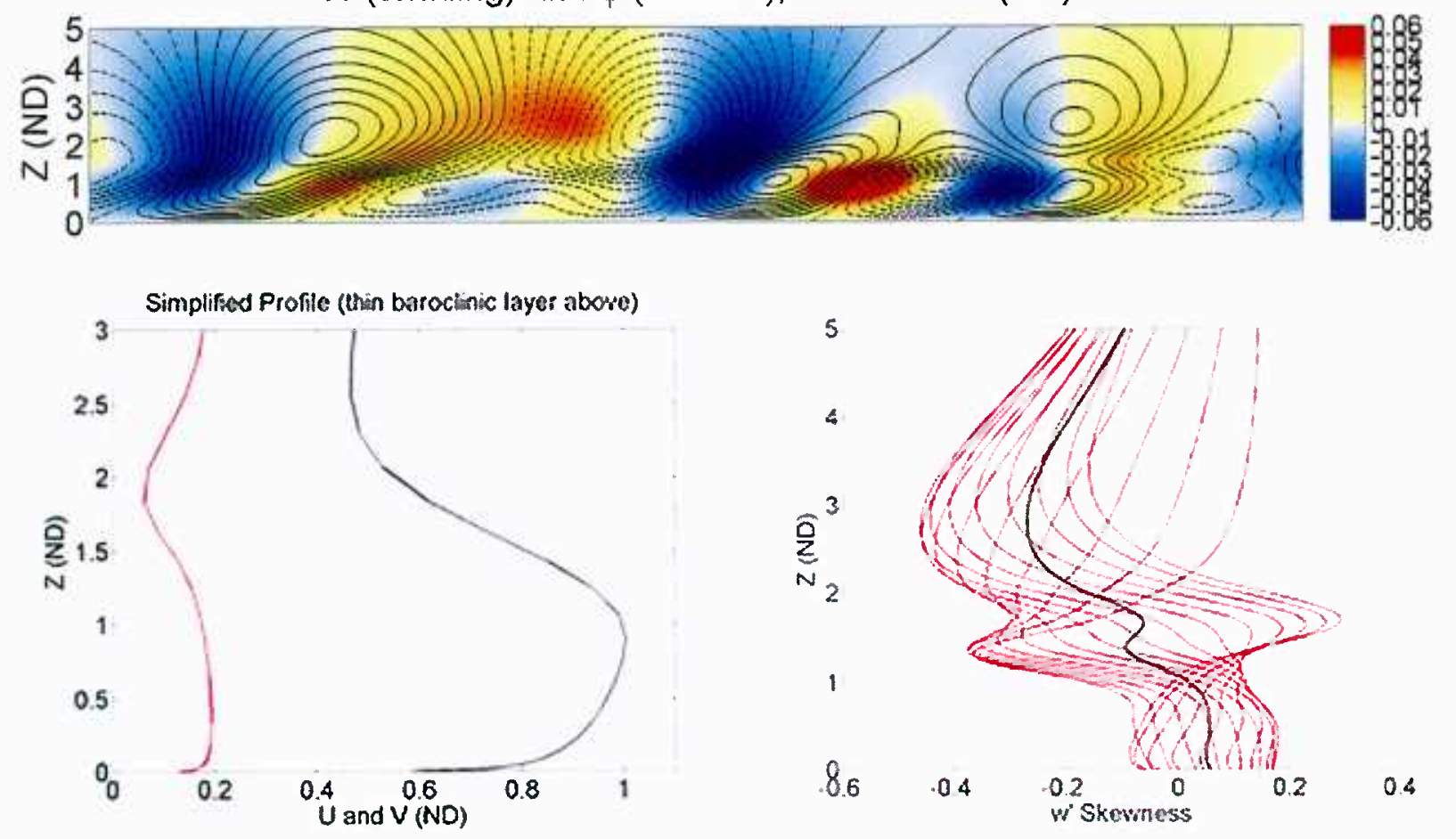

Figure 6 
Subcontract report for Simpson Weather Associates regarding the ONR DRI project:

Investigation of the representation of OLEs and terrain effects within the coastal zone in the EDMF parameterization scheme: an airborne Doppler wind lidar perspective.

Stephan F.J. De Wekker

University of Virginia

Reporting period: 1 July 2013-30 June 2014

The planned tasks for year 3 of this project that involved subcontractor UVA were:

Task 3.1 - Processing and analysis (including algorithm and software development)

of new TODWL data after completion of field program

Task 3.3 - Analysis of turbulence obtained from the standard instruments on the

Twin Otter

Task 3.7 - Analyze TODWL data and compare with Radiosonde data (UVA and SWA)

Accomplishments:

During year 3, a majority of the effort was in the analysis of TODWL research flights. The UVA contribution was focused on investigating of turbulence and boundary layer structure over land, in particular during the ONR funded MATERHORN field campaign. Seven research flights in total were conducted during the MATERHORN field campaign.

We analyzed PBL heights from the TODWL data for all research flights. An example of the results for five flight legs oriented north-south for the morning of 10 October 2012 is shown in Fig. 1. A terrain following PBL height is evident with maximum heights up to about $2000 \mathrm{~m}$. The TODWL derived PBL heights compare well with PBL height derived from temperature profiles from radiosonde and unmanned aerial vehicle measurements.

A typical feature of the boundary layer structure around Granite Peak is the presence of layers with large amounts of shear in wind speed and direction. We hypothesize the presence of these layers play an important role in modulating turbulence intensities and turbulence structures. An example is shown for the afternoon of 14 October 2012 for a north-south oriented flight leg east of Granite Peak. In a layer below the PBL height at around $2200 \mathrm{~m}$, there was large shear in wind speed and direction, especially on the northeastern part of Granite Peak (Fig. 2). In situ measurements from the Twin Otter aircraft indicate enhancement of turbulence kinetic energy on the northern part of this flight leg (Fig. 3). The low level Twin Otter flights were designed to prospect for organized convective structures and for quantifying vertical heat and momentum fluxes associated with these structures. Forward stares from the lidar indicate the presence of organized structures that align well with the in-situ turbulence measurements (Fig. 4) 

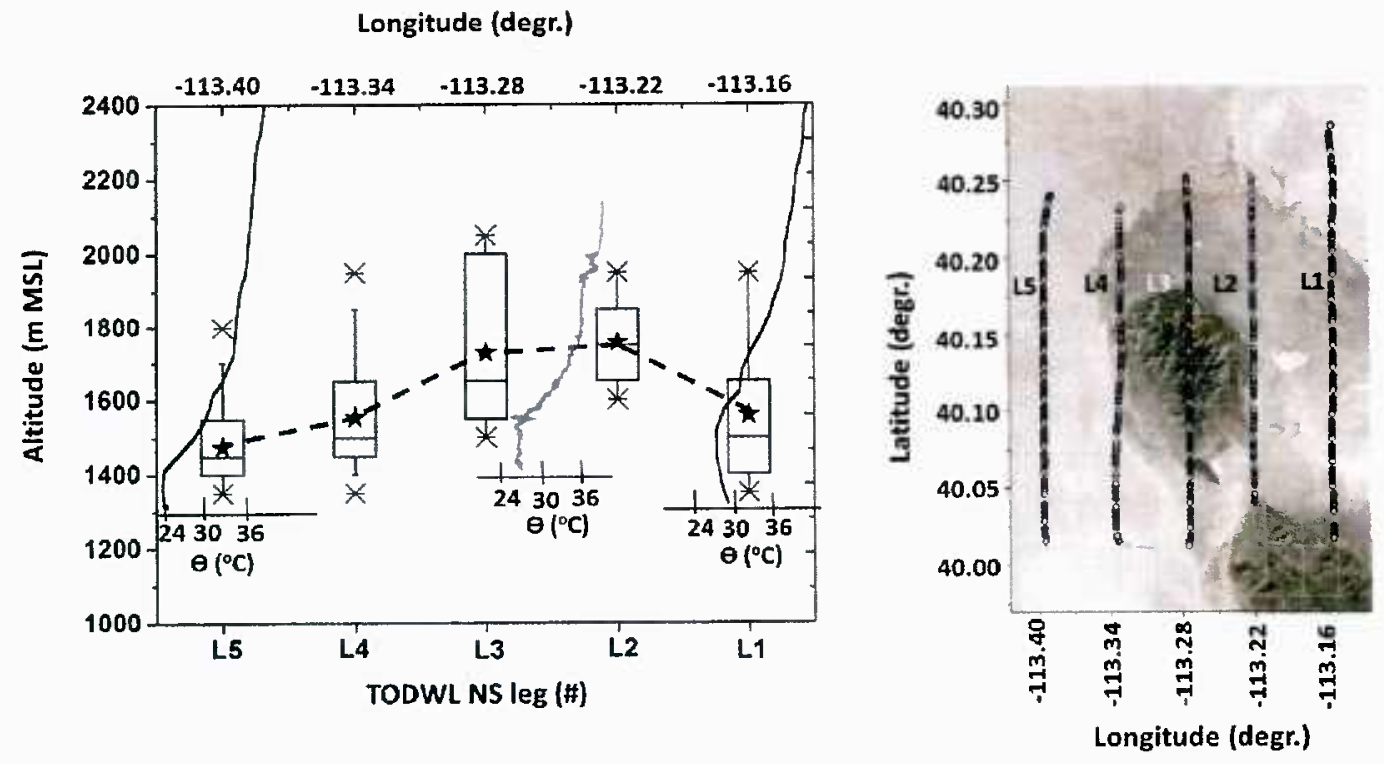

Figure 1: (a) Box-and-whisker plot of the PBL heights derived from aerosol backscatter profiles along the north-south flight legs (b) performed during a morning TODWL mission between 1012 and 1052 MDT on 10 October 2012. The horizontal line in the box and the bottom and top line of the box show the median of the data, and the lower and upper quartiles ( $25 \%$ and $75 \%)$, respectively. The whiskers show the minimum and maximum values while the solid star is the mean value. Vertical potential temperature profiles obtained over the Playa and Sagebrush sites are shown on the western and eastern part of the domain. Also shown is the potential temperature profiles obtained from DATAHAWK (UAV) measurements located between TODWL legs L2 and L3.
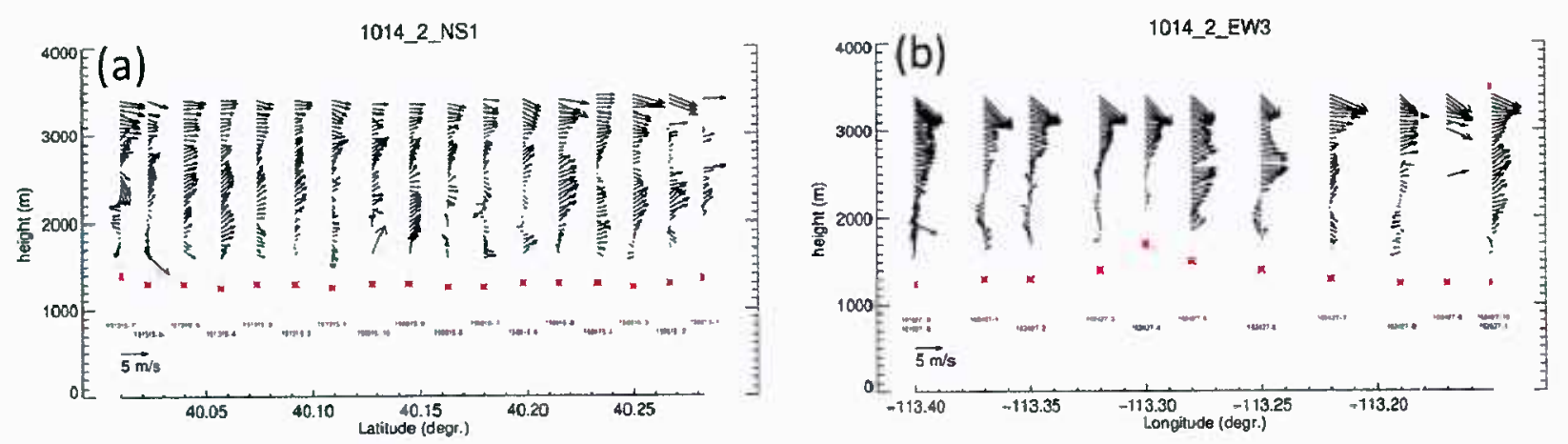

Figure 2: Vertical profiles of TODWL derived wind speed and direction along a north-south flight leg east of Granite Peak (a) and an east-west flight leg over Granite Peak (b) on the afternoon of 14 October 2012. 


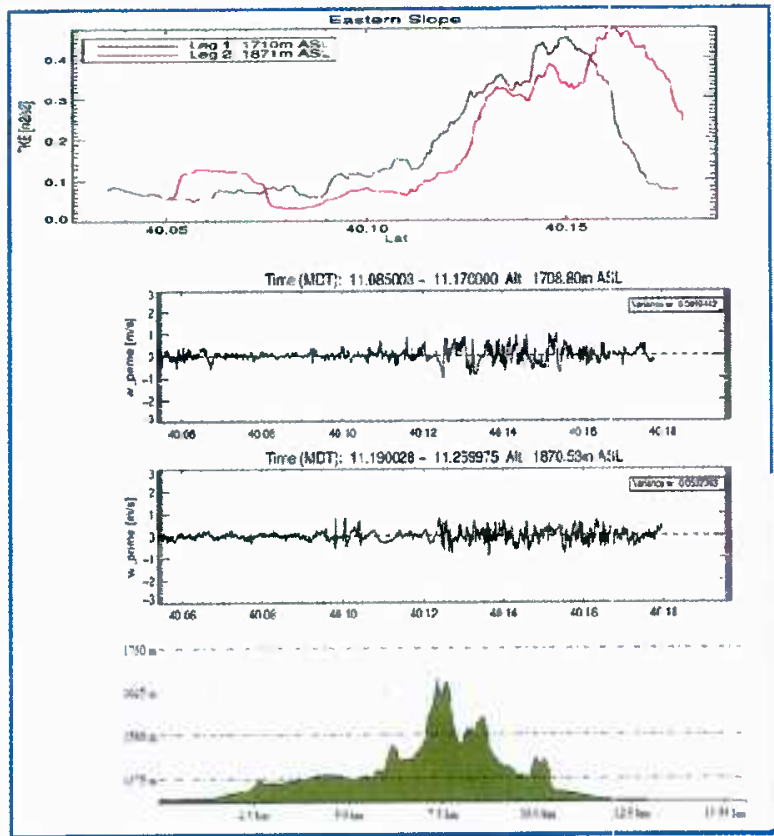

Figure 3: From top to bottom, horizontal profile of turbulence kinetic energy, vertical velocity vat two heights, and topography below a flight leg east of Granite Peak on 14 October 2012

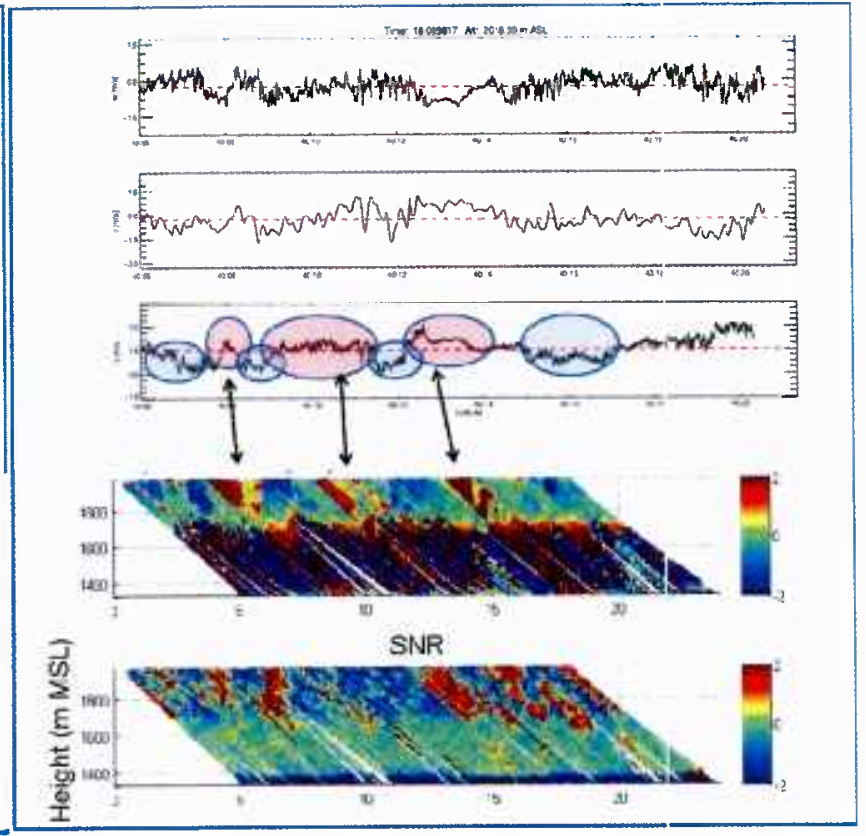

Figure 4: From top to bottom: $w$, $u$, and $v$-wind component along a flight leg east of Granite peak on 14 October 2012. The flight leg shown here is about $10 \mathrm{~km}$ further to the east than the flight leg shown in Fig. 3. Shown in the bottom two panels are the line of sight velocity and the signal-to-noise ratio of a forward stare on the same flight leg. In these panels, coherent turbulence structures are visible that align well with velocity fluctuations from the in-situ aircraft measurements.

These coherent turbulence structures are sub-grid scale for regional to global scale models and therefore one would expect an EDMF based parameterization scheme to represent the effects of these structures on the turbulent transport. We are currently collaborating with Dr. James Doyle at NRL in the use of the COAMPS to simulate these MATERHORN case studies. Doyle's group has now implemented the EDMF scheme in COAMPS and will perform simulations for one of the intensive operational periods during MATERHORN. Simulations will be done with and without EDMF parameterization at horizontal grid spacing of 4,3,2, and $1 \mathrm{~km}$ in the innermost domain with the overall goal to evaluate the sensitivity of the simulations to ED and MF parameters in the EDMF parameterizations. PBL structure and the simulated fluxes of heat and momentum in the PBL will be compared against the in-situ and lidar measurements from the Twin Otter flights. In addition, De Wekker has continued a collaboration with the Research Application Laboratory at the National Center for Atmospheric Research (NCAR-RAL - Knievel and Liu) to perform 'very large eddy simulations' (VLES) with a $300 \mathrm{~m}$ grid spacing for the various days of the research flights. Idealized simulation have also been performed in collaboration with the University of Vienna (Serafin). Output will in the next year be analyzed to detect the presence of coherent structures similar as in the observations and quantify their effect on turbulence fluxes. The general question we will investigate is whether the effect of these structures are properly represented in an EDMF based PBL parameterization.

A post-doc (Sandip Pal) and a graduate student (Mark Sghiatti) at UVA will contribute to the analysis of the model output and comparisons with observations during the next year. Graduate student Mark Sghiatti successfully defended his Master thesis proposal entitled "Spatial Variability of Turbulent 
Kinetic Energy and Turbulent Fluxes around an Isolated Mountain". He is expected to graduate in fall 2015.

Publications related to the project:

Sghiatti, M.D., S. Pal, G.D. Emmitt, and S.F.J. De Wekker, 2014: Turbulence structure in the daytime boundary layer around an isolated mountain from in-situ airborne measurements. American Meteorological Society Annual Meeting, Atlanta, GA, 3-7 February 2014.

Knievel, J.C., Y. Liu, S.F.J. De Wekker; J. Pace, W.Y. Cheng, and Y. Liu, 2013: Simulation of mesogamma-scale morning-transition flows at Granite Peak, Utah with NCAR's WRF-based 4DWX and observations from the MATERHORN 2012 field campaign. American Geophysical Union, San Francisco, 9 - 13 December 2013.

De Wekker, S.F.J., Y. Liu, J.C. Knievel, S. Pal, G.D. Emmitt, 2013: Observations and simulations of the wind structure in the boundary layer around an isolated mountain during the MATERHORN field experiment. American Geophysical Union, San Francisco, 9 - 13 December 2013.

Godwin, K.S., G.D. Emmitt, S. Greco, and S.F.J. De Wekker, 2013: Evaluating the accuracy and representativeness of Airborne Doppler Wind Lidar winds in complex terrain. American Geophysical Union, San Francisco, 9 - 13 December 2013.

Pal, S., S.F.J. De Wekker, and G.D. Emmitt, 2013: Investigation of the spatio-temporal variability of atmospheric boundary layer depths over mountainous terrain observed with a suite of ground-based and airborne instruments during the MATERHORN field experiment. American Geophysical Union, San Francisco, 9 - 13 December 2013.

Liu, Y., Y. Liu, J.C. Knievel, J. Pace, D. Zajic, S.F.J. De Wekker, LES simulation of synoptic, mechanic-forcing, and thermally-driven flow interaction of Granite Mountain, UT. American Geophysical Union, San Francisco, 9 - 13 December 2013. 


\section{REPORT DOCUMENTATION PAGE}

\section{Form Approved}

OMB No. 0704-0188

Public reporting burden for this collection of information is estimated to average 1 hour per response, including the time for reviewing instructions, searching data sources,

Thering and maintaining the data needed and complefing and reviewing the collection of information. Send comments regarding this burden estimate or any other aspect of this collection

of information, including suggestions for reducing this burden to Washington Headquarters Service, Directorate for Information Operations and Reports,

1215 Jefferson Davis Highway, Suite 1204, Arlington, VA 22202-4302, and to the Office of Management and Budget,

Paperwork Reduction Project (0704-0188) Washington, DC 20503

PLEASE DO NOT RETURN YOUR FORM TO THE ABOVE ADDRESS

\section{REPORT DATE (DD-MM-YYYY)}

20-10-2014
2. REPORT TYPE

Annual

\section{TITLE AND SUBTITLE}

Investigation of the Representation of OLEs and Terrain Effects Within the Coastal Zone in the EDMF Parameterization Scheme: An Airborne Doppler Wind Lidar Perspective

3. DATES COVERED (From - To)

1 July 2013-30 September 2014 5a. CONTRACT NUMBER

5b. GRANT NUMBER

N000141110450

5c. PROGRAM ELEMENT NUMBER

5d. PROJECT NUMBER

5e. TASK NUMBER

5f. WORK UNIT NUMBER
7. PERFORMING ORGANIZATION NAME(S) AND ADDRESS(ES)

Simpson Weather Associates, Inc.

809 E. Jefferson Street

Charlottesville, VA 22902-5131

9. SPONSORING/MONITORING AGENCY NAME(S) AND ADDRESS(ES)

DCMA Manassas-S2404A

10500 Battleview Pkwy, Suite 200

Manassas, VA 20109-2342
8. PERFORMING ORGANIZATION REPORT NUMBER

\section{DISTRIBUTION AVAILABILITY STATEMENT}

Approved for Public Release, distribution is Unlimited

\section{SUPPLEMENTARY NOTES}

\section{ABSTRACT}

More than 50 hours of TODWL data from both the Monterey and DPG areas has been processed. We are continuing efforts to combine the information from the TODWL, CTV and Twin Otter sensors to establish the relationship between the local fluxes and the energetics of LLJs and OLEs. Effort has also continued on modifying the EDMF parameterization to account for the differences between thermally driven convection and dynamically driven vertical transports.

We continue to modify the EDMF parameterization to account for the differences between thermally driven convection and dynamically driven vertical transports.

\section{SUBJECT TERMS}

OLE, EDMF, Doppler Wind Lidar

\begin{tabular}{|c|c|c|c|c|}
\hline \multicolumn{3}{|c|}{ 16. SECURITY CLASSIFICATION OF: } & \multirow{2}{*}{$\begin{array}{l}\text { 17. LIMITATION OF } \\
\text { ABSTRACT } \\
\text { U }\end{array}$} & \multirow{2}{*}{$\begin{array}{l}\text { 18. NUMBER } \\
\text { OF PAGES } \\
116\end{array}$} \\
\hline $\begin{array}{l}\text { a. REPORT } \\
U\end{array}$ & $\begin{array}{l}\text { b. ABSTRACT } \\
U\end{array}$ & $\begin{array}{l}\text { c. THIS PAGE } \\
\text { U }\end{array}$ & & \\
\hline
\end{tabular}

19a. NAME OF RESPONSIBLE PERSON George D Emmitt

19b. TELEPONE NUMBER (/nc/ude area code) 434-979-3571 